\title{
E HINE, NGĀ WHĀEA: TEEN MOTHERING IN THE GAZE
}

BY

ANNA ADCOCK

\begin{abstract}
A thesis
submitted to the Victoria University of Wellington in fulfilment of the requirements for the degree of

Master of Arts
\end{abstract}

Victoria University of Wellington

(February 2016) 


\section{Tuhinga Whakarāpopoto (abstract)}

In Aotearoa New Zealand, teen pregnancy is associated with social disadvantage and being 'Māori'. Research on teen motherhood typically focuses on 'risks' and 'dangers', such as lower educational attainment and welfare 'dependency'. These images cast young Māori mothers as abnormal and deviant - as perpetually deficit. Hence, public (and public service) perceptions of these women are often negative. This study displaces the deficit lens, and explores the lived realities of fifteen young (teen) Māori mothers, and the perspectives of their whānau. The purpose of this research was to understand the life circumstances of young Māori mothers, to examine the role of the state in their lives, and to make suggestions for service improvements. It draws on data from the E Hine study (Women's Health Research Centre, Otago University, Wellington). Young mothers participating in E Hine were interviewed three to seven times over a three-year period, with up to two whānau interviews conducted for each young woman. The data set for this thesis, comprising of fifteen young Māori mothers and their whānau, totalled eighty-four in-depth, semi-structured interviews. Data analysis was thematic, and was informed by Foucault's concepts of the medical and disciplinary gazes, and postcolonial notions of the colonial gaze. The research suggests that public health and social services, as well as public perceptions, seek to regulate these young women according to Eurocentric conceptions of normality; and in doing so, stigmatize and disengage them, thus creating barriers to positive outcomes. Despite this, these young mothers resist disempowerment, and hope for a better future for themselves and their whānau. Their stories are a testament to the fact that being young and Māori and mothering does not equate to failure. By treating young Māori mothers with respect and empathy, support services could be improved. 


\section{Ngā Mihi (acknowledgements)}

Ngā mihi nui ki a Rōpū Māmā ā rātou whānau. Immense 'thank you' to the young women (and whānau) who took part in this study. By sharing your experiences, you have made this research possible. Also, thank you to the Women's Health Research Centre team, especially Bev, Fiona, and Charrissa, for supporting me on my research journey.

I would like to acknowledge Te Kaunihera Rangahau Hauora o Aotearoa (the Health Research Council of New Zealand) for funding E Hine; and the Dominion Post Master's by Thesis Scholarship for funding my research.

Thank you to my supervisors, Kevin and Chamsy, for humouring my Foucault obsession for two years running, and for reminding me about word choice, pitch, and theorists who are not Foucault.

To my friends on the ninth floor and beyond, thanks for being sounding boards and ngā kaitautoko.

Ko Taranaki te maunga. Ko Urenui te awa. Ko Tokomaru te waka. Ko Ngāti Mutunga te Iwi. Ko Urenui te marae. Ko Ngātiki Te Aho tōku tupuna. Ko Te Aho tōku whānau. To my ancestors, and my whānau today - thank you, thank you, thank you. You give me endless joy and pride. Special thanks to my mum, Hazel, who, aside from being an incredible mum, taught me how to question. 


\section{TABLE OF CONTENTS}

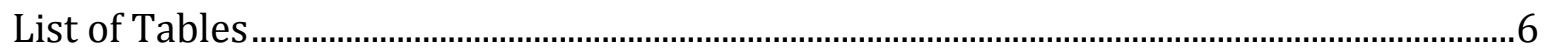

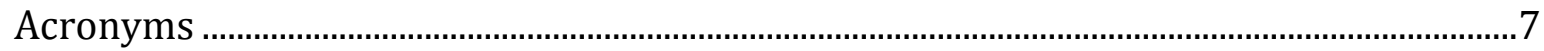

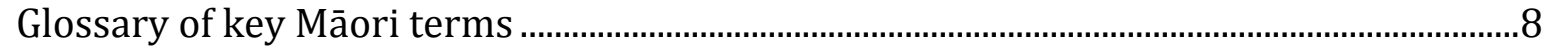

CHAPTER ONE: TĪMATANGA KŌRERO (introduction) .............................. 9

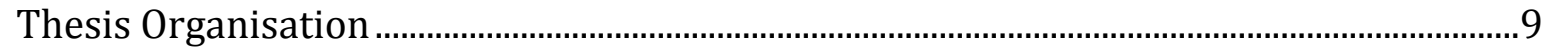

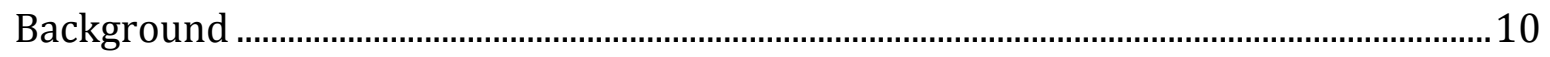

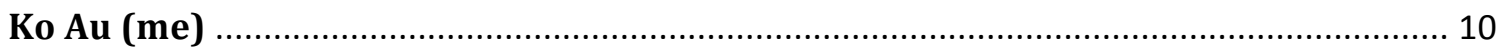

E Hine: Reducing barriers to care for pregnant Māori women $<20$ years and their

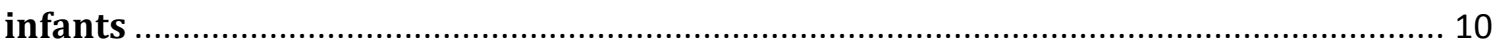

'E Hine, Ngā Whāea: Teen Mothering in the Gaze' Research Objectives........................ 11

Historical Context of Aotearoa New Zealand: Pre-colonial, New Arrivals, \& Beyond ..12

CHAPTER TWO: NĀ REIRA (contextual and theoretical orientation)..18

Contemporary Context: Statistics, Constructions and Experiences of Māori Teen

Motherhood in Aotearoa New Zealand …….......................................................................... 18

International Context: A Global Problem? …...........................................................................23

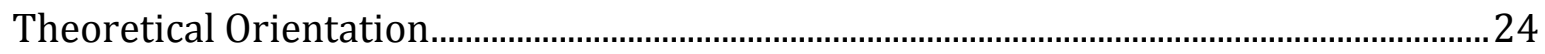

Foucault and Poststructural Conceptions of Power and Resistance ........................... 24

Bhabha and Postcolonial/Anticolonial Conceptions of Power and Resistance ........... 27

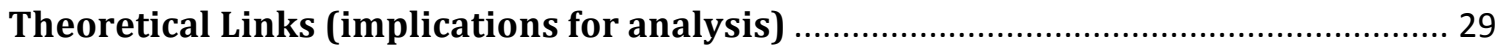

CHAPTER THREE: NGĀ TIKANGA (methods \& analysis) .......................30

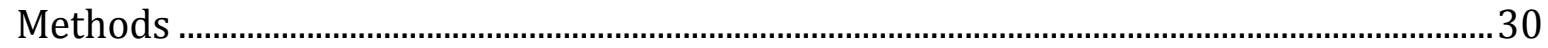

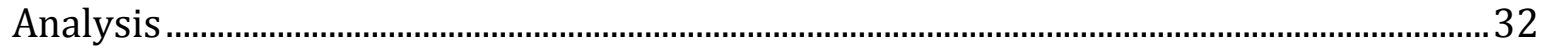

Ngā Whāea (mothers): brief biographical contexts..................................................................33

CHAPTER FOUR: THE MEDICAL GAZE OF HEALTH SERVICES..................38

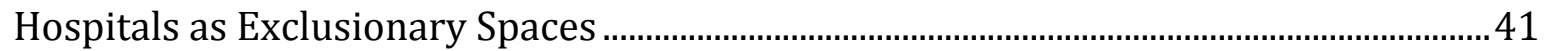

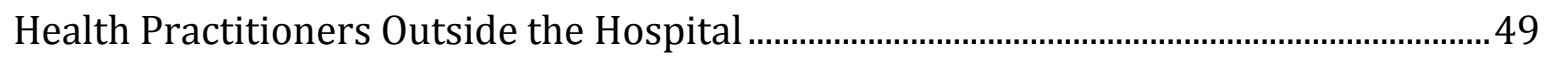

Resisting the Totalizing Gaze? A preference for Māori health practitioners .....................53

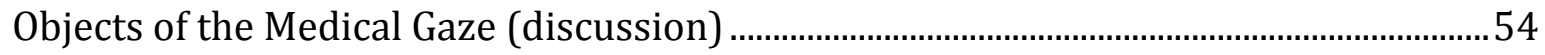

CHAPTER FIVE: THE DISCIPLINARY GAZE OF 'SOCIAL' SERVICES .........56

Teacher Judges (the education system). .59 


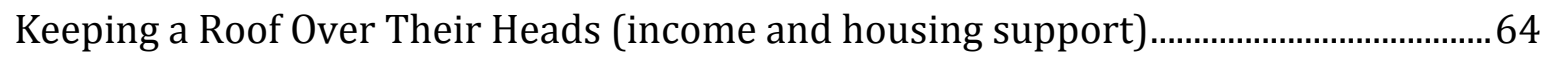

Social Worker Judges: Child, Youth and Family ..................................................................... 75

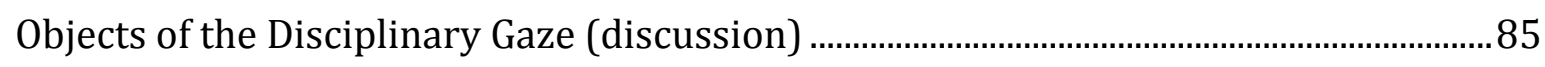

CHAPTER SIX: THE COLONIAL GAZE (ĀTETANGA!/RESISTANCE!) .......88

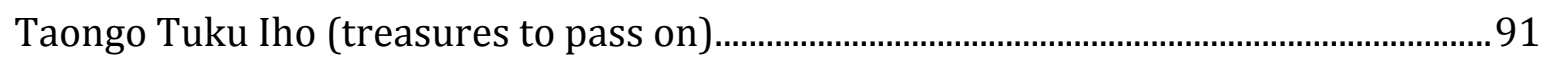

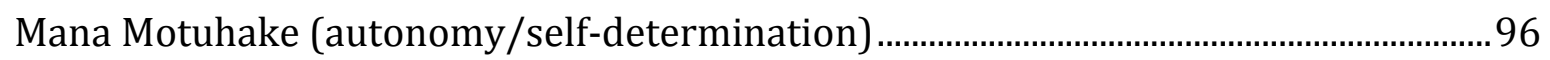

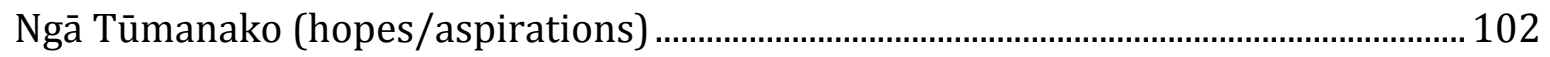

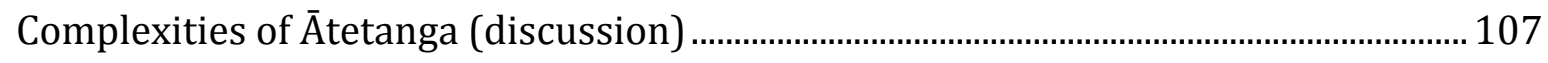

POROPOROAKI (farewell) .................................................................... 110

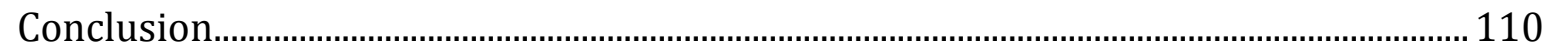

Reflections and Possibilities for Further Research......................................................... 115

Implications of the Research ..................................................................................... 116

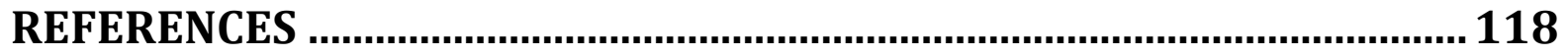

APPENDIX A: E HINE INTERVIEW SCHEDULE 1 ................................... 130 


\section{List of Tables}

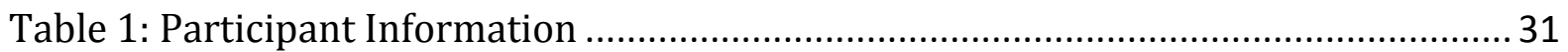

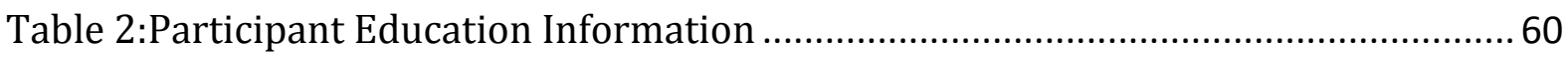

Table 3: Participant Living Situation Information (at time of last interview) ..................65 


\section{Acronyms}

CYF

CYPF Act

GP

HNZC

NCEA

NICU

NZE

SIDS

TPU

WINZ

WfFTC

YPP
Child, Youth and Family

Children, Young Persons, and their Families Act (1989)

General Practitioner (doctor)

Housing New Zealand Corporation

National Certificate of Educational Achievement

Neonatal Intensive Care Unit

New Zealand European

Sudden Infant Death Syndrome

Teen Pregnancy Unit (attached to a secondary school)

Work and Income New Zealand

Working for Families Tax Credit

Young Parent Payment 


\section{Glossary of key Māori terms}

\begin{tabular}{|c|c|}
\hline E Hine & Girl \\
\hline Hapū & Sub tribe or pregnancy \\
\hline Hōhā & Exasperating/annoying/to be fed up \\
\hline Hui & Meeting \\
\hline Iwi & Tribe or bone \\
\hline Kāinga & Home/s \\
\hline Karakia & Incantations \\
\hline Koha & Gift \\
\hline Kōhanga reo & Māori medium early childhood centre \\
\hline Kura kaupapa & Māori medium primary or secondary school \\
\hline Mana & Prestige \\
\hline Māori & Indigenous New Zealand Peoples \\
\hline Marae & Māori community centre/meeting place \\
\hline Mātauranga Māori & Māori knowledge systems \\
\hline Ngā whāea & Mothers \\
\hline Pākehā & Non-Indigenous New Zealander \\
\hline Papatuanuku & Earth Mother \\
\hline Pito & Umbilical cord \\
\hline Rangatahi & Youth \\
\hline Rōpū Māmā & Mothers' group \\
\hline Taonga & Treasure/s \\
\hline Tapu & Sacred \\
\hline Te reo Māori & Māori language \\
\hline Te Tiriti o Waitangi & The Treaty of Waitangi (1840) \\
\hline Tikanga & Customs/protocols \\
\hline Wahine/wāhine & Woman/women \\
\hline Waiata & Songs/to sing \\
\hline Whānau & Family, extended family or childbirth \\
\hline Whenua & Earth or afterbirth/placenta \\
\hline Urupā & Cemetery/graveyard \\
\hline
\end{tabular}




\section{CHAPTER ONE: TĪMATANGA KŌRERO (introduction)}

\section{Thesis Organisation}

This thesis displaces the deficit lens typically assigned to research on young (teen) mothers, with a lens that is trained, not on their deficiencies, but on the technologies that support and regulate them. Chapter One sets the scene for this research. I introduce myself, and the E Hine project, and state my research objectives. I also present the historical context of Aotearoa New Zealand as a colonial nation state. Chapter Two establishes the contextual and theoretical orientations of this thesis. It begins with a literature review of research on teen pregnancy and motherhood in Aotearoa New Zealand, along with some global and Indigenous comparisons. It ends with an overview of the main theoretical concepts that I draw on: Foucault's medical and disciplinary gazes, as well as poststructural theories of resistance; and postcolonial/anticolonial notions of the colonial gaze, and strategies of resistance. Chapter Three covers methodological procedures, including methods of data collection and a description of thematic analysis. It also includes a brief biography of each of the young mothers in this study. Chapter Four explores participants' experiences as objects of the medical gaze in the hospital, and with local practitioners; as well as considering preferences for Māori practitioners. The disempowering effects of the medical gaze are discussed, as well as resistance to them. Chapter Five explores the disciplinary gaze of 'social' services, discussing participants' experiences with education, income support, housing support, and Child, Youth and Family. The punitive and disempowering work of these 'support' services are examined, as well as resistance to them. Chapter Six considers the agentic identities of the young mothers in this study, as they resist the colonial gaze. It includes a discussion on the complexities of resistance. I conclude this thesis with a 'poroporoaki' (farewell) - drawing together the medical, disciplinary and colonial gazes, and discussing their effects on teen Māori mothers. I reflect on my research journey and make suggestions for further work in this area. Finally, I outline the implications of this research and suggest that a range of people working in the public sector would benefit from engaging with it. 


\section{Background}

\section{Ko Au (me)}

My experience of being Māori in Aotearoa New Zealand is unique to myself (although perhaps similar to a great many others). My fair skin means I am usually confused for Pākehā, so I cannot say that I have ever experienced first-hand discrimination due to my ethnicity. I am not a teen mother, or a mother at all. But, as a wahine Māori (Māori woman) with a background in education, I am passionate about the health and wellbeing of our rangatahi (youth). I have been working with the Women's Health Research Centre at the University of Otago, Wellington, for the past two years, on a project entitled E Hine (Girl). This thesis critically examines the role of state support services for teenage Māori mothers, by exploring their lived experiences, and the perspectives of their whānau, as captured in extensive interview data from the E Hine study.

\section{E Hine: Reducing barriers to care for pregnant Māori women $<20$ years and their infants}

E Hine is a Kaupapa Māori informed, qualitative research project led by the Women's Health Research Centre (WHRC) at Otago University, Wellington. The aims are:

1. To understand the circumstances and range of needs of pregnant Māori women under 20 years old and their infants during their journey through the health system.

2. To examine both the barriers to, and facilitators of, appropriate health care and wellness for pregnant Māori women under 20 and their infants.

3. To use this evidence, in combination with the results from a related cohort study, to design an intervention(s) based on whānau ora (Māori family wellness) to improve maternal and infant health outcomes. (Lawton et al., 2013, 255)

Kaupapa Māori research respects and prioritizes Māori ways of knowing and being, acknowledges Māori as active agents rather than victims, and ultimately benefits the 
Māori community (Smith et al., 2012; Hoskins, 2012). Extensive local Iwi, community and key stakeholder consultation took place before the E Hine project started, with the support of kahui kaumātua (a council of elders), ensuring that the study would be relevant and culturally appropriate (Lawton et al. 2013). Interviews with 44 Māori teen mothers and their whānau were conducted in Wellington and Hawke's Bay, over a three-year period, with data collection completed in 2014. Key stakeholders from government agencies, the Family Planning Association, and from District Health Boards were also interviewed. I joined the WHRC team as an honours student in 2014, analysing data from the key stakeholder interviews. In 2015 I was invited to analyse data from the Rōpū Māmā (mothers' group) for my Master's thesis. And so I began 'E Hine, Ngā Whāea (Girl, Mothers): Teen Mothering in the Gaze'.

\section{'E Hine, Ngā Whāea: Teen Mothering in the Gaze' Research Objectives}

Aligning with the original E Hine aims, the objectives of this research are:

1. To understand the life circumstances of teen Māori mothers - in particular, to understand how social factors influence health outcomes.

2. To examine the role of the state in the lives of teen Māori mothers, as support mechanism, and as regulatory mechanism.

3. To use the findings to augment E Hine recommendations that will inform state policy and initiatives, in order to improve the lives of young Māori mothers and their whānau. 


\section{Historical Context of Aotearoa New Zealand: Pre-colonial, New Arrivals, \& Beyond}

\section{Te Ao Mãori (the world of Mãori): Pre-colonial}

Prior to European arrival in Aotearoa New Zealand (in the late $18^{\text {th }}$ century), Māori society was comprised of many separate and autonomous Iwi (tribes). Everyday life was lived collectively within whānau and hapū (sub-tribe) groups. Gender roles within pre-colonial Māori society relied on "balance and mutual collective responsibility" (Moewaka Barnes, 2010, 43), with tamariki (children) taken care of by the wider family group. Sex was not a shameful act, and menstruation, pregnancy and childbirth held special tapu (sacred) significance. From a traditional Māori perspective, women have unique, special and exclusive mana (authority) that is related to their position as 'whare tangata', literally meaning 'house of mankind' and translating as "she who carries and gives birth to the next generation" (Rimene et al., 1998, 28). As this name suggests, the ability of women to "shelter and bring forth life into this world" (Rimene et al., 1998, 29) was venerated in te ao Māori (the Māori world).

Māori women traditionally gave birth in Te Whare Kōhanga (a nest house), "a special building constructed for the labour of the expectant mother and the birth of her child" (Rimene et al., 1998, 38). Karakia (incantations) were chanted, and waiata (songs) sung. Traditionally, the whenua (placenta) was buried in a special place in the whenua (ground) to form a bond between the baby and Papatuanuku (Earth Mother), and the pito (umbilical cord) "was placed in the cleft of a rock or tree, or buried in a spot marked by a stone or post" (Rimene et al., 1998, 68). The birth of a new member of a whānau/hapū/Iwi represented the preservation of the whakapapa (bloodline), and was celebrated as such (Rimene et al., 1998).

\section{Māori and Early Settlers}

When Pākehā (non-Māori) arrived in steady numbers from the late $18^{\text {th }}$ century, "Māori had a keen interest in the new relationship" (Orange, 2004, 4). Initially, Māori outnumbered Pākehā, and Pākehā relied on Māori for provisions and safety (Orange, 2004). The British Crown "had little choice but to allow chiefly institutions and Māori customs to continue" (Hill, 2004, 31). Māori were technologically savvy, and traded 
enthusiastically for European items and knowledge. Metal objects (previously unavailable to Māori), like nails (that could be used for carving) and scissors; and skills like the written word were highly sought after (Orange, 2004). Unfortunately, with European technology came the introduction of the musket, to a tribal society that could formerly only engage in hand-to-hand combat (King, 2003).

\section{The Declaration of Independence and Te Tiriti o Waitangi (The Treaty of Waitangi)}

During the 1820s and 1830s the Māori population plummeted due to introduced disease, and intertribal warfare. While intertribal warfare was a staple part of precolonial Māori society, the introduction of the musket meant that war could now cause a lot more damage. It is estimated that at least 20,000 Māori died during the 'musket wars', which spanned from the early 1800s until the late 1830s (King, 2003). Around this time, James Busby (British Resident in New Zealand, representative of the Crown) encouraged 34 northern chiefs to sign 'A Declaration of Independence of New Zealand' in 1835. One explanation is that he thought it might end intertribal warfare by creating a sense of collective sovereignty (Orange, 2004). This declaration proclaimed New Zealand as an independent state, with authority to remain exclusively with chiefs and tribal heads. British subjects would be protected and permitted to go about their business, with the expectation that the King would retain a friendly, paternal relationship with the United Chiefs (Orange, 2004).

Not long after the acceptance of the Declaration of Independence, British officials sought for Māori to cede their sovereignty to the Crown, by way of treaty. Rather than a British colony where settlers would be accommodated by Māori (like outlined in the Declaration), "the plan was for a settler New Zealand in which Māori people would have a special 'protected' position" (Orange, 2004, 19). In January of 1840, Governor-to-be William Hobson (with the help of James Busby) drafted a treaty consisting of three articles, which was then translated into Māori by missionary Henry Williams and his son Edward. Māori chiefs were invited to a hui (meeting) in Waitangi to discuss. On the $6^{\text {th }}$ of February 1840, a number of northern chiefs signed Te Tiriti o Waitangi (The Treaty of Waitangi), with many more signatures (over 500 in total) gained over the following months, as Te Tiriti was taken around the country (Orange, 2004). 
There are significant ambiguities in, and discrepancies between, the English and Māori texts of Te Tiriti. In article one of the English text Māori cede sovereignty to the Queen, whereas, in the Māori text they only give the Queen kawanatanga (governance or government). In article two of the English text Māori are guaranteed possession of their lands, properties, forests and fisheries, whereas, in the Māori text they are guaranteed te tino rangatiratanga (chieftainship/sovereignty) over these things, listed as: whenua (land), kāinga (homes), and taonga (treasures). The 'taonga' that is given protection here can be interpreted as including such ('non-physical') things as language and health. Article three of both English and Māori versions convey the similar message, that Māori should have all the rights and privileges of British subjects (Orange, 2004).

\section{Post-Tiriti Turmoil}

After the signing of Te Tiriti, Māori became gradually more disillusioned with the Crown. The settler population grew rapidly, and by 1860 it was about the same as the Māori population. Settlers wanted more land, did not agree with assertions of Māori independence, and "thought that a war to assert British sovereignty was inevitable" (Orange, 2004, 61). War broke out in the early 1860s, throughout the central North Island, between those Māori resisting the loss of land, and colonial forces. Colonial troops were replenished from Australia, and supported by settlers, and Māori collaborators. Māori 'rebels' were eventually greatly outnumbered and overpowered, and the formation of the New Zealand Settlements Act in 1863, which allowed the confiscation of Māori 'rebel' land, added further damage. This confiscation left "a permanent legacy of bitterness" (Orange, 2004, 73).

Towards the end of the $19^{\text {th }}$ century, after many years of war, a "policy of amalgamation" (Orange, 2004, 77) was adopted. Early colonial ideas - "that the superimposition of a 'superior culture' on an allegedly inferior one would create a 'fatal impact'" (Hill, 2004, 19) changed to assimilationist policies that endeavoured to "'make good Europeans out of Maoris'” (Hill, 2004, 19). Māori gained certain levels of citizenship, such as voting rights (for males aged over 21) and parliament representation. Māori were encouraged to assimilate into Pākehā ways of living through strategies like the Native Schools Act (1867), which encouraged the suppression of te reo Māori for more than one hundred years (Orange, 2004). Various Native Land Acts, 
from the 1860s on, attempted to convert traditional tribal (collective) ownership of land into individual titles. This resulted in mass land loss for many Māori, as shoddy deals were made with settlers and government alike. By the early 1890s, almost the entire South Island had moved out of Māori hands, while only one third of the land area of the North Island remained in Māori ownership (Orange, 2004).

\section{Twentieth Century in the 'Land of Plenty'}

The early $20^{\text {th }}$ century saw more government reforms that abetted the loss of Māori land and cultural freedom (Orange, 2004). In 1900, the Māori Councils Act was devised in the name of ensuring "the 'health and welfare and moral well-being' of Māori" (Hill, 2004, 50). However, unofficially, these Māori Councils were a product of government anxiety to further the assimilation of Māori and to "neutralise dangerous opposition to its hegemony" (Hill, 2004, 56). While Māori saw some health benefits from the organisation of Māori Councils, those benefits "came at the price of continued tightening of the Crown's general surveillance and control of Māori" (Hill, 2004, 58). The Tohunga Suppression Act (1907), which was introduced by James Carroll and endorsed by Apirana Ngata (both prominent Māori politicians who would later receive knighthoods), also had complicated repercussions (Durie, 1997). It was created in the name of public health - to encourage modern medicine in Māori communities. However, it outlawed Māori traditional healers (tohunga), undermined Mātauranga Māori (Māori knowledge systems), and sought to eradicate resistance to Pākehā ways of living (Durie, 1997; Hill, 2004).

The period following World War Two saw a significant diaspora of Māori to urban (mostly Pākehā) centres (King, 2003; Tauri, 1998). This urbanization resulted in increasing comparison of Māori to middle class Pākehā, always through a deficit lens (O’Sullivan, 2007), and "cultural and emotional dislocation" (King, 2003, 473) for many. The Māori Affairs Act (1953), allowed further appropriation of and meddling with Māori land, in the name of economic rationalisation (Orange, 2004). By the 1970s, te reo Māori faced near extinction due to the effects of the Native Schools system and the breakdown in tribal and family links following urbanisation (King, 2003). The economic downturn of the end of the $20^{\text {th }}$ century also hit Māori the hardest, "most of whom were still at the lower end of the socio-economic scale" (Orange, 2004, 138). 
Protests against state racism and the disregard for Te Tiriti increased in the 1960s and 1970s (Orange, 2004; King, 2003). International Indigenous rights and human rights campaigns influenced Māori self-determination politics, and a Māori renaissance began, challenging assimilationist views (O’Sullivan, 2007). The Race Relations Act (1971) was set up to outlaw discrimination and to help race relations (King, 2003). The Treaty of Waitangi Act (1975) meant that historic grievances with the Crown would finally be heard (Orange, 2004). Kōhanga Reo (Māori language pre-schools) and kura kaupapa (Māori medium) schools were developed to reinvigorate te re Māori, and Māori demanded more representation across all social spheres (King, 2003).

\section{The New Millennium}

Today, at approximately $15 \%$ of Aotearoa New Zealand's population (Statistics New Zealand, 2015), Māori are largely over-represented in negative statistics. Māori tend to fare worse in the education system (Ministry of Education, 2014a); suffer worse health (Ministry of Health, 2015); have lower income, higher benefit receipt, and more involvement with the criminal justice system (Ministry of Social Development, 2013); and are more likely to experience intergenerational disadvantage (Welfare Working Group, 2011). The detrimental effects of loss of land (physical sustenance) and loss of culture (emotional sustenance), caused by colonisation, are ignored in favour of neoliberal rhetoric of 'personal responsibility', which shifts the blame for the marginalized position of Māori from the state onto 'deviant' individuals (Poata-Smith, 2008).

Neoliberalism is a political strategy of laissez-faire (free-market) ideology that has gained momentum in Aotearoa New Zealand in the new millennium. It promotes deregulation, competition and privatization. It generally leads to the devolution of welfare services, a shift from 'welfare' to 'workfare' states, and the proliferation of precarious work conditions (Wacquant, 2009). Neoliberalism has become synonymous with 'best practice' governance, entrepreneurialism and individualism (Leitner et al., 2007). Neoliberal governmental technologies monitor and calculate. Individuals are subject to this gaze, and are obliged to work on themselves as "personal and social responsibility are equated with self-esteem" (Leitner et al., 2007, 4). Thus neoliberalism 
embeds itself in individuals as a form of governmentality ${ }^{1}$ and allows the state to 'govern at a distance' (Rose, 1996).

Māori world views; struggles for tino-rangatiratanga (self-determination), mana motuhake (autonomy) and the protection of taonga (treasures); and resistance to freemarket ideology are perceived as barriers to neoliberalism (Bargh, 2007). Neoliberalism relies on the principle of meritocracy, the adage that 'everyone is equal', in terms of equal to participate and succeed (if working hard enough). And so cultural difference and historically induced disadvantage are disregarded. In this lens, the special status of Māori as tangata whenua (original peoples/peoples of the land) is seen as unfair and irrelevant to other New Zealanders (Came, 2012).

1 Governmentality is discussed further in the theoretical section. 


\section{CHAPTER TWO: NĀ REIRA (contextual and theoretical orientation)}

\section{Contemporary Context: Statistics, Constructions and Experiences of Māori Teen Motherhood in Aotearoa New Zealand}

\section{Statistics \& Deficit Based Constructions}

Aotearoa New Zealand has the second highest rate of 'teen pregnancy' in the Organisation for Economic Co-operation and Development (OECD) countries, ranking only after the United States of America (Families Commission, 2011; Ministry of Social Development, 2010). Rates of teen pregnancy vary significantly between and within regions, but are higher in areas with the highest levels of deprivation ('poverty'), and amongst Māori (Families Commission, 2011). Māori women are more likely to become pregnant and give birth during their teenage years than their non-Māori counterparts. For example, they are generally three times more likely to give birth during their teenage years than New Zealand European (NZE) women (Families Commission, 2011).

The rate of births to teen mothers in Aotearoa New Zealand has decreased significantly since the 1960s, and two thirds of teen mothers are legally adult (aged 18 or 19 years at birth) (Families Commission, 2011). However, in media, medical literature and public policy, teen pregnancy/motherhood is treated as a cause for concern (Breheny, 2006; Jackson, 2004). Research has tended to be "biomedical... [using] quantitative methodologies" (Collins, 2005, 63), with a focus on the 'risks' of teen parenthood for young mothers and their children.

Recent examples of such risk-focused research are drawn from Aotearoa New Zealand's two birth cohort longitudinal studies, undertaken in Christchurch and Dunedin. From the Christchurch study, Boden et al. (2008) found that teen motherhood negatively impacts educational achievement and economic viability. The Ministry of Social Development (2010) has published findings from both the Christchurch and Dunedin studies, listing risks associated with teen pregnancy. In the Christchurch study, women who mothered before age 17 (compared to those who mothered at 21 years old or over) were more likely to have had parents with drug problems, to have experienced sexual 
and/or physical abuse, to have had depression, and to have had behavioural issues at school. After the birth, they were more likely to be on a benefit, have no qualifications, and have mental health and/or substance abuse issues (Ministry of Social Development, 2010). From the Dunedin study, children of teen mothers were more likely to leave school early, face long term unemployment, be involved with the criminal justice system, and become teen parents themselves (Ministry of Social Development, 2010).

By focusing on the risks of teen parenthood, research frequently frames teen mothers as the problem, instead of exploring the structural issues at play (Breheny, 2006). Health interventions often "focus on identifying deviant individuals and families, rather than on ways to address the social context of disadvantage" (Breheny \& Stephens, 2008, 754). While teen pregnancy/motherhood is often portrayed as a Māori problem (Breheny, 2006), the socio-historic context of colonization is ignored.

\section{Challenging Deficit Based Constructions}

A valuable body of work to call upon is Breheny's (2006) doctoral thesis. While this thesis does not explore the perspectives of teen mothers, it attempts to problematize negative stereotypes about teen mothers by shedding light on constructions of teen motherhood in health professional literature and talk. Breheny found a number of different discourses used by health professionals, that were all called on in order "to construct a 'cycle of disadvantage'" (2006, iii), where individual women and families are blamed for their poor choices or deviance. These individuals are then open to intervention, with structural issues and the social location of teen motherhood ignored (Breheny, 2006).

According to Breheny, "health professionals have considerable influence over mothers" $(2006,25)$, as they monitor mothers through their children. With maternity care for mothers, Well Child (Plunket or Tamariki Ora) care for infants, and school nurse care for children, the "child becomes the object of scientific gaze and by assessing the normality of the child the mother can be assessed" (Breheny, 2006, 26). This creates a power imbalance between health care provider, who is the judge of normality, and teen mother, who is open to the intense scrutiny and surveillance of the medical gaze. 
Resistance to such scrutiny can result in barriers in access to care, as teen mothers might avoid health professionals (Breheny, 2006).

Breheny asks us to consider how teen pregnancy is constructed as a public health issue, and argues that it is not coincidental that "what is best for [teen women] is also what makes them most useful to the state" (Breheny, 2006, 42). She draws upon Foucault's 'medical gaze' to describe how the young female body is deemed in need of "careful management through reproductive technology and by medical and public health institutions" $(2006,43)$. Breheny also argues that young Māori women in particular are targeted, as targeting Māori fertility in general "would be outrageous" $(2006,114)$. However, when framing it as concern for the "poor outcomes [of] the children of Māori adolescent mothers it appears acceptable" (Breheny, 2006, 114). This alternative way of viewing the construction of teen motherhood challenges the 'neutral', 'objective' positioning of scientific/medical research.

\section{Research 'With' Teen Mothers in Aotearoa New Zealand}

There is very little research that specifically addresses te ao Māori (Māori world) views of teen parenthood, or considers the lived experiences of Māori teen parents (Families Commission, 2011; Jackson, 2004). A small number of qualitative studies in Aotearoa New Zealand explore the perspectives and experiences of teen mothers (Collins, 2010; Collins, 2005; Makowharemahihi et al., 2014; Rawiri, 2007), with two specifically focusing on Māori teen mothers (Makowharemahihi et al., 2014; Rawiri, 2007). ${ }^{2}$

E Hine, a qualitative study into the lived realities of 44 young Māori mothers (aged 1319 when becoming pregnant with their first child), of which this thesis is connected, has so far produced one findings based publication, related to the initiation of maternity care for teenage Māori mothers (Makowharemahihi et al., 2014).

\footnotetext{
2 Other relevant research has been undertaken by Felicity Ware and Maxine Graham, who were suggested as further reading by one of the examiners of this thesis. Ware (2014) advocates culturally appropriate support for young Māori parents, and Graham (2014) explores the experiences of teen mothers who have transitioned to tertiary education.
} 
The majority of participants sought out early engagement with health care services "contrary to published literature" (Makowharemahihi et al., 2014, 52). However, participants generally reported feeling "inadequately supported to be able to identify, confirm, and enrol with a midwife or hospital care" (Makowharemahihi et al. 2014, 52). This indicates a barrier in the maternity care pathway between initial health service contact (that was sought out by these young women) and contact with a lead maternity carer. Finding a lead maternity carer may be difficult for young women who have little experience with health care services (and possibly none with maternity services) (Makowharemahihi et al., 2014). While these young women were initially willing to engage with health services, a lack of appropriate support hindered further (ideal) engagement, putting them at a disadvantage to older/more experienced women.

For her Master's thesis about adolescent Māori mothers' experiences with social support, Rawiri (2007) interviewed 9 Māori mothers aged between 15 and 20 years old. She found that "motherhood can actually improve the life outcomes of some adolescents" (Rawiri, 2007, 18), and that many teen mothers disengage from education before they become pregnant. However, the four participants that attended a Teen Pregnancy Unit (TPU) found the support they received there invaluable.

Rawiri (2007) found that her participants often felt stigmatized by state services, and that they disliked/avoided approaching them. This contributed to an atmosphere of mistrust, and affected the level of participation in and knowledge about support services (for the participants). Immediate family members provided the most support to the participants in her study, and Rawiri recommends that more support be available to those families, and to those young mothers wishing to become more independent. She also argues for more culturally responsive support services, such as bi-lingual antenatal classes (Rawiri, 2007).

For Collins' (2005) doctoral thesis, she interviewed 18 young mothers (who had been 19 or under when they gave birth). The participants predominantly identified as Pākehā (11), with 6 identifying as Māori or Māori/Pākehā, and 1 identifying as Pasifika. Collins found that young mothers are stigmatized in a number of ways, including because of "age, gender, ethnicity, lone parenthood, and benefit receipt" $(2005,286)$. Many of 
Collins' participants experienced discriminatory treatment, even in interactions with supposed support providers, such as medical practitioners and Work and Income New Zealand (WINZ) staff (Collins, 2007). An example is that many participants "felt uncomfortable in maternity wards where others were significantly older, believing that the insensitive treatment they received was related to the stigma of teenage pregnancy" (Collins, 2005, 275). Collins' (2005) participants also faced difficulties finding appropriate housing, employment and education/training; and hardships related to sole parenthood and health/mental health issues.

Collins (2005) suggests training for hospital and medical staff, in engaging with young women who are pregnant or mothering. She also calls for "more enlightened social policies and practices" $(2005,299)$ that support young mothers rather than punish them for their 'poor choices'. Collins argues that support service staff need to hear the voices of young mothers and consider their lived experiences of those services, as not doing so will continue to "perpetuate their powerlessness and the domination of adults who speak for them or about them" (Collins, 2005, 288).

Collins (2010) revisits 13 of the young mothers (10 Pākehā and 3 Māori) who she interviewed for her doctoral thesis (2005). Collins argues that many of the participants in her study challenge stereotypes, and show resilience in the face of adversity (2010). The participants in Collins' (2010) study did not see their lives through a deficit lens, instead seeing motherhood as a positive influence in their lives. While many participants had faced stigma and other adversities, such as mental health issues and relationship breakdowns, they reported feeling proud of what they had achieved in the seven years since the initial interviews. In 2008, six participants were no longer receiving financial assistance, and of the seven still receiving support, four were doing some kind of part time work (Collins, 2010). Collins' (2010) highlights the importance of strong social support (by whānau, friends and state services) in encouraging positive outcomes for young mothers and their children. 


\section{International Context: A Global Problem?}

\section{Resisting Risk Research}

In recent decades there have been a number of international studies using qualitative methods that explore the lived experiences of teen mothers, and challenge 'risk' centred research and the deficit lens. Studies in Australia (Hanna, 2001), America (Furstenburg, 2007; Gregson, 2010; Luker, 1996; SmithBattle, 2009) and the United Kingdom (Arai, 2009; Hadfield et al., 2007; Lawlor \& Shaw, 2002; Yardley, 2008) question the construction of teen pregnancy as a public health issue and social ill. These studies highlight the immense stigma attached to teen mothers and the disempowering impact this has on them. They also argue that it is not teen pregnancy that results in poor outcomes for young mothers and their children, but the disadvantage and adversities that preceded any pregnancies. Findings in these studies suggest that socio-economic disadvantage is the fundamental issue that needs to be addressed (not teen pregnancy).

\section{Indigenous Teen Mothers and Indigenous Framing of Teen Motherhood}

Research projects with Indigenous mothers in Australia (Larkins et al., 2007; Senior \& Chenhall, 2008; Watson et al., 2002) and Canada (Eni \& Phillips-Beck, 2013; Mann, 2013; Browne \& Fiske, 2001), where (like Aotearoa New Zealand) Indigenous women are more likely to mother as teens, have exposed similar themes as Rawiri (2007) and E Hine (Makowharemahihi, 2014). While mothers (in these studies) often commended specific health care and support workers, many also reported that they felt like they had experienced race/ethnicity-based discrimination at times, such as being given insufficient information, or experiencing differential treatment/being treated with suspicion.

It would be erroneous to promote an assumption that all Indigenous peoples are the same. However, Eni and Phillips-Beck state, "[t]eenage pregnancy and parenthood in First Nation communities happens within ongoing (post)-colonization, socio-ecological inequalities, marginalization, and poverty" $(2013,1)$, a succinct point that I believe is relevant to Māori. Eni and Phillips-Beck also argue that the teen mothers in their study did not see themselves as the social problems that they were made out to be, and that as such, the problematizing of teen motherhood, and of certain communities, is a 
"byproduct of exclusion" (2013, 3). From whose perspective is someone/some community not normal/good/unproblematic?

\section{Theoretical Orientation}

This thesis draws on concepts of 'the gaze'. Michel Foucault's medical gaze and disciplinary/panoptical/carceral gaze, added to by Nikolas Rose, are considered alongside poststructural conceptions of the social construction of identity and youth, and strategies of resistance. Homi K. Bhabha's articulation of the colonial gaze is considered alongside Indigenous perspectives of the colonial gaze, and postcolonial/anticolonial conceptions of resistance. These 'gazes' provide a conceptual framework for problematizing the problematization of Māori teen motherhood in Aotearoa New Zealand.

\section{Foucault and Poststructural Conceptions of Power and Resistance}

\section{The Medical Gaze (Unhealthy/Healthy, Normal/Abnormal)}

Foucault (2003a; 2002; 1995; 1977; 1973; 1972) argues that disciplines, such as Medicine and Science (and the disciplinary practices involved in these professions), work to maintain power imbalances by accepting/promoting certain ideas as Truths, and excluding others. These disciplines adhere to Enlightenment values of rationality, objective truth and progress - the body can be known and mastered. Truths/dominant discourses impose on society an order, where deviation can be identified, confined, evaluated, and treated. This 'gaze' has a normalising function (Foucault, 2003a; 2002; 1973; 1972).

According to Foucault, the 'medical gaze' is the imposition of medical Truths over society. Health practitioners observe, judge and seek to cure illness and abnormality (Foucault, 2003a). The medical gaze produces knowledge from these interactions, and this knowledge reinforces the authority of the medical discipline through the perpetuation of binaries, such as healthy/unhealthy and normal/abnormal (Foucault, 2002; 1972). Foucault (1977) implores us to challenge the authority of dominant 
discourses (Truths), such as Medicine - to see that these discourses of Truth are really games of veridiction that attempt to legitimate dominant ideologies.

\section{The Disciplinary/Panoptical/Carceral Gaze (Good/Bad, Normal/Abnormal)}

Foucault (1995) argues that the disciplines, such as Medicine and Science (adhering to Enlightenment values as discussed previously), have led to a 'disciplinary' technique of government, where bodies are manipulated so that they "may operate as one wishes, with the techniques, the speed and the efficiency that one determines" $(1995,138)$. The disciplinary/panoptical/carceral gaze (henceforth 'disciplinary gaze') uses observation and surveillance, individualization and separation (confinement), and normalization to produce useful 'docile bodies' (Foucault, 1995). Under the disciplinary gaze, individuals subject themselves, their bodies and minds, to the "universal reign of the normative" (Foucault, 1995, 304). And so, we become the very tools through which we are controlled. From birth we are disciplined, installed with a desire to conform to society's norms, to appease the judges of normality. To do otherwise is to risk being labelled deviant.

According to Foucault $(2014 ; 2001 ; 1997 ; 1988 a)$, 'technologies of the self' are the techniques that we perform on ourselves, our bodies and souls that transform us with the goal of reaching "a certain state of perfection, of happiness, of purity, of supernatural power" (Foucault, 1997, 181). By enacting technologies of the self (taking care of the self), the subject (self) takes on the task of 'to gaze,' and the gaze is directed inwards (Foucault, 2001). For Foucault (1988a), modern techniques of selfimprovement and ascetics (self-discipline) are tightly bound with truth games of morality and normality.

Nikolas Rose has further developed Foucault's concept of technologies of the self, using the term 'governmentality'. According to Rose, governmentality is a disciplinary technique of contemporary neoliberal nation states (1996), whereby individuals are encouraged to desire freedom insomuch as being 'free' requires appropriate engagement in acceptable practices (and avoidance of unacceptable practices). And so, individuals may practice freedom insomuch as it conforms to acceptable social/cultural/political norms. Rose (1999) argues that the disciplines, particularly 
those utilizing psychological expertise, produce subjects that are governable through their own desires - through the work they do on their souls. This allows the state to 'govern at a distance' (Rose, 1996), as subjects work on themselves, to become experts of themselves.

Rose posits that childhood has become the most regulated "sector of personal existence" $(1999,123)$, as children embody hopes of an ideal future. Similarly, academics critically examining the notion of 'youth' and 'adolescence' argue that the social construction of youth and adolescence has become a disciplinary tool for creating the 'right' kinds of citizens. Adolescence invokes very specific medical/scientific discourses about appropriate cognitive development and naturalized life course (Lesko, 2001a; 2001b; Jenks, 2001; Raby, 2002). Age (and adolescence), as a naturalized category "organizes, homogenizes and regulates social behaviour... [and] may also trigger anxiety, selfcritique, and/or resistance" (Raby, 2002, 19). Childhood and youth are cultural events, products of, and producing, knowledge; abiding by particular rationalities, rules, conditions and forces (Pena, 2006).

\section{Resisting the Gaze}

According to Foucault (1980), power is not a single institution, figurehead, entity, or an individual strength. Rather, power is a process (or set of processes) in constant disequilibrium, a tug-of-war between various nodes, reversible and transformational. Power can be understood as these "ceaseless struggles and confrontations" (Foucault, 1980, 92). For Foucault, power "is the name that one attributes to a complex strategical situation in a particular society" $(1980,93)$, and is the result of the many apparatuses at work (1995). All relationships (with others and with the self) involve relations of power that reflect or hint at wider networks of hegemonic power. Relations of power reinforce established values and norms, but also produce opposing strategies/techniques. Foucault highlights the interdependent relationship of power/resistance. He states "[w]here there is power, there is resistance, and yet, or rather consequently, this resistance is never in a position of exteriority in relation to power" (Foucault, 1980, 95). For Foucault, power relationships rely on resistance for their very functioning. This affords individuals some agency - to be able to resist domination. 
Poststructural feminists argue that all power relations should be contested regardless of their destabilizing effects (Gannon \& Davies, 2007). The problematizing of universal Truths (and 'the gaze') acknowledges that the road to liberation/empowerment is also problematic, as 'everything is dangerous' - a sentiment articulated by Foucault (1988b), and taken up by many other poststructuralists (McLeod, 2001). As "one can never stand outside of discourse... [so] subjectivity is also subjection to the available ways of being" (Gannon \& Davies, 2007, 78). Agency is possible, albeit "contingent and situated" (Gannon \& Davies, 2007, 73). Butler (2006; 2004) draws on Foucault to explain how power not only happens to the body, but also is "the occasion in which something unpredictable (and, hence, undialectical) happens to power; it is one site of its redirection, profusion and transvaluation" (Butler, 2004, pp. 186-187). We are never outside discourse, and the discursive practices that shape us. But although we are influenced and constrained by discourse/power structures, we also have agency to redirect/resist these forces (Butler, 2006; 2004).

\section{Bhabha and Postcolonial/Anticolonial Conceptions of Power and Resistance}

\section{The Colonial Gaze (Us/Other, Civilised/Savage)}

The colonial gaze is Eurocentric and imperialist. Eurocentrism is a bias preferencing European history, ideas and values. Eurocentric beliefs are founded on the idea that the progress of modernity, of 'civilisation', is due to European culture; and that the spread of such civilisation "through trade, settlement, emulation, conquest, and colonialism" is a positive thing (Seth, 2014, 311). According to Bhabha (1994), the colonial gaze sees colonized peoples as perpetually deficit. The colonizer imposes an identity on the Other; and the colonizer's own identity is reassured through this binary of Us/Other, civilised/savage (Bhabha, 1994; Fanon, 2008).

For Indigenous peoples the world over, "[i]mperialism still hurts, still destroys and is reforming itself constantly" (Smith, 1999, 19). Colonization has re-ordered Indigenous worlds - in deficit, in the margins, in strict oppression and subjugation (Smith, 1999). The disciplinary order of colonial society has negatively impacted Indigenous peoples, causing destruction of Indigenous knowledge systems, language, and spiritual/cultural 
practices, familial relations, gender relations and relations to the self (Smith, 1999). Societal/structural issues have been framed as Indigenous issues, put "in the 'indigenous problem' basket, to be handled in the usual cynical and paternalistic manner" (Smith, 1999, 153). The colonial gaze continues to marginalize Māori today.

\section{Postcolonial and Anticolonial Strategies of Resistance}

Smith (1999) argues that reframing research is one way of challenging Eurocentric, colonial worldviews and the "taken for granted as... natural link between the term 'indigenous' (or its substitutes) and 'problem'” (Smith, 1999, 92). Reframing research in Aotearoa New Zealand (as with Kaupapa Māori research), placing Māori (and Mātauranga Māori) in the centre (de-marginalizing), is a way of challenging deficit views of Māori that are all too common in research and political tropes (Smith, 1999). Thus this thesis acknowledges the validity of Mātauranga Māori and problematizes deficit constructions of Māori teen pregnancy. This is an act of resistance to the hegemonic, colonial gaze of traditional research.

By reconceptualising Māori subjectivity (as not deficit) it is possible to acknowledge other ways of being, including acts of subaltern resistance. Bhabha's (1994) theory of the Third Space offers insight into such resistance. Bhabha (1994) argues that there is a Third space in-between the Other and the image of the Other that is imposed by the colonizer. This is a space of articulation/enunciation and ambivalence, where there is a "productivity of meanings that construct counter-knowledges" (Bhabha, 1994, 22). In the Third Space, self-articulation troubles the projected image of the Other, as the Other is able to negotiate their own identity. Identity in this space is non-static, and primacy is given to none.

Bhabha (1994) describes three such acts of resistance. Through 'mimicry', colonized peoples can pretend to conform, acting almost exactly as they are expected to act, all awhile turning the gaze back on their oppressor, observing and constructing counterknowledges. 'Sly civility' involves the almost-total, almost-over courteous acting of the colonized self, a secret mockery, masking a contempt that is sometimes suspected but not quite proven. Finally, 'hybridity' occurs when colonized peoples take on aspects of their 'given' identity, aspects of their oppressor's identity and other traits as they please, 
to negotiate their own hybrid identity that troubles the objectifying categorisation of them (by colonial forces). These acts of self-articulation afford agency to colonized peoples by denying their strict subjugation to totalizing power (Bhabha, 1994).

\section{Theoretical Links (implications for analysis)}

The medical and disciplinary gazes seek to identify, separate and regulate/normalise those unhealthy/abnormal/deviant subjects. In contemporary neoliberal nation states, the extension of governmentality (an inner gaze) encourages subjects become more adept at regulating themselves. Teen Māori mothers are supported and regulated by the state through the medical and disciplinary gazes, through surveillance and interventions (varying in intensity). They are also encouraged and coerced to work on themselves, to become 'better' citizens. While these gazes have normalising intentions, these young women can also resist their totalizing effects.

The colonial gaze seeks to contain and maintain colonized peoples in a perpetual state of Otherness. In Aotearoa New Zealand, the colonial gaze envisions Māori as deficit and Other. Racial/ethnic discrimination (sometimes combined with too-young-to-mother discrimination) affects the young women in this study on a regular basis. However, they resist being completely disempowered by the effects of this colonial gaze - they resist by standing up for themselves overtly, and also covertly, with what Bhabha describes as subaltern agency.

While I draw on a number of different theoretical perspectives for this research, I believe they are all complementary in their critique of normalizing, disciplining (colonizing) discourses, and their recognition of agency. They engender a complex, nuanced understand of the ways in which young Māori mothers are supported and regulated through different techniques of power. 


\section{CHAPTER THREE: NGĀ TIKANGA (methods \& analysis)}

\section{Methods}

\section{E Hine Access and Participant Selection}

Participants in the E Hine project were identified and recruited through local health, education and social service providers. Young women who identified as Māori, and had been under 20 years of age at the birth of their first child, or for the majority of their first pregnancy, were eligible. Eligible young women who were interested in taking part in the study were given information sheets, and consent forms to sign. Forty-four young Māori mothers were recruited, with half in Wellington and half in Hawke's Bay. Half of the total participants were recruited while pregnant, and the other half were recruited following childbirth. Most of the young women also recommended whānau members to be interviewed. Those whānau members were contacted and provided with information sheets and consent forms as well.

\section{E Hine Interviews}

Interviews followed an in-depth, semi-structured kanohi ki te kanohi (face to face) format. Participants were asked about their pregnancy journey, from 'finding out' about it, to birth and looking after their infant; and in the case of whānau members, about their perspectives on the motherhood journey. Participants were also asked about their life stories and about the significance of their Māori identities. An example of an interview schedule (interview 1 ) is included as Appendix A. ${ }^{3}$ Interviews were conducted by researchers Charrissa Makowharemahihi and Tina Ngata of the Women's Health Research Centre, University of Otago, Wellington. These experienced researchers developed rapport with the interviewees and used open-ended questions to encourage rich, detailed responses. A small koha (gift), a supermarket or phone credit voucher, was given to each participant at the conclusion of every interview to show appreciation for their participation. Young mothers were interviewed 3-7 times in total,

\footnotetext{
3 The information forms, consent forms, and interview schedules total around 5000 words, and so are unable to be included here due to restricted word count. But interview schedule 1 is included as Appendix $\mathrm{A}$, as an illustrative example of the type of open-ended questioning used in the interviews.
} 
approximately once every 6 months, over the course of the study. Whānau members, usually the mother or partner of the participant, were interviewed once.

\section{E Hine: Ngā Whāea Sample Selection}

I selected interview data for 15 participants ranging from 14-19 years old when they first gave birth. The original rationale was to choose those youngest, aged under 16 years old when they gave birth (n7), and those oldest (teens), aged 19 years old when they gave birth (n8). I wanted to compare the experiences of those very young (under the age of consent/below benefit receipt eligibility) and those older (post-secondary school age). However, when going through the data, I realised that two of the '19 year old' participants had actually been 17 years old when they first gave birth. I felt like their stories were important too, so I kept the data on the basis that having two participants in a 'mid' age range would also be informative. See Table 1 for participant information, including whānau interview details. In total I analysed 84 interviews, each ranging from 20 minutes to 80 minutes in length. All of these interviews were conducted between June 2011 and October 2014.

\section{Table 1: Participant Information}

\begin{tabular}{|l|l|l|l|l|l|l|l|l|}
\hline & Name* & $\begin{array}{l}\text { Age at } \\
\text { first } \\
\text { birth }\end{array}$ & $\begin{array}{l}\text { No. of } \\
\text { children } \\
\text { @ last int. } \\
\text { interview. }\end{array}$ & $\begin{array}{l}\text { NCEA level } \\
\text { last } \\
\text { int. }\end{array}$ & $\begin{array}{l}\text { No. of } \\
\text { int. }\end{array}$ & $\begin{array}{l}\text { Whānau } \\
\text { interview } \\
1\end{array}$ & $\begin{array}{l}\text { Whānau } \\
\text { interview } \\
2\end{array}$ & $\begin{array}{l}\text { Total no. } \\
\text { of ints. } \\
(84)\end{array}$ \\
\hline 1 & Awhina & 14 & 1 & 2 & 3 & Mother & - & 4 \\
\hline 2 & Marama & 14 & 1 & 2 & 3 & - & - & 3 \\
\hline 3 & Tui & 14 & 1 & 3 & 3 & Mother & - & 4 \\
\hline 4 & Waimarie & 14 & 1 & 1 & 6 & Mother & - & 7 \\
\hline 5 & Irihapete & 15 & 2 & 0 & 3 & - & - & 3 \\
\hline 6 & Manaia & 15 & $1+$ preg. & 2 & 3 & Nan & Friend & 5 \\
\hline 7 & Ngaio & 15 & 2 & 1 & 3 & P., FIL, SIL & - & 4 \\
\hline 8 & Tia & 17 & 1 & 2 & 4 & Mother & Father & 6 \\
\hline 9 & Tina & 17 & $3+$ preg. & 1 & 6 & Mother & FOB & 8 \\
\hline 10 & Anahera & 19 & 1 & 3 & 6 & Mother & - & 7 \\
\hline 11 & Ariana & 19 & 1 & 3 & 4 & Mother & FOB & 6 \\
\hline 12 & Hana & 19 & 1 & 1 & 5 & Mother & FOB & 7 \\
\hline 13 & Kiri & 19 & 1 & 1 & 3 & Mother & FOB & 5 \\
\hline 14 & Mere & 19 & 3 & 1 & 7 & FOB & Brother & 9 \\
\hline 15 & Pania & 19 & 2 & 1 & 6 & - & - & 6 \\
\hline
\end{tabular}

Key:

FOB = father of baby $\quad$ P. = partner $\quad$ FIL = father-in-law $\quad$ SIL = sister-in-law preg. = pregnant int. $=$ interview $*$ all names are pseudonyms 


\section{Ethics}

E Hine was granted ethics approval by the Central Health and Disability Ethics Committee on the $6^{\text {th }}$ of October 2010, and an extension of the study was approved on the $18^{\text {th }}$ of December 2013. Ethics reference: CEN/10/09/036/AM02. My thesis aligns with the objectives of the original E Hine study, and will complement the findings already garnered by the WHRC. The Victoria University Human Ethics Committee agreed that no further ethics approval was required (as of 23.03.15).

The safety of the participants in this study is of utmost importance. Raw data is kept on password-protected computers, and will be destroyed from non-WHRC facilities upon thesis completion. Participant talk is represented using pseudonyms. No information that could lead to a participant or their whānau being identified is included in the thesis.

\section{Analysis}

\section{Thematic Analysis}

Upon receiving the data for the 15 teen mothers and their respective whānau, totalling 84 interviews, I checked the transcripts of the interviews against the audio recordings, to enable a more reliable understanding of the conversations unfolding. As I went through each participant's data chronologically I prepared a short summary of their 'life story' as told through various narratives.

A thematic analysis of the narratives seemed like the most appropriate analytic tool for such an immense, rich data set. I hoped to reveal each participant's "understanding of the meanings of key events in their lives... and the cultural contexts in which they live" (Gibbs, 2007, 46).

I began a detailed coding of the transcripts (Gibbs, 2007). Although I had some ideas about what themes were occurring in the data from my initial reading and summarizing, I used open coding (codes that arose during analysis) (Gibbs, 2007). These codes were then grouped into themes that were common across the whole data set (Gibbs, 2007). A case-by-case comparison of specific events (such as discovering pregnancy) and 
experiences (such as schooling) revealed similarities and differences between participant narratives (Gibbs, 2007).

The interpretation of the data was informed by the theoretical orientation discussed earlier. While the narratives of whānau members are considered, the voices of the young mothers, as the focus of this study, are prioritized in the analysis.

\section{Ngā Whāea (mothers): brief biographical contexts}

\section{Awhina (14 years old at the birth of her child)}

Awhina was a high academic and sporting achiever until her parents separated and she started living with her father and his new girlfriend. She started playing up at school, and going out all weekend. When she was at intermediate she started going out with Tiare, who was 2 years older. Tiare started getting into drugs and gangs, and was eventually detained in a residential (correctional) unit. Awhina was already excluded from high school when she got pregnant at 13 , and at first wanted to get an abortion, but Tiare and her mother were against it. At first she did correspondence school, and then got into a TPU. At the time of the last interview, Awhina was about to turn 18, and was working towards a certificate for NCEA level 3 and looking after her daughter Kora. She was living with her mother, had separated from Tiare, and was dating someone new.

\section{Marama (14 years old at the birth of her child)}

Marama was taken into CYF custody when she was 11. She lived in a CYF home for a while, but after being strangled by another child there, went to live with an older sister, and her sister's father. She lived happily with them for a while before reuniting with her mother, who had completed drug and alcohol programmes. She was 13 and attending a mainstream college when she started going out with Callum, who was 17 at the time. They dated for 10 months before she got pregnant with her daughter Terina. When she was pregnant, Marama left her college for a TPU, and while she did not want to move at first, she soon grew to enjoy the supportive atmosphere there. Marama broke up with Callum after 4 years together, as their relationship had been strained for a long time, and he stopped contacting her. She lost custody of Terina to her mother after an argument, and got kicked out of home. At the time of the last interview, Marama was 17, living with a family friend, and studying towards NCEA level 3 in hospitality. She was able to see Terina from Friday to Sunday, at her mother's house. 


\section{Tui (14 years old at the birth of her child)}

When Tui got pregnant she moved (with her parents and boyfriend Hohepa) from her local, rural area into the city so she could attend a TPU. Tui and Hohepa lived with her parents until baby Atamarie was around six months old, and then they moved (with baby) into a house together. Tui found it difficult to be away from her friends and missed having a social life. Tui and Hohepa split up for a little while and Tui was the victim of verbal and social media abuse about her choice to go out socializing. At the time of the last interview, Tui and Hohepa were back together. He worked full time in a factory while Tui (who had turned 18) studied at a local polytechnic (having gained NCEA level 3) and looked after Atamarie. The young parents were supported a lot by both of their whānau.

\section{Waimarie (14 years old at the birth of her child)}

Waimarie attended a kura kaupapa school until intermediate, when she started at a mainstream school. After being excluded from college she attended an alternative one. When she found out that the she was pregnant she was 10 weeks along, and was not in a relationship with the father, who was 20 and already a father. She had to leave her alternative college to attend a TPU. By the time her son Hayden was born, 8 weeks early, the father was in prison for theft and burglary. Hayden had to spend a couple of months in the NICU. Waimarie had a number of complications after the birth and ended up being readmitted to hospital 6 times, receiving 9 blood transfusions. CYF was involved due to Waimarie’s age. However, as her mother took over main caregiving responsibilities for Hayden, no further action was taken. Waimarie moved around a lot, living at her mother's house, her father's house, and with other family members while her mother looked after Hayden. At the time of the last interview, when Waimarie was about to turn 17 , she was living with a cousin, studying at a local polytechnic, looking for work, and seeing Hayden every second day.

\section{Irihapete (15 years old at the birth of her first child)}

Irihapete was already doing correspondence school when she found out that she was pregnant. She knew immediately that she wanted to keep the baby and work hard at school. She moved in with her partner (also 15) and his family. About a year after her baby boy Nikau was born, she got pregnant with Anika. While her partner's parents helped a lot with her son, she took on more responsibility for her daughter. After the birth of her son, Irihapete suffered post-natal depression and had some issues with her partner because he would go out a lot leaving her at home alone. However, after her daughter was born, her partner stayed home more and their relationship improved. At the time of the last interview, Irihapete was 18 and studying via correspondence, working on NCEA level 1 and 2. 


\section{Manaia (15 years old at the birth of her first child)}

Manaia was raised by her mother and nan (grandmother), as her mother was also young when she had her. She moved to another city with her mother when she was 11 years old and attended a range of Māori medium (kura kaupapa) and mainstream schools. Her grandmother described her as a naughty, stubborn and fearless adolescent. When Manaia found out that she was pregnant she moved in with her boyfriend Josh and his family. She gave birth while she was visiting her sick grandmother, in another area. A few months after returning home with baby Matiu, Manaia and Josh decided to live apart to work on their relationship. During that time she got pregnant again. She attended a TPU where she completed NCEA level 1 and 2. At the time of the last interview she was 19, pregnant with her second baby and about to begin studying to become a hairdresser.

\section{Ngaio (15 years old at the birth of her first child)}

Ngaio was 14 when she found out that she was pregnant. Her boyfriend (also 14) broke up with her when she told him. When Ngaio revealed her pregnancy to her mother (at 7 months) she was sent to a respite home for vulnerable mothers in another city. When Ngaio returned home after baby Ariki's birth, she was planning to adopt him out, but the father and his family prevented it. Ngaio attended a TPU and started a new relationship with Charlie. She moved in with him and his whānau. After some visits to the hospital, doctors were concerned about bruises on Ariki and notified CYF. Charlie was accused of abuse, and Ariki was put in custody of a paternal aunt. Ngaio left her TPU because she felt too sad to be there without Ariki. A few months later Ngaio became pregnant with her second child, and she decided to go back to the TPU. Ngaio and Charlie attended parenting classes to appease CYF. A few months after baby Wiremu was born Ngaio left Charlie as she was given an ultimatum by CYF. At the time of the last interview, Ngaio (18 years old) had retained custody of Wiremu, and was living with her aunt and nephew, struggling to make ends meet. Ngaio was studying physical education at a local polytechnic, hoping that she could eventually join the police force or military.

\section{Tia (17 years old at the birth of her child)}

Tia described her childhood as difficult because they had to move around a lot. She has some health and behavioural issues, and always struggled at school. Tia was 17 and working part time (as well as attending college) when she met the father of her baby. He was 5 years older and already a father, and stopped contact with her when he found out about the pregnancy. Tia moved to a TPU but still found it challenging. When Kauri was a few months old he almost died due to Sudden Infant Death Syndrome (SIDS). Tia spent 2 weeks in hospital with him, and it was there that she first encountered social workers and CYF. Tia had some issues with her TPU, and their care of Kauri (in the nursery), so she left. At the time of the last interview, Tia (20) had enrolled Kauri in a kōhanga reo, and was studying for a level 3 NCEA certificate. Her parents helped her with childcare and support. 


\section{Tina (17 years old at the birth of her first child)}

When Tina was 15 she started looking after her younger siblings while her mother went out partying. Tina first got pregnant after being with Anaru for about 6 months, but she miscarried. She got pregnant with her son, Hemi, about a year later. When Hemi was five months old she became pregnant with her daughter May, and less than two years later she had her third child Jayla. Tina had to be readmitted to hospital after Jayla's birth due to an infection in her womb. She stayed there for a week, but finally asked to be discharged because her partner was not coping with looking after the other two children. Anaru was mostly on the job seekers allowance, and money was always tight. Tina organized the household bills and children. She also looked after her younger brother and sometimes sister. At the time of the last interview, Tina was 21 and pregnant with her 4th child. Hemi was about to start school.

\section{Anahera (19 years old at the birth of her child)}

Anahera attended kōhanga reo and kura kaupapa until high school, and so she was fluent in te reo Māori. She met her boyfriend Rawiri when she was 14, but they began dating when she was 17 . Anahera gave birth to their son Kahurangi when she was 19, and left Rawiri 1 year later, after she realised that their relationship was not healthy, and was contributing to post-natal depression. At the time of the last interview, Anahera (21) had signed up to a modelling agency, and was planning to continue studying after achieving NCEA level 3, while Kahurangi attended kōhanga reo. Rawiri was also studying and looking after Kahurangi on the weekends. Anahera was dating someone new, but taking it slowly.

\section{Ariana (19 years old at the birth of her child)}

Ariana moved around a lot as a young child, and after getting into some trouble at high school was moved to another school for girls. She enjoyed high school, especially kapa haka, and finished with NCEA level 3. Ariana got a job after she finished high school and started saving to go overseas with a friend. It was during that year that she met Mikaere and became pregnant. Ariana's birth experience was negative because the midwife and staff at the hospital were not respectful or caring in their treatment of her. At the time of the last interview, Ariana (22) and Mikaere were both working full time, saving to buy their first home, while baby Erina attended day-care.

\section{Hana (19 years old at the birth of her child)}

Hana left secondary school with NCEA level 1 . When she found out that she was pregnant, her boyfriend Paul went to Australia to work, but he was able to return for the birth. Paul (working overseas) sometimes helped Hana out with financial assistance. Hana was involved in a fight one night, outside a bar, and she ended up getting periodic detention (PD). At the time of the last interview, Hana was 22 and completing some hours for her PD at the kōhanga reo that Aroha attended. Hana was also studying business at a local polytechnic. She struggled financially to look after Aroha on her own, and she did not declare her relationship with Paul to WINZ for financial reasons. 


\section{Kiri (19 years old at the birth of her child)}

Kiri went to an alternative primary school and then a mainstream college. After year 12 she quit school with NCEA level 1, got a job and went flatting. Around this time, she met her boyfriend Pita, who is about 15 years older than her. She became pregnant and they moved in with her koro (grandfather). She miscarried that pregnancy but became pregnant again and had a baby boy called Te Koha. When Te Koha was around two years old, Pita lost his business and started working for friends on a casual basis. Te Koha and Pita experienced financial hardship for the first time, and so had to apply for welfare assistance. At the time of the last interview, Kiri (22) was studying (an online course) and Pita was looking for more work.

\section{Mere (19 years old at the birth of her first child)}

Mere lives with her partner Rewi, and their three sons Tyler, Josiah and Tamati. Rewi is looking for a job, and Mere is a full time mum. Mere was 19 when she had Tyler, and CYF became involved because of past history with Rewi. However, after Mere and Rewi had some parenting training, they closed the case. When Josiah was born CYF became involved again, amidst allegations that Rewi had hit Mere. Mere and Rewi got kicked out of their home because of a rift with family members, so they went to stay with other family. When Tamati was born, prematurely, CYF became involved again. Mere worried a lot about her children being taken off her, and about being in an undeclared relationship with Rewi (for financial reasons). At the time of the last interview, Mere (21) said that she did not want any more children, except in the future if she was to have a well-paid job where she knew she could take care of everyone financially.

\section{Pania (19 years old at the birth of her first child)}

Pania did not enjoy secondary school, and left after year 12 (with NCEA level 1). On her 18th birthday she got together with James, and became pregnant soon after. She gave birth to her son Tane when she was 19 years old, and a few months later became pregnant with her second child, a daughter named Allyssa. Pania suffered post-natal depression after having Allyssa, but it was picked up quickly by her Plunket nurse. At the time of the last interview, Pania was 22 and had separated from James after discovering him with another woman. She was living with her parents (and children), and depending on a welfare benefit. Pania and James had the courts involved over custody and property issues, and Pania was also concerned over James' drug use. 


\section{CHAPTER FOUR: THE MEDICAL GAZE OF HEALTH SERVICES}

According to Foucault, the medical gaze involves the detached, clinical observation of the body. It separates the body from the person, dehumanizing illness and abnormality, and offering treatment and cure (2003a). The medical discipline draws on Eurocentric ideas of normal cognitive development and naturalized life course trajectories, and is founded on Enlightenment values of rationality and objective truth. According to the medical gaze, adolescent pregnancy and motherhood is a deviation from the norm and thus invites regulation and preventative measures (Breheny, 2006; Raby, 2002).

I was so happy when I first heard her heartbeat. I just couldn't stop laughing I was so happy... [At the birth] I started crying and I was so happy. Probably the happiest I've ever been. (Marama, interview 1)

As expressed by Marama (above), who was 14 years old when she gave birth, the discovery of a pregnancy and the birth of a child can be, and often is, a joyous and wonderful experience, even for mothers who are perceived of as 'too young'. However, by becoming pregnant and deciding to continue their pregnancies, women like Marama are deemed abnormal/unhealthy by the medical gaze.

The young female body, an "ambivalent object" (Walkerdine, 2001, 25) of innocence and erotica, is problematized from the outset, and is particularly liable to surveillance and regulation (Breheny, 2006). Dominant discourses on adolescence tend to adhere to biologically driven, naturalized life course and developmental theories (Jenks, 2001; Lesko, 2001a; 2001b; Raby, 2002). These discourses lock adolescents into a constant state of becoming - neither child nor adult (Lesko, 2001a; 2001b; Raby, 2002). Discourses about children and adolescents perpetuate Enlightenment notions of progress and binaries of Us (adult, rational, civilized) and Other (youth, irrational, uncivilized) (Hultqvist \& Dahlberg, 2001; Lesko, 2001a; 2001b; Raby, 2002; Walkerdine, 2001). They are produced in the realm of adults and are universally applied to all (Bloch et al., 2006; Raby 2002). 
Health discourses, as mechanisms of power, "discursively construct and normalize what is meant by health... [and] legitimatize certain forms of conduct, shaping particular subjectivities" (Weyenberg, 2006, 102). They problematize certain aspects of the physical and emotional, tell individuals how to become better/healthier/more normal, and how to make the right choices. The production of truths about being a normal (healthy) female adolescent is a technique of government, a governmentality, creating self-regulating subjects, with the goal being the "successful transition to adulthood, especially in terms of heterosexual involvement, acceptable femininity, and participation in capitalism" (Raby, 2002, 193). Young women are taught how to look after themselves 'appropriately' - which usually equates with what is in the best interests of the state (Breheny, 2006). Within such discourses, young women who become pregnant are seen as medically and sexually deviant, defying the "bounds of the appropriately disciplined body" (Breheny, 2006, 43). This causes a conundrum. It disrupts the in-between space that teenaged girls are supposed to inhabit (Raby, 2002). Teen mothers must negotiate a number of unequal power relationships - at school (pupil-teacher), home (child-parent), and in clinics (patient-doctor) - where their behaviour is continually monitored and judged (Breheny, 2006).

"Doctors in general practice and in hospital have professional, if not legal obligations to scrutinize the children they see for whatever reason for signs that they may be 'at risk' and notify statutory authorities of their suspicions... [and] health visitors exercise a surveillance, in principle comprehensive and universal, over the care of young children in their homes" (Rose, 1999, 123).

Rose argues that the health system, comprising of hospitals, general practices, and health visitors, keeps surveillance over children and families, where their abnormalities/deviances are judged, documented and disseminated to the wider authorities. Under the New Zealand Public Health and Disability Act of 2000, maternity care is publicly funded and free in Aotearoa New Zealand. However, despite this, Māori mothers and their infants are more likely to experience poor health outcomes during and following childbirth (than New Zealand European mothers and infants), with young Māori mothers and their infants further at risk (Makowharemahihi et al., 2014). This indicates that there are inequalities in our healthcare system that might be attributed to 
institutional racism (Came, 2012) - the "prejudices embedded in the institutions and systems of a society... disadvantaging one group and privileging another" (Came, 2012, 88). In Aotearoa New Zealand, the medical gaze of the health system continues to marginalize Māori through public policy that excludes Māori "input and influence [and] normalises western bio-medical discourses" (Came, 2012, 273). Came (2012) argues that the privileging of Eurocentric knowledge (and being Pākehā) in our health system is so normalized, that it has become taken-for-granted and invisible.

Institutional racism shapes policy direction, funding and allocation of resources. It is much 'bigger' than day-to-day, face-to-face interactions, although it follows that it would affect these too (Came, 2012). However, another way that racism can materialize in health service delivery, in practitioner-patient interactions, is through 'aversive racism'. Aversive racism is where individuals who belong to dominant/privileged groups, and who might consider themselves to be liberal or opposed to racism, avoid interacting with 'Other'/non-dominant/marginalized groups because they feel "ill at ease with the social chitchat" (Dew, 2014, 100). Aversive racism can therefore affect the level of interpersonal connection built between practitioner and patient (Dew, 2014), and could be construed by patients as snobbery or discrimination. This can affect health outcomes. As Durie points out, "[t]here is abundant evidence that where clinician and patient are from different cultural backgrounds there is greater likelihood of misdiagnosis and noncompliance" $(2004,182)$.

As pregnant women, the young mothers in this study were reliant on the health care system for their maternity care, and later, for the care (and monitoring) of their children (and themselves) through Plunket or Tamariki Ora and their local doctors and nurses. They faced assumptions about their decision-making capabilities and their life choices/living situations. While some of the participants spoke positively of particular health practitioners, there were many stories that illuminated the precarious position that these young women occupy when navigating relationships with health care providers, and being subject to the medical gaze. Many young mothers described feeling unwelcome or isolated in the hospital, and also misunderstood or frustrated with local medical practitioners (outside the hospital). Some participants also spoke about a 
preference for Māori (or more culturally understanding) health practitioners. These experiences and perspectives are discussed in this chapter.

\section{Hospitals as Exclusionary Spaces}

More than half of the young women in this study (and sometimes their whānau) talked about negative experiences in the hospital, not because of medical issues, but because of the way they were treated by staff. Some participants also talked about positive experiences, or just (unremarkable) experiences. However, the stories of struggle are particularly interesting because they illuminate some of the ways in which young Māori mothers can be 'Othered' and hence disempowered by hospital practices. The hospital, as a place of care, can also be a place of exclusion, where the gaze establishes itself as an authority - "the eye that knows and decides, the eye that governs" (Foucault, 2003a, 108).

\section{Ariana and Waimarie's Birth Experiences}

Ariana (19 years old) and Waimarie (14 years old) had particularly difficult birth experiences. Their birth stories illuminate the power imbalance between patients and health professionals, in this case, when the patients are young and Māori and mothering, hence non-normative according to the medical gaze.

The whole attitude is wrong. It's like they are so disconnected from the patient, even though the patient is there, in severe pain, it's just like, 'No. This is the process. And that's it.' (Ariana's mother, whānau interview 1)

Ariana was denied admittance to the maternity ward in the hospital because her midwife did not believe that she was really in labour.

They didn't even acknowledge I was there, but when the lunch trolley came, the three of them came out and started talking really nicely to the lunch lady... and they were looking at the sandwiches and I was just watching... My daughter's out there, in tears, and I'm just looking at them like, 'This is a twilight zone! Is this a 
maternity hospital?' I was upset by that... I don't know whether they're used to this but they just completely ignored me. (Ariana's mother, whānau interview 1)

When Ariana's mother (but not Ariana herself) was finally allowed into the maternity ward, after explaining the situation, she was ignored by staff who appeared too busy deciding what to eat for lunch.

They had already predetermined that she wouldn't be having her baby. (Ariana's mother, whānau interview 1)

They eventually let Ariana in, but they added that the midwife was going to do an assessment and then send her home. Ariana's midwife arrived at one o'clock in the afternoon and was angry.

Attitude! Not happy! Head down. Attitude. Huffing and puffing... Like really upset... and she's pointing at Ariana, 'You go home, and I don't want to see you again, especially if you're only four centimetres.' Really talking down to her and pointing at her. Ariana, is like clenched, her eyes shut, having contractions in severe pain, not even comprehending what she's saying. Boy, was I mad. (Ariana's mother, whānau interview 1)

Ariana's mother reprimanded the midwife for talking to her daughter like that, and refused to leave the maternity ward. The midwife finally told them they could stay in the operating room until it needed to be used (and then they would have to leave). Shortly after four o'clock baby Erina was born.

She had nothing to say. No apology. No nothing. She had nothing to say... (Ariana's mother, whānau interview 1)

The midwife did not take the time to apologize for her brusque treatment of Ariana, or to admit that she had been wrong. Ariana did not go into much detail about the experience except to say: 
[If it wasn't for mum] I would have ended up having Erina in the car probably. (Ariana, interview 2)

She also said that she did not see that midwife again afterwards, even though she spent three nights in the hospital after the birth. Ariana's grandmother, who was present during her second interview, said that she thought the hospital staff had talked down to Ariana because they saw her as a young person. Ariana's mother suspected that part of the poor treatment may have been because they are Māori:

Maybe looking at me, and being Mãori, just the whole perception... Didn't want to hear what I have to say. ... That sort of an attitude... I think you get that in a lot of different situations.

I did worry about a lot of other young Māori Mums... I know they were busy, they were busy. Not too busy to look at the kind of sandwiches that were being sold though.

I think that these young ones are at risk of not receiving the service that they deserve... In the way that they are spoken to, in the way that they're made to feel comfortable... There's no feeling of nurture.

(Ariana's mother, whānau interview 1)

Ariana's mother articulated that some of the poor treatment her daughter received might be due to her identity as a young Māori woman. By talking down to Ariana, ignoring her, and offering no apology in the end, the health practitioners that she dealt with contributed to a negative birthing experience for her. Foucault (1977) argues that contrary to popular Enlightenment notions of civilisation and progress, law does not replace warfare as a less violent means of dispute resolution or domination. Instead, the very violence of one system (warfare) is installed in another system (rules), where domination is still exacted. The impersonal treatment of Ariana (and her whānau) by the midwife and hospital staff, in the name of due process and rules, could be interpreted as a kind of domination (Foucault, 1977) - 'Othering' them by treating them like a nuisance because they were not following the correct protocols. 
Like Ariana, Waimarie also had a negative birth experience. When Waimarie went into labour early and baby Hayden needed to be rushed to the Neo-natal Intensive Care Unit (NICU), Waimarie's mother went with Hayden, leaving Waimarie with the doctors and some other family members. However, she regretted that, as she thought that the doctors did not treat Waimarie properly. Waimarie ended up with severe haemorrhaging, being re-admitted to hospital repeatedly, and having many blood transfusions. There were also issues with the nurses in the NICU:

The neo-natal nurses, they have high expectations of mothers coming in to tend and feed the baby, and she was admitted in [another ward]... So she was caught up between two wards and ended up pretty much getting upset and confused about where she would be and what she should be doing.

My daughter's bleeding out, she's got no energy... and she needed to rest in the other ward and they just couldn't accept that... she wanted to be there because they said so, but at the same time, you know, she wasn't healing. She didn't get to heal so I pretty much blew my top. It was frustrating...

(Waimarie's mother, whānau interview 1)

Waimarie's mother took on the responsibility of tending to baby Hayden in the hospital so her daughter could heal after a difficult birthing experience. However, the nurses in the NICU did not seem to appreciate what was going on, and subsequently made Waimarie feel distressed. Waimarie also spoke of this time:

After I had my baby, I had to have a rest. This doctor was coming in [and] he was growling me 'cause I wouldn't talk 'cause I was too tired, 'cause I'd just had my baby... They don't wait around for you. I hated those nurses in the neonatal where my baby was... they were just like mean, like stuck up. You know how some people look at Māori's like yuck? Well that's how they were looking at me and my mum. I don't like hospitals. (Waimarie, interview 2) 
Waimarie not only felt poorly treated by the NICU nurses, but also by one of the doctors treating her. She also ventured that the poor treatment by the NICU nurses might be because of her Māori identity. The nurses' reactions to her could be attributed to aversive racism, whereby the nurses might not have intended to be racist, but that they were "uncomfortable or uneasy" (Dew, 2014, 100) around her (because of her Māori identity), and so did not know how to interact with her and her whānau. This may have also been the case with Ariana (whose mother suggested that being Māori affected her treatment), as discussed earlier. Whether we interpret the actions of these health practitioners as aversive racism, or intentional 'racism', the effects are still dehumanizing and disengaging for the whānau picking up on subtle (or not so subtle) clues about how they are perceived.

Straight away they really pushed the issue of bloody injecting her with... these [contraceptive] rods, and she'd just sort of, not come right, but just got her colour back, got a bit more energy back... and when they put that in her she just flooded out again so it was just a bad experience for her. (Waimarie's mother, whānau interview 1)

Waimarie was pressured to have a contraceptive device inserted in her arm after the birth of Hayden. This triggered further health issues for her because she had not yet healed from the birth. Waimarie's mother was unhappy about this coercive treatment of her daughter. The hospital seemed more concerned about preventing further pregnancies for Waimarie, than her actual health. Under the guise of serving the best interests of Waimarie, the hospital took on a paternalistic and disciplinary role that threatened her health. The medical gaze decided what was best for Waimarie - that she needed a contraceptive device, as she had 'obviously' shown that she was sexually active at too young an age (and further pregnancies 'needed' to be prevented).

While Waimarie's birth experience was traumatic because of health complications, the trauma was compounded by negative interactions with health practitioners, who made her feel unhappy and discriminated against, and coerced her into a contraceptive device. Ariana's birth experience was physically non-traumatic, an 'easy' birth. However, the poor treatment that she and her whānau received at the hospital was 
dehumanizing (or thingifying). She encountered physical barriers to care, in that they would not allow her into the maternity ward, and then when they did, they would not give her a birthing suite, but rather made her stay in the operating room - with the disclaimer that it was just until someone else had to use it. When she did give birth (after they had determined that she would not), there was no apology from the staff. They had treated Ariana like she was a nuisance rather than a patient in need of care. The medical gaze judged these two young women as abnormal, as they defied norms around appropriate child-rearing age. From their mothers' perspectives, Waimarie and Ariana's Māori identity contributed to their negative treatment.

\section{Other Hospital Experiences}

After the birth of their children, many other participants also felt isolated or unwelcome in the hospital. For some it was the fact that their partners were not allowed to stay with them, for others it was because they were not adequately supported or understood, or that they witnessed discriminatory practices.

The first night, it was hard 'cause Rawiri couldn't stay and... [baby] wasn't feeding properly... It was kind of lonely. (Anahera, interview 2)

They said Rawiri wasn't allowed to stay so they both cried. She had this new baby... and he didn't want to go. Anahera needed him and he had a new baby. So they both cried and nobody got much sleep, so they decided to go home [early]. (Anahera's mum, whānau interview)

Anahera had to spend her first night as a mother alone. It was a sad experience for her and her partner Rawiri, and resulted in Anahera leaving the hospital early so that she could be with her whānau.

It was just sad that Paul was sleeping on the floor. They weren't going to tell him to leave 'cause by the time I got out I couldn't do anything at all with her... he was already asleep there holding her and they came and woke me up and moved me and him to another ward and they just left us alone so at least I got the first night with him and her. (Hana, interview 1) 
Hana gave birth to Aroha in a main hospital, and after the first night was transferred to a smaller, local hospital, where her partner Paul was not allowed to stay with her. In the second whānau interview, Hana, Paul and Hana's sister discussed those first few days after baby was born:

Paul: Nah [the staff at the hospital did not make me feel included].

Hana: $\quad$ Some of them in [a main hospital] were alright... brought him in a [chair] for him to sleep on, but then some of the others were like, 'Get out. You can't sleep there. You can't lay there with her.' Being eggs... He wasn't allowed to be in the same bed as the baby.

Hana's sister: Wouldn't even let him use the toilet [at the local hospital]. Hana: I Ididn't want him to go, so that's why I left [the local hospital] early 'cause he came and got me... 'cause I didn't want to be there anyway.

(Hana's whānau interview 2)

These interactions that Hana describes with Paul and her sister were negative. In the larger hospital Paul was allowed to stay, but not be in the bed with the baby. In the local hospital Paul was not allowed to even use the bathroom. As with Anahera, the hospital failed to take into account the implications of separating these young women from their whānau (the fathers of the babies) at a time when whānau support is crucial. Anahera and Hana's reactions were to discharge themselves from the hospital early, claiming some agency in a situation where they were made to feel unhappy/powerless.

They [doctors] were assholes. Because I would have my whole family around and they were quite loud. (Marama, interview 3)

For many Māori whānau, the birth of a new baby is a 'whānau' affair. Grandparents, aunts, uncles, cousins, siblings and parents of both the mother and father-to-be are often included (Rimene et al., 1998). In Marama's case, this resulted in friction between her and the doctors at the hospital, who possibly did not quite know how to deal with Māori cultural practices. Marama's reaction was to criticise the doctors, who she called 
'assholes', indicating that she was disengaging from their services because of perceived animosity.

In more certain terms, Tia's mother discussed feeling like nurses were being discriminatory towards Māori mothers in the Children's Ward, where Tia's son was admitted after almost dying from Sudden Infant Death Syndrome (SIDS):

Tia did talk with some of the other[Māori] mums that were being dealt with by CYF, and then nurses would drop little hints about, "Don't associate with them, they haven't got the best parenting skills and stuff like that, you need to stay away from them." (Tia's mother, whānau interview 1)

The nurses tried to regulate Tia's interactions with other Māori mothers, who they did not think were good influences. Tia's mother talked further about how it seemed like the nurses were acting in that way because of stigma around Māori parents. She also said that Tia resisted the nurses' directions and ended up spending more time with those mothers, acting as an 'informer' for them, telling them what the nurses were saying about them. Tia was put in an unfair position by the nurses, but chose to resist and undermine their regulation, standing up for the other mothers, who she could relate to because of her traumatic experience.

Many of the young mothers (and their whānau), like Irihapete (below), felt like they were not adequately supported or communicated with in the hospital.

The midwife wasn't really there and didn't explain things. 'Cause I'm young, I don't know... Some of them were rude. They pretty much left me on my own with my baby... And the midwives in there said I wasn't their responsibility... So they wouldn't take care of me, they'd just take care of the baby... In the hospital they didn't help me at all. I felt like I was on my own. [I felt] sad [and] scared 'cause I wasn't getting any help... The midwives there wouldn't help me so my family would come and help. (Irihapete, interview 1) 
Irihapete had to rely on her whānau for support, because the staff did not meet her needs. She felt sad and scared, and her whānau ended up reporting the midwife. Participants often mentioned that nurses, doctors or midwives did not take the time to explain what was happening, or make them feel at ease. Some participants also talked about hospital staff seeming more interested in writing notes rather than talking to their patients.

By not communicating well, not supporting properly, or by exhibiting discriminatory attitudes (as discussed earlier), hospital staff can (intentionally or unintentionally) disengage these young mothers from their services. If medical practitioners treat these young women like they are abnormal and problematic, like they do not deserve the best care, they are likely to end up disliking hospitals, and they may be less likely to seek medical help when it is needed.

\section{Health Practitioners Outside the Hospital}

Many of the young women in this study (and sometimes their whānau) also talked about negative experiences with health practitioners outside the hospital, especially their local GPs.

\section{A waste of time?}

The young women in this study frequently talked about feeling frustrated with their local doctors, saying in one way or another, that they believe their doctors are a waste of time, sometimes adding that they are a waste of money too. Pania articulates this particularly robustly:

I think my doctor's all for the money. He doesn't actually care, 'cause he thinks, 'Oh yeah, they're here for a quick five minute session and all of that.' It's like he just rushes. He doesn't even tell you the problem, he doesn't even look it over properly... It's a waste of time. (Pania, interview 5)

Going to see their local doctor was often seen as a waste of time for the young mothers in this study, because the doctor often did not attempt to engage with them. They felt 
like they were not being listened to, like they were being rushed along and not taken seriously. Because of this, many of the young mothers talked about simply not going to the doctors when they suspected a minor illness. Instead they would take over-thecounter painkillers or home remedies. Treating themselves for minor illness is not a particularly negative thing, but if it is because they feel frustrated with local health services, then it could lead to health care avoidance when more serious illness arises.

\section{A lack of engagement?}

Some participants also described instances where health practitioners ignored them, for example, not responding to text messages or calling back. A common theme from the young mothers' narratives was that practitioners (nurses, GPs and midwives) who made an effort to engage with them were appreciated and respected. Those who actively made contact with the young women, and made them feel like they were respected (rather than regulated), for example, by organizing pick-ups and drop-offs, made a significant difference to their perspectives of the health care system. Marama provides an example of this kind of engaging practice, when describing a Māori health provider that does home visits:

[They're] good. Supportive and.... I just think they are. They're just like talkative and funny. Like sometimes it's not even to do with like their service type thing. (Marama, interview 2)

As articulated succinctly by Marama, good health service interactions seem to be just as much about the practitioner-patient relationship as about the medical aspect. By building rapport with these young women, by treating them like they were deserving of quality care (and not 'abnormal'), the practitioners were more likely to keep them engaged with their services.

Practitioners who did not work on developing respectful relationships with the young women disengaged them. One example is from Waimarie: 
I was at the doctor's with my best friend once... I was like, 'Look there's Doctor John,' and he walked straight past me and I was about to say hi. He's a snob... Honest, he's a snob. (Waimarie, interview 2)

Waimarie interpreted Doctor John's actions as him showing contempt, or at least disinterestedness in her, when she was not in his clinic as a patient. This highlights the power imbalance between Waimarie and her doctor, who made her feel inferior. This could be aversive racism, or simply that the doctor did not notice Waimarie. But either way, this experience impacted Waimarie's perspective of her doctor.

\section{Normalising Practices}

Some participants (or their whānau) also talked about instances where local health practitioners did not show sensitivity or respect in regards to their choices. Mere, Tui and Marama are three varied examples of how doctors or nurses imposed their perspectives on the young women in this study, misunderstanding, ignoring or going against their wishes - subjecting them to normalising practices.

I was thinking of getting an abortion 'cause I didn't want any more kids, and the doctor was so rude and arrogant about it... 'Cause I was crying 'cause I had a miscarriage and he was like, 'Why are you crying? Aren't you happy that you had a miscarriage? You said you didn't want a baby.' (Mere, interview 6)

Mere's doctor made assumptions about her feelings towards losing a pregnancy. He thought that because she had talked about getting an abortion she would be happy that she had a miscarriage. He did not take into account that even if Mere had decided to abort her pregnancy, she still wouldn't be 'happy' about it. It was a decision that she talked about being very difficult, and only considered due to her already having two small children. Furthermore, Mere had not miscarried her full pregnancy. She was still pregnant (with what might have been a twin) and ended up delivering her third son very prematurely. She thought that it was wrong of the doctor to not run more tests when she 'miscarried'. She interpreted it as a lack of care by the doctor. 
The [school nurse] was like, 'Do you want an abortion?'...I didn't say nothing. I was thinking, 'Why would I kill my baby for?'... And then [after a few weeks] I told her that I wasn't gonna get it and then she goes, 'Well I actually thought that you would and I told the lady that I was 100\% sure.' Yeah. And I didn't say that I wanted one. (Marama, interview 1)

In Marama's case, her school nurse had assumed that she would get an abortion because of her age (14), and while she had asked Marama (if she wanted one), she had not waited for an answer before starting preparations for her. The nurse thought that she knew what was best for Marama, and that her authority would sway Marama in the end.

We expressed that we weren't into immunization and then when Tui had an appointment with the doctor they made her do it... They said that it was the best thing for her and they did it while I wasn't there... I don't like the fact that while she's alone in a professional's care they manipulate her into things that she's uncomfortable with. They don't respect her opinions when she states what her worries are. (Tui's mother, whānau interview 1)

Tui's mum was angry that the doctor coerced Tui in this situation. This raises the question of consent. If the doctors already knew that the whānau did not want to immunize baby Atamarie, waiting until Tui (at 14 years old) was alone to do it, was unethical. It is an example of doctors using their position of power/authority to discipline these whānau - forcefully normalising them.

The health practitioners discussed here imposed their normative views on the young mothers that they were 'supporting'. Mere's doctor assumed that she would not be upset about her miscarriage, because he considered it to be a fruitful outcome for her. Marama's school nurse assumed that she knew what was best for her, and attempted to coerce her to do the right/normal thing. And Tui's doctors coerced her into immunizing her baby, abusing their power and disciplining her according to their normative conceptions of infant health. The young women (and in some cases whānau) discussed in this section overwhelmingly felt not listened to, not respected, and not cared for. By acting in these ways, the health care practitioners imply that these young women are 
not worthy of attention, respect or empathy. We cannot say without a doubt that this is because of their (non-normative) age or ethnicity or class, but these factors probably all feed into it in some way. And the pre-existing power imbalances that are weighted against young Māori mothers because of their age, ethnicity, and in many cases class, can only be reinforced through such interactions, which disengage them from health services and create distrust and discord.

\section{Resisting the Totalizing Gaze? A preference for Māori health practitioners}

While some participants talked about appreciating health services that are more culturally understanding, regardless of whether they are delivered by Māori, for many, dealing with Māori health practitioners (and social services) was preferable, or more comfortable. This may be because there is, or there is a perception that there will be, a shared sense of identity and understanding. An examples of this is from Pania, who talked about her preference for Māori practitioners on more than one occasion:

I would have been more comfortable with a Māori [Plunket person], 'cause it seems like every time she [non-Mãori Plunket nurse] sees me it's like she just wants to get out... I feel like I can talk better you know... I'm not racist or anything, but I don't want to say something wrong and then... oh it's hard to say actually... I chose Plunket 'cause I heard they were really, really good... but I was like, oh I should have gone with a Mãori health worker. I would have felt more comfortable. (Pania, interview 4)

Yeah [being Māori matters]. 'Cause some Plunket ladies... can be quite... I wouldn't say racist but prejudiced... My midwife referred me to... a nice Māori lady anyway and she was good, but I only met her on my last day at hospital. (Pania, interview 5)

Pania felt like her non-Māori Plunket nurse rushed through appointments with her and did not engage with her in a warm, comfortable way. Pania wanted the interviewer to know that she did not prefer Māori practitioners because 'she' is racist, but that she is 
often made to feel self-conscious of what she says with her Pākehā Plunket nurse, afraid of saying something wrong and perhaps being thought of as stupid. In the next interview, she talked about this situation again and added that she thought that some Plunket ladies are prejudiced. Another example of suspected discrimination is from Ariana's mother:

She was really excited about going to [antenatal classes], but she only went to one... and she had all the dates and the times written down on her wall... and I know they only went to one... and then she got hōhā [annoyed/fed up] to go to the rest, so maybe that was it. (Ariana's mother, whānau interview 1)

Ariana's mother suspected that her daughter stopped going to her antenatal classes because she felt fed up. She went on to venture that it might have been because Ariana felt discriminated against for being young and Māori. Ariana did not talk about this experience, but her mother's narrative indicates that Ariana and her partner were disengaged from a health service that did not meet their needs as a young Māori couple.

By preferring Māori practitioners/support workers, many of the young women (and their whānau) in this study might be seen as attempting to avoid the totalizing medical gaze that sees them as abnormal for their non-Pākehā-ness and their non-normative life choices/age of mothering. The desire to potentially eliminate one side of judgement is understandable.

\section{Objects of the Medical Gaze (discussion)}

By their ethnicity, the young mothers in this study were already not 'normal' in the medical gaze. The colonial legacy of social disadvantage for Māori sets Māori in the sights of the medical gaze, perpetually as abnormal/unhealthy and in need of intervention. The medical gaze is ready and waiting for more specimens. Teen pregnancy is also treated as abnormal and abhorrent, and these values trickle through to practitioner-patient interactions. 
The young women in this study challenge dominant discourses on adolescence that adhere to binaries of adult (mature, ready to be independent) and youth (immature, in need of regulation) - mother (adult) and child (youth). By becoming pregnant 'too young' these women are subject to an intense medical gaze of health practitioners who seek to measure and judge their (and their children's) health according to Eurocentric ideas of normality.

Many of the young women (and their whānau) described experiences in the hospital that were exclusionary and made them feel discriminated against, disempowered, and disengaged. Outside the hospital, experiences with health practitioners often created similar feelings. By experiencing discrimination, racism or aversive racism, these young women were constantly reminded of their subjugated position in our society. The power imbalance between health practitioners, as judges of normality, and young Māori mothers, as objects of a totalizing medical gaze, is evident and evidently selfperpetuating through these interactions.

Some of the young women tried to conform to medical regulations/expectations. For example, Waimarie tried to do what the NICU nurses expected of her following the premature birth of her son. But most of the young women disengaged from health services; physically, like Hana and Anahera who discharged themselves early; or emotionally, like Marama who called her doctors 'assholes'.

The power imbalance between medical practitioners and young Māori mothers is reinforced through practices that make young Māori mothers feel judged (as abnormal). These judgments convey a clear message - a perpetuation of the colonial binary of Us/Other (normal/abnormal). In response to that, many participants talked about preferring to see Māori health practitioners because (it was perceived) they would not inflict the same level of judgement on them. 


\section{CHAPTER FIVE: THE DISCIPLINARY GAZE OF 'SOCIAL' SERVICES}

"The judges of normality are present everywhere. We are in the society of the teacher-judge, the doctor-judge, the educator-judge, the 'social worker'-judge; it is on them that the universal reign of the normative is based; and each individual, wherever he may find himself, subjects to it his body, his gestures, his behavior, his aptitudes, his achievement" (Foucault, 1995, 304).

Foucault (1995) argues that we are all subject to the normalizing gaze of professional 'judges', be they doctors, teachers, educators or 'social' workers. Akin to the medical gaze (as discussed in the previous chapter), the carceral/panoptical/disciplinary (henceforth disciplinary) gaze is the surveillance and individualization of subjects, and the examination and ranking of their normality according to dominant discourses, like science and medicine (Foucault, 1995). The gaze is all-seeing and all-judging. The body can be observed, documented and known. Rose describes normality as more than an observation. It is a valuation that "contains not only a judgement about what is desirable, but an injunction as to a goal to be achieved" $(1999,133)$. The abnormal are subject to intense scrutiny, and are thus subject to manipulation (Foucault, 2003a; 1995). Uneven power relations are maintained through these interactions. Who is gazing, and who is the object of the gaze?

Rose argues "[c]hildhood is the most intensively governed sector of personal existence... [and] the child - as an idea and a target - has become inextricably connected to the aspirations of authorities" $(1999,123)$. According to Rose (1999), children are targeted through a variety of apparatuses: their health is monitored by health professionals (like Plunket and school nurses), their develpoment is monitored through schools (and school social workers), their safety is monitored through the child welfare system, and their well-being is monitored thorugh the surveillance and education of their parents. By regulating the family unit, and the child within it, the state produces practical, useful citizens (Rose, 1999). 
Lesko (2001b) argues that adolescence, and the continual focus on youths' futures, can be seen as a particular governmental (in a Foucauldian sense) technology (or tool), which aims to discipline individuals, to "produce certain kinds of persons within particular social arrangements" (Lesko, 2001b, 50). Raby (2002) also equates 'adolescence' with a disciplining technology, that calls on and reinforces normalizing and naturalized discourses. This technology exhorts adolescents to regulate their own behaviours in order to "fit categorizations of normality" (Raby, 2002, 41). Such categorizations of normality do not include pregnancy and motherhood.

"The body of the illegitimately pregnant teenager is particularly troublesome... youthful but physiologically mature; childlike yet maternal; innocent while sexual; the object of both compassion and censure... [T] ransgressing sexual and parental norms, the body of the pregnant teenager exposes the limits of what is culturally thinkable about proper sex and motherhood" (Reekie, 1997, 77).

As stated by Reekie above, the pregnant youth represents an ambivalence of Eurocentric conceptions of family, safety and well-being. Young female bodies (that are not yet 'mature') represent the promise of the future, yet teen pregnancy challenges this (Lesko, 2001b) by breaching prescribed moral values and rules (Foucault, 1990). Teen mothers are depicted as social problems, in "violation of normative chronology" (Lesko, 2001b, 138), causing moral panic (Lesko, 2001b; Walkerdine, 2001). This ultimately leads to the marginalization of teen mothers, who become more visible targets for the medical and disciplinary gaze.

Rose argues that the disciplinary gaze of the contemporary neoliberal nation state intends to "create individuals who do not need to be governed by others, but will govern themselves, master themselves, care for themselves" $(1996,45)$. Wacquant further argues that within contemporary neoliberal nation states, the 'welfare state' (of the post-World War Two era) is positioned as having infantilized its subjects, creating welfare 'dependency' and social detritus (2009). This belief has proliferated the neoliberal rhetoric of 'personal responsibility', and justified increased surveillance over individuals who deviate from their responsibility to be independent self-actualizing citizens (Dean, 1996; O’Malley, 1996; Rose, 1996; Wacquant, 2009). Stricter regulations 
and increased intervention for social welfare recipients means the state is better able to identify and discipline accordingly (Wacquant 2009).

Neoliberal rhetoric of personal responsibility is aided by media representations of 'welfare scroungers' (LaClau \& Mouffe, 2001), which encourage the general acceptance that those who do not work are manipulating the system/stealing taxpayers' money. LaClau and Mouffe (2001) argue that the idea of the welfare scrounger is discursively constructed (as are other 'deviant' groups) to create a fixed antagonism - reinforcing the binary of normal (working, contributing) and abnormal (unemployed, reliant). As with LaClau and Mouffe (2001), Wacquant (2009) argues that this is by no coincidence. By shedding responsibility for high levels of poverty, the neoliberal nation state embodies the Social Darwinist survival of the fittest axiom, which justifies the de-structuring of the welfare system, and the rise of a 'sub-proletariat' class of individuals who are rendered useful by being diverted "onto the track of deskilled employment... or [to] the penitentiaries" (Wacquant, 2009, 12), in what Wacquant (2009) calls the 'carceralassistential' net. This is akin to Foucault's (1995) theory that the carceral state actively produces 'delinquents' in order to maintain a politically safe criminal class. According to Foucault, the proliferation of delinquents is not a failure of the prison system (and discipline in general), but a purposeful success of it - "a way of handling illegalities, of laying down the limits of tolerance, of giving free rein to some, of putting pressure on others, of excluding a particular section, of making another useful, of neutralizing certain individuals and of profiting from others" $(1995,272)$.

Both Wacquant's (2009) 'sub-proletariat' and Foucault's (1995) 'delinquent' evoke striking images of a system that is stacked against marginalized peoples. Wacquant (2009) calls this the centaur state ${ }^{4}$ - liberal 'head' for corporations and upper classes, and a paternalist/punitive 'body' for lower classes; while Foucault (1995) calls it the carceral system - an economy of power functioning off the very creation/maintenance of those it 'aims' to reduce/rehabilitate. From either perspective, as colonized peoples, Māori are no strangers to this kind of contradictory message - the uncivil side of 'civilising'. As discussed in the historical context of this thesis, policies and services

\footnotetext{
${ }^{4}$ This is most probably a reference to Machiavelli who described the benefit of benign seeming, consensual Princely power as like a centaur; and Gramsci who used the metaphor of a centaur to describe the dual nature of hegemonic powers, combining consent with coercion (Cox 1983).
} 
purporting to have the best interests of Māori in mind have frequently brought about further disadvantage. In the context of contemporary 'social' services, drawing on Foucault (1995), Rose (1999) and Wacquant (2009), we might query the earnestness of the support that they offer, and look to their regulatory/disciplinary intentions.

The education system, financial assistance (administered by Work and Income New Zealand), social housing support (administered by Housing New Zealand Corporation), and social services (including Child, Youth and Family), can be seen as supporters of specific ('appropriate') forms of living, and regulators of other ('inappropriate') forms of living. As young Māori mothers, the women in this study often faced discrimination and/or were made to prove themselves as deserving of support. Accessing that support was often problematic. The participants in this study frequently articulated an acute awareness of their subjugated positions, and in turn, often disengaged from support services. The complicated relationships between these young Māori mothers and social services are examined in this chapter.

\section{Teacher Judges (the education system)}

Rose argues that "universal and compulsory schooling catches up the lives of all young citizens into a pedagogic machine that operates not only to impart knowledge but to instruct in conduct and to supervise, evaluate, and rectify childhood pathologies" (1999, 123-124). Engaging techniques of observation and comparison (and hence normalization), like standardised testing, schools work to create what Foucault (1995) would call 'docile bodies' - subjects who willingly participate in their own subjection. 'Normal' students are granted unproblematic passages, while 'abnormal' students/children are subject to heightened surveillance (and regulation), stretching beyond the classroom and into their homes and family lives.

Since the Native Schools Act of 1867, education has been a governmental technique for the assimilation/normalization of Māori (into European culture), with exclusion a common by-product. Today, schooling is compulsory for all children and young people aged 6-16 years old, and the statistics for Māori educational engagement and achievement are telling. Around 30\% of Māori students will leave secondary school 
(college) without a qualification, as opposed to $11 \%$ of Pākehā students. Similarly, 13\% of Māori youth aged 15-19 years old will become disengaged from any/all education, as opposed to $6 \%$ of Pākehā (Ministry of Education, 2014b). If the education system is not teaching (many) Māori the intended academic objectives, then what is it teaching?

Table 2:Participant Education Information

\begin{tabular}{|l|l|l|l|l|l|l|}
\hline & Name & $\begin{array}{l}\text { Age at } \\
\text { first } \\
\text { birth }\end{array}$ & $\begin{array}{l}\text { Mainstream ed. } \\
\text { experiences (before } \\
\text { pregnancy) }\end{array}$ & $\begin{array}{l}\text { TPU (\& } \\
\text { feelings about } \\
\text { it)? }\end{array}$ & $\begin{array}{l}\text { NCEA } \\
\text { level @ } \\
\text { last int. }\end{array}$ & $\begin{array}{l}\text { Studying at time of last } \\
\text { interview? }\end{array}$ \\
\hline 1 & Awhina & 14 & Excluded & Y (Satisfied) & 2 & Polytechnic \\
\hline 2 & Marama & 14 & Truant/'Trouble' & Y (Satisfied) & 2 & Polytechnic \\
\hline 3 & Tui & 14 & Satisfied & Y (Satisfied) & 3 & Polytechnic \\
\hline 4 & Waimarie & 14 & Excluded & Y (/) & 1 & Polytechnic \\
\hline 5 & Irihapete & 15 & Left early & N & 0 & Correspondence \\
\hline 6 & Manaia & 15 & Truant/'Trouble' & Y (Satisfied) & 2 & No (FT mum of $1+$ preg.) \\
\hline 7 & Ngaio & 15 & Truant/'Trouble' & Y and N (/) & 1 & Polytechnic \\
\hline 8 & Tia & 17 & Truant/'Trouble' & Y then N (/) & 2 & Polytechnic \\
\hline 9 & Tina & 17 & Left early & N & 1 & No (FT mum of 3 +preg.) \\
\hline 10 & Anahera & 19 & Satisfied & N & 3 & No (but planning to) \\
\hline 11 & Ariana & 19 & Satisfied ${ }^{*}$ & N & 3 & No (FT work) \\
\hline 12 & Hana & 19 & Truant/Trouble' & N & 1 & Polytechnic \\
\hline 13 & Kiri & 19 & Difficult & N & 1 & Online course \\
\hline 14 & Mere & 19 & Excluded & N & 1 & No (FT mum of 3) \\
\hline 15 & Pania & 19 & Left early & N & 1 & No (FT mum of 2) \\
\hline
\end{tabular}

Key:

int. $=$ interview $\quad$ ed. $=$ education $\quad /=$ mixed feelings $\mathrm{FT}=$ full time $\quad$ preg. $=$ pregnant

* Ariana changed school/college because of bullying, and was happy after that.

While pregnancy set the young mothers in this study in the sights of the medical gaze, as abnormal and problematic, for many of them, their lives were already problematized by an education system that seemed set to fail them. In fact, contrary to popular discourse and 'risk' research that assumes teen pregnancy results in lower academic achievement (like Boden et al., 2008), many of the young women in this study had already disengaged from education prior to becoming pregnant. Table 2 provides a summary of the academic achievement and feelings towards education of the participants. Only Anahera, Ariana and Tui spoke of enjoying school prior to their pregnancies. They are also the only three participants who had achieved NCEA level 3 by the end of the interviews (see Table 2). Anahera and Ariana both gained NCEA level 3 before their pregnancies, and Tui finished hers after the birth of her child (through a TPU and 
polytechnic). For a majority of the young mothers in this study, school was already a negative experience, and in some cases, it was their pregnancy and the ability to attend a TPU that reconnected them with education.

\section{Exclusion and Disengagement}

Most of the young mothers in this study had negative experiences in their mainstream colleges prior to becoming pregnant. Some of them had relationship breakdowns with teachers or their peers (including experiencing racism/discrimination), some had learning difficulties and so struggled academically, some were 'excluded' due to disciplinary measures, and some chose to end their schooling early or attend alternative education/study via correspondence. These negative experiences indicate that the mainstream education system is inclusive in its 'catching up' of individuals - into its pedagogic machine (Rose, 1999), but exclusive in its culture of pathologizing abnormalities.

Some of the young women in this study talked about experiencing racism at school. Two examples are from Mere and Pania:

I didn't like [college], got kicked out at 14... I thought the teachers were racist about us Māoris, didn't even pay attention to us or help or anything... [Alternative course was better] 'cause... they paid more attention to you... Yeah it was good, they helped you. They weren't racist or anything, and they helped you try and get a job. (Mere, interview 2)

My teacher was full racist, fully... I just moved myself from the situation, but I had to go and ask, write a letter to the school saying why. The principal spoke to her but quite a few people felt like that. (Pania, interview 5)

Mere was excluded from college (4 years before becoming pregnant at 18) and so attended an alternative course. She enjoyed it (more) and achieved NCEA level 1, but did not continue studying after she turned 17 years old. Pania left school (early) with NCEA level 1, also before becoming pregnant. She did not complete any further study. These two examples indicate that experiencing racism is more detrimental to 
educational achievement than pregnancy. In this data, pregnancy, if anything, has the reverse affect.

An example of disengagement from the education system before and after pregnancy is from Tina:

I wagged a lot and then at the end of term two my mum rang the school and I heard her talking to them and she said, "Six days?" and then looked at me. And I said, "Told you I've only had six days off school" and then she hung up and said "No, you've only had six days at school". And then I started laughing. (Tina, interview 1)

She left school early because she did not enjoy it (and was more truant than present). After starting her family she began a course, which she enjoyed:

I got kicked off course... but I really enjoyed it and I was going in every day like doing NCEA levels and that... They didn't force us to do the things and we didn't have a time period to do our work... they wouldn't give us too much to do, and... when I first started [it] was stuff I'd already done at school, so I was just flying through it quite fast. (Tina, interview 3)

Tina was happily working towards NCEA level 2 but was 'kicked off' her course because of some unavoidable extended absences (when she had her third baby, and then her grandmother died). There was potential there for Tina to be reengaged with the education system, and achieve higher NCEA levels, but a lack of understanding meant that she was unable to continue.

These cases, and the information in Table 2, exemplify how many of the young women in this study were disengaged from education prior to their pregnancies; and also, in Tina's case, how the education system continues to disengage some rangatahi Māori (Māori youth) when they try to reconnect. 


\section{Teen Pregnancy Units (TPUs) as Inclusive Spaces?}

For many of the young women in this study, joining a TPU upon becoming pregnant (or another alternative course before or after pregnancy) ended up re-engaging them with education and being a positive influence. Some examples of the positive experiences described from attending a TPU are:

It gives you an opportunity to come back to school, and they look after your kids so you can get your levels and that. Yeah, it's so good. (Awhina, interview 2)

[TPU teachers] help you heaps here, like if you're struggling they do catch up classes so you can catch up on work and they try and simplify it all so that you understand it. Yeah, it's good as. (Manaia, interview 2)

[The TPU teachers] were supportive. They were helpful... like they helped me get my license and my levels and stuff. Just heaps of stuff aye. (Marama, interview 4)

Having childcare support, help with academic work, and assistance with practical things (like gaining a driver's licence) made TPUs successful for most of young women in this study (who attended them). As illustrated in Table 2, most of the young mothers who attended TPUs achieved at least NCEA level 2 by the time of their last interview. Ngaio and Waimarie were the only women who did not achieve NCEA level 2, and both of them had mixed feelings about their TPUs. Ngaio left her TPU after she lost custody of her son because she was too sad to remain there without him, and she returned when she had her second son. However, the grief from losing custody of her first son, and then a relationship breakdown meant that she was not focused on her academic work. Waimarie did not enjoy her TPU:

I reckon it's the colour and the way you look... the white girls, well when they won't do their work [the principal] won't say anything. She'll just let them carry on. Me and my brown girls, we won't do our work and she'll come up to us and growl us and tell us this and that and we all just felt judged. We all felt discriminated so we just didn't listen. (Waimarie, interview 6) 
Waimarie was excluded from her mainstream college (for disciplinary reasons), and then was excluded from her alternative college because she got pregnant. So she had already been formally excluded twice in her secondary education. After all of that, her time at the TPU also felt exclusionary because Waimarie perceived her principal (and other staff and pupils) to be racist. So while TPUs were generally described in positive terms, there is still some indication that they can be exclusionary/disempowering too.

\section{Inclusive/Supportive or Exclusive/Regulatory?}

Apart from Ngaio and Waimarie's experiences, TPUs appear to be a successful support system for young mothers. Only two out of the seven young women who did not attend a TPU achieved more than NCEA level 1 by the time of their last interview, even though most of them were older. This indicates that disengagement from education, for these participants, is not an effect of teen pregnancy - in this study young mothers who could access a TPU were more likely to achieve NCEA level 2 than those who finished school before becoming pregnant - but part of a wider picture of exclusion within our school system. Schools, as important disciplinary devices, teach students important skills for participating 'positively' in our society (namely the workforce). The experiences described by the young women in this study highlight how many youths are being disengaged by their schooling, and so seemingly prepared for menial work as a subproletariat class, as argued by Wacquant (2009). And, as illustrated in Table 3 (in section 5.2 below), achieving NCEA level 2 (or 3) did not necessarily mean an easy transition into the work force, or financial independence for the young women in this study. Only Ariana could rely on her salary (and her partner's) to survive. All of the other young women received a welfare benefit (or no income in Waimarie's case). So, those young mothers who were disengaged from education were in a poor position (in terms of being able to be financially independent), and even those women who had managed to achieve NCEA levels 2 or 3 while looking after their young whānau (mostly) did not fare much better.

\section{Keeping a Roof Over Their Heads (income and housing support)}

We're angry people now (laughs). I think 'cause it's crunch time and... knowing that not much is coming in, and just scraping by. (Pania, interview 2) 
Rose argues " $[\mathrm{t}]$ he environment of the growing child is regulated financially, through benefits and allowances to the family, and pedagogically through programmes of education directed at the parent-to-be" $(1999,123)$. Thus, through the child, parents are regulated by the kinds of support that they are offered (and the obligations entailed). Most of the young mothers in this study relied on financial assistance from Work and Income New Zealand (WINZ) to survive (see Table 3). With that support came obligations for self-improvement and also increased surveillance of their lives. Housing was also a major issue for these young women, who often could not secure their own permanent accommodation - through private rental or Housing New Zealand Corporation (HNZC) - and so ended up boarding or staying with whānau or friends, often in overcrowded situations. These financial and housing struggles are discussed in this section.

Table 3: Participant Living Situation Information (at time of last interview)

\begin{tabular}{|c|c|c|c|c|c|c|c|}
\hline & Name & Age & $\begin{array}{l}\text { Parental } \\
\text { responsibility }\end{array}$ & $\begin{array}{l}\text { Study or } \\
\text { work }\end{array}$ & Relationship & Housing & $\begin{array}{l}\text { Main } \\
\text { Income }\end{array}$ \\
\hline 1 & Awhina & 17 & Y (1) & Study & Dating & Boarding (wh.) & YPP \\
\hline 2 & Marama & 17 & $\mathrm{~N}\left(1 \mathrm{VR}^{*}\right)$ & Study & Single & Boarding (f.) & WINZ \\
\hline 3 & Tui & 18 & $\mathrm{Y}(1)$ & Study & De facto (FOB) & Boarding (wh.) & YPP \\
\hline 4 & Waimarie & 16 & $\mathrm{~N}\left(1 \mathrm{VR}^{*}\right)$ & Study & Single & Living with wh. & None \\
\hline 5 & Irihapete & 18 & $Y(2)$ & Study & De facto (FOB) & Boarding (wh.) & YPP \\
\hline 6 & Manaia & 19 & $\mathrm{Y}(1+$ preg. $)$ & No & Trial separation & Renting with wh. & WINZ \\
\hline 7 & Ngaio & 18 & $\mathrm{Y}(1) \mathrm{N}\left(1^{*}\right)$ & Study & Single & Renting with wh. & YPP \\
\hline 8 & Tia & 20 & $\mathrm{Y}(1)$ & Both & Dating & Renting (Private) & WINZ \\
\hline 9 & Tina & 21 & Y (3+preg.) & No & De facto (FOB) & Renting (HNZC) & WINZ \\
\hline 10 & Anahera & 21 & Y (1) & Enrolled & Dating & Boarding (wh.) & WINZ \\
\hline 11 & Ariana & 22 & $Y(1)$ & Work & De facto (FOB) & Renting (?) & Salary \\
\hline 12 & Hana & 22 & $\mathrm{Y}(1)$ & Study & De facto (FOB) & Renting (Private) & WINZ \\
\hline 13 & Kiri & 22 & $\mathrm{Y}(1)$ & Study & De facto (FOB) & Renting (?) & WINZ \\
\hline 14 & Mere & 21 & $\mathrm{Y}(3)$ & No & De facto (FOB) & Renting (HNZC) & WINZ \\
\hline 15 & Pania & 22 & $\mathrm{Y}(2)$ & No & Single & Boarding (wh.) & WINZ \\
\hline
\end{tabular}

Key:

$\mathrm{VR}=$ visitation rights $\mathrm{FOB}=$ father of baby $/$ babies $\quad$ preg. = pregnant $\quad$ wh. = with whānau $\mathrm{f} .=$ with friends $\quad$ YPP $=$ Young Parent Payment $\quad$ WINZ $=$ undisclosed benefit

* These young women's experiences will be discussed in the section dedicated to Child, Youth and Family interactions. 


\section{Work and Income New Zealand (WINZ)}

Work and Income New Zealand (WINZ) manages our state welfare system. Whānau in need of financial assistance apply to WINZ and must meet certain criteria in order to receive a benefit. While most of the young mothers in this study continued to study (after completing their schooling), theoretically building their employability skills, only Ariana was able to secure full time employment (see Table 3) - and even she talked about financial struggle:

We get stressed out most of the time about finances. (Ariana, interview 3)

All of the young women except Ariana and Waimarie (who had no income) were reliant on WINZ for their income at the time of the last interview. All of the young mothers in this study (as well as some of their whānau) described financial struggle. Worrying about outstanding bills, making ends meet week-to-week, and negative experiences dealing with WINZ were common themes.

For some, financial struggles were exacerbated by the young age of the mothers (those under 16), meaning they were not entitled to receive a benefit (until they turned 16). This is illustrated by Marama, who was 14 when she gave birth:

Whatever I need I don't get it. No income. No pay. (Marama, interview 3)

Almost half of the mothers in this study were too young to receive a benefit when they began their motherhood journey, although their parents were able to collect a Working for Families Tax Credit (WfFTC) for the baby (financial assistance for families with dependent children). They had to rely on their caregivers (usually their own mothers) for financial support:

I can't [treat myself to anything]. I've got no money. My mum doesn't even give me 5 bucks. (Waimarie, interview 5)

This often added strain to their relationships with their caregivers, as the young mothers felt like they should be entitled to money in order to be more independent. 
However, they were not able to get any benefit from the state, and their caregivers were often struggling financially, so any extra money (from WfFTC) needed to go towards supporting the new baby.

Parents aged 16-18 years old are eligible for the Young Parent Payment (YPP) benefit. With the YPP benefit, young parents work with a youth service provider who pays their rent and utilities for them out of their benefit. A $\$ 50$ weekly allowance is deposited in their bank account, and any leftover money from their benefit is uploaded onto a special card to use for groceries. Young parents must attend budgeting and parenting courses, be studying or available to study/train for NCEA level 2, and enrol their infants with a Well Child provider (Plunket or Tamariki Ora) and a GP or local health service (Parliament, 2012). Some of the young women in this study who received the YPP benefit found the system confusing, or had trouble with the cards, as illustrated by Awhina:

I think [the YPP] is so stupid. I hate those payment cards because I don't even get money [on it]. (Awhina, interview 3)

Another participant questioned why they had to attend budgeting classes to receive the YPP, but that they were not allowed to actually budget (fully) for themselves as that responsibility has been taken away from them (and given to their youth service provider). These services, set up to 'support' young parents to become 'better', are paternalistic and authoritarian.

Many of the mothers in this study (and sometimes their partners) talked about having to attend budgeting, parenting, or educational courses (in order to receive a benefit). These courses are intended to teach parents how to improve their life skills, make them more self-reliant, and set them up for integration into the workforce. Some participants found that the courses they had to attend were not appropriately designed for their needs. One example (another example of frustration with 'budgeting support') is from Pania: 
This stupid budgeting thing... they gave me a piece of paper and I'm like, 'I don't get this.' And the caseworker wouldn't even explain it to me... I was like, 'Oh, they're saying how to budget with money that you don't have... How can I budget with what I've got, and you've got down here all this stuff which I don't even need, and then it adds up to be way more than what I even receive?' (Pania, interview 4)

Pania was not supported properly with the task that she had to undertake, and then, when she figured out what she had to do, she was surprised that the example was not relevant to her circumstances.

For many of the young mothers in this study, who were in relationships with the fathers (or 'step-fathers') of their children, the decision of whether to declare their defacto relationships or not was a cause of stress. By not declaring their relationships, the young women could receive a separate income - a 'single' person's benefit, and financial independence from their partners, but would worry that they were breaking the rules and would be found out. Two examples are from Hana and Pania:

WINZ and stuff they make it easier for families to be apart rather than to be together... like I wouldn't have a roof over my head if they knew about him...He's never here. Even when he is here he's always being an idiot and ends up in court, locked up... I tell him all the time I'm a single mum because I am. Even when he's here I'm still a single mum, and dad. (Hana, interview 6)

Really I'm not lying to them 'cause I'm not always with him. I'm always kicking him out. We're together, we're not together, but it would be nice to let them know... and not hide behind their backs. But I'm doing it... to keep my baby... I don't know how I would cope on so little money if I only get a little bit at the moment. (Pania, interview 1)

Hana and Pania's living situations (with their partners) were so changeable, that not telling WINZ about their relationships did not seem like such a lie. However, this still caused them anxiety. Mere also worried about not declaring her relationship to WINZ, but she was more concerned that she would not be able to support her whānau if her 
benefit changed. These young women lived in anxiety about breaking the rules and being found out. However, in order to put the welfare of their babies first, they chose to live with that anxiety. Other participants decided to declare their relationships, and suffered for it:

It was a hard decision because it cut down our money. And when they cut off my benefit they cut off my child subsidy so I owe money. (Tui, interview 2)

Tui (above) and Tina were too worried about being caught out, so they declared their defacto relationships to WINZ, resulting in their benefits changing and their income reducing. Tui ended up owing money to WINZ, and Tina ended up having to move out of her flat because her rent got in arrears.

More than half of the young women in this study, and some of their whānau, recounted frustrating or demeaning experiences with WINZ staff. This resulted in many of them declaring that they hate/dislike WINZ, and would avoid going there if at all possible. Mere articulated this sentiment particularly clearly:

I just don't want to go to WINZ by myself. I hate going to that place. (Mere, interview 6)

Mere did not want to go to WINZ alone, indicating that WINZ does not comfort or reassure those who need their support. An exchange between Hana and her sister (also a teen mother) highlights how difficult it can be to navigate the WINZ system:

Hana's sister: They're never helpful...They don't really offer much.

Hana: WINZ made me go [on a course] or they were going to cut my benefit... They just cut my benefit last week, because I went to a funeral and I had an appointment... Yeah, they said that there was no record of me calling or anything. There's so many times I've called to make an appointment and I go there and no one made an appointment for me. 
Hana's sister: I'm always with a different person. That sucks because they don't really understand...Yeah. All they can see is notes.

(Hana and her sister, interview 6)

Not only did they find WINZ staff uninformative, but also unfair. This punitive power, the threat to cut benefits when obligations are not met, regulates/disciplines beneficiaries, who must work to appease WINZ just to survive. Hana's sister also made the comment that 'all they can see is notes'. This dehumanization invokes Césaire (1972), who names the process of turning colonized peoples into instruments of production (thus dehumanizing them) 'thingification'. The feeling of being treated as a number, a piece of paper, or 'notes' is disempowering and dehumanizing (or thingifying), and is a recurrent theme throughout the narratives. Many other young mothers also talked about WINZ staff being uninformative, unhelpful, or frustrating. Some examples are:

I've just recently [found out about the disability allowance for my son]... [WINZ never told me and] I didn't think about it either because... I just go there when I have to. (Manaia, interview 3)

WINZ, they don't help, they don't help at all. I don't' reckon they'd care if you were starving on the street. They still wouldn't help you. (Ngaio, interview 2)

[WINZ appointments] suck... I hate them... Just sit there and wait for them for ages... and you don't know whether you're gonna get it or not. (Mere, interview 2)

These young mothers, as well as others, felt little care or compassion from staff working at WINZ. They were treated like scroungers, and if they wanted to retain their benefits (in order to survive) they needed to keep subjecting themselves to that poor treatment. Their experiences were incredibly disempowering. Tina offers more insight into this power imbalance:

I don't really like talking to WINZ. I really dislike them. Sometimes they're a bit funny. Some are like, 'Why haven't you done this or that?' I'm like, 'Well 'cause I 
haven't got a car no more... I don't have a car to just easily do things.' And then they're like, 'Oh well couldn't you catch a bus or a taxi?' I was like, 'With three kids and no pram? You've got to be kidding me!' (Tina, interview 5)

The lack of empathy on the part of the WINZ staff is apparent. They espoused 'personal responsibility', expecting Tina to meet her beneficiary obligations, without considering her situation. Their patronizing attitudes and unrealistic expectations did not make Tina feel supported. She felt frustrated and sought to avoid dealing with WINZ if at all possible.

With the exception of Ariana, all of the participants in this study (and some of their whānau) described financial struggle and stress (at some point over the course of the interviews). Those young women who were under the age of 16 when they gave birth were completely reliant on their caregivers for financial support until they were old enough to receive a welfare benefit. This can be seen as a punitive measure for those young women who did not act 'appropriately' (and got pregnant) and were thus denied independence. They are forced to remain 'children' even though they have become mothers themselves. It can also be seen as a punitive measure for their parents (usually mothers) who had to support them with little government assistance (except for family tax credits). For those participants (and their whānau) trying to survive on welfare benefits, making ends meet while meeting obligations (to attend meetings or courses) was a struggle. Participants often felt encouraged to either leave their partners, or pretend that they were not in a relationship, in order to have enough money to survive. Struggles were compounded by the condescending and discriminatory attitudes of some WINZ staff, who did not make navigating the welfare system easy. The participants in this study overwhelmingly felt confused and/or annoyed by WINZ, where 'personal responsibility' is encouraged without adequate support.

\section{Housing New Zealand Corporation (HNZC)}

Many of the young mothers in this study (and sometimes their whānau) talked about experiencing difficulties finding appropriate housing:

The hardest [thing] is finding a house. (Tina, interview 1) 
As articulated by Tina (above), the stress of trying to find a house was often listed, along with 'making ends meet', as one of the hardest aspects of their lives. The impact of colonisation on Māori land ownership is worth noting here. As discussed in the introduction to this thesis, the state sanctioned (or perpetrated) dispossession of Māori land throughout the $19^{\text {th }}$ and $20^{\text {th }}$ centuries has had far reaching consequences for Māori whānau today. Rates of home ownership for Māori are less than half of those for New Zealand Europeans (Statistics New Zealand, 2014). It follows that Māori make up a large (disproportionate) number of families on the Housing New Zealand Corporation (HNZC) social housing register (Flynn et al., 2010).

While some of the young women in this study talked about trying to find housing through HNZC, most ended up going into the private market, or boarding with friends/whānau. Two examples of difficulties navigating HNZC are from Manaia and Mere:

We tried to go with Housing New Zealand... we'd email them questions with the social worker and by the time they emailed us back... it was like, 'You have this date to get this and that,' and we only had one day to get it so every question that we asked they just kept declining us and then we just finally closed it. (Manaia, interview 2)

I couldn't get housing [from HNZC]. 'Cause I'm not an emergency... They were like, 'Yeah, go to private and if you get rejected by a couple of houses ring us back with the proof that they rejected you and then we'll give you a house.' [I won't do that] if they're going to put me on a waiting list... I don't know I just feel a bit lost at the moment. (Mere, interview 5)

Manaia and Mere both tried to get HNZC housing. Manaia ended up frustrated because the process did not allow her enough time to get organized. Mere ended up frustrated because the process meant that she needed to get 'rejected' from private rentals first. These 'hoops' for the young women to jump through compounded already difficult living situations. 
For many of the young mothers, finding their own permanent housing was out of the question (because of difficult processes or lack of affordability). That meant that they ended up having to move around a lot, often staying with whānau in overcrowded situations. For some, this had a very strong impact on their personal wellbeing, causing stress and feelings of insecurity. Two examples of this are from Pania and Tui:

[My sister] don't mind us being here, not at all, but her partner... I think that's... why me and James [partner] are in two separate places all the time 'cause he doesn't feel comfortable here. (Pania, interview 2)

Yeah, just everything got real down like I was going from house to house. (Tui, interview 3)

Pania and Tui, like others, found their unstable living situation stressful and demoralizing. Other participants also described settling for substandard housing because they had no choice. Tina gives a poignant description of one such situation:

It's depressing. I don't even want to come home sometimes. Like if I've had a good day out I don't want to come home... It gets warm fast if you cook and close all the windows but then it goes away after a while and it's kind of cold... It's cold in here... There's only an open fire but I don't use it. (Tina, interview 2)

Tina felt depressed because of her distressing living situation. Her (HNZC) house was cold and unhealthy for raising a young whānau (with no heating except for an unusable open fire), but she felt like she had no choice.

For many of the young mothers, there was an intergenerational factor to their housing struggles. They often experienced housing insecurity and 'moving around a lot' as children, and then ended up in a similar situation as adults/parents. An example of this is from Hana and her whānau: 
It was horrific [being a young pregnant Māori woman]. There was no support... Money, money was a hard one and that more or less gauged what the outcomes would be really. Housing, you know, it depended on how much money I had, where we lived. (Hana's mother, whānau interview 1)

Hana's mother had been a young mother too. Her financial struggles prevented her from housing security, resulting in the whānau moving around a lot. Hana faced similar obstacles as a young mother, staying with whānau or friends, and at one point being 'kicked out' due to tensions:

I went to [a rental agency]... and she said, 'How bad do you need the house?' and I said, 'Pretty bad, I've been kicked out, I've got until tomorrow.' (Hana, interview 2)

Hana managed to secure a rental property from the agency that she went to, and was relieved to finally have her own space. Hana's sister also struggled with housing. She settled for a rental property that was substandard:

I'm pretty sure that it's my house that makes [my kids] sick. It's the mould, it's the coldness, it's that house. (Hana's sister, interview 6)

Hana's sister thought that her house was making her children sick, but she also felt like she had no choice but to stay there. By not being given enough support, young Māori mothers are vulnerable to financial insecurity, meaning housing insecurity, and subsequently (sometimes) health insecurity. Wacquant (2009) and Foucault (1995) (invoking their respective theories of sup-proletariats and delinquents, as discussed earlier) might argue that this kind of poverty-rut is actually encouraged by the state, in order to keep marginalised peoples marginalised - a politically safe/docile class of menial labourers/women who will not challenge the patriarchy, and are abundant targets of moral panic campaigns.

Many of the participants in this study described feelings of stress and disempowerment because of their lack of financial security, and their strained and changeable living situations. Lacking a healthy and stable physical space took a toll on their emotional 
wellbeing. Some participants found navigating the WINZ and/or HNZC system difficult, especially when having to deal with staff that treated them poorly. By expecting these women to meet certain, often illogical seeming or frustrating obligations - by making them jump through such hoops - social welfare and social housing services created stress and anxiety for these young mothers, who wanted to provide safe and healthy homes for their whānau.

\section{Social Worker Judges: Child, Youth and Family}

"The policies and practices of welfare... [function] to maintain inequality, to legitimate existing relations of power, and to extend social control over potentially troublesome sectors of society... the extension of surveillance and control over the family...[especially] the families of the working class" (Rose, $1999,125)$.

In the Crimes Act 1961, the legal age of consent to sex for females is 16 years old (Collins, 2005). Pregnancy and childbirth before the age of 16 years old, while not ciminalizing the young woman, might warrant investigation by Child, Youth and Family (CYF) under the provisions of the Children, Young Persons, and their Families Act (CYPF Act) 1989. A young woman and her whānau are then open to scrutiny, subject to the disciplinary gaze of CYF. Family history of CYF intervention, or the judgements of school and hospital social workers can also lead to CYF involvement with young mothers. The core objective of the CYPF Act is to promote the well-being of families, children and young persons. It sets out provisions to support whānau, and also provisions for the care and protection of children and young persons who might be at danger from their whānau (Ministry of Social Development, 2014). A quarter of a century after the creation of the CYPF Act, Māori whānau are grossly overrepresented in Child, Youth and Family (CYF) interventions.

While Māori are a young population (almost 30\% of children born in Aotearoa New Zealand are Māori), Māori make up 57\% of children involved with CYF before the age of 5, and $60 \%$ of all children in care (Ministry of Social Development, 2015). Because Māori whānau are already more likely to be involved with CYF, new generations are 
born into 'the gaze'. The Ministry of Social Development has recently stated that CYF is "not preventing or adequately protecting children from harm" $(2015,4)$, and that existing reviews of CYF have led to little positive change (2015). So, not only are Māori whānau more likely to be involved with CYF, they are more likely to be failed by them. Out of the fifteen young women in this study, five experienced CYF interventions into their mothering (others had experienced CYF when they were children). Marama, Waimarie, Ngaio, Mere and Tia's experiences of CYF intervention, as objects of the ultimate, punitive disciplinary gaze, are discussed in this section.

\section{Judges of Normality}

Social workers (connected to CYF) played an important role in the judgment, support and regulation of the young mothers in this study. Observation and questioning were used to moniter Marama, Waimarie, Ngaio, Mere and Tia, and judge whether they were capable of looking after their children. The standards by which the young mothers were judged sometimes seemed strange/irrational or unfair to them.

Marama and Waimarie were both observed in the hospital following the birth of their children, because of their young ages (both 14 years old) and previous family history with CYF. They were questioned, monitored, and judged:

I wasn't really happy but my mum said to go with [CYF], go with what they have to say, so I did... 'Cause my sister's kids were just going through that. (Marama, interview 1)

Cause it was procedure for them to come to the party, at the hospital. They're informed... they monitored us for the first two weeks. (Waimarie's mum, whānau interview 1)

Marama, Waimarie (and their whānau) had to go along with the CYF protocols to avoid further CYF intervention. Ngaio's first experiences of CYF were more punitive. She gave birth to her first son in a specialist respite home for vulnerable mothers, where she was well supported by the staff. She had never had contact with CYF before, nor had anyone in her (Pākehā) family who she was living with at the time. Ngaio decided to adopt out 
her son, however, the adoption was prevented, so she kept custody of baby Ariki. It was not until Ngaio lost custody of Ariki suddenly, due to abuse allegations, that she experienced CYF measures. When she became pregnant with her second son Wiremu, Ngaio was subject to intense scrutiny and expectations about self-improvement:

Cause CYF got involved with my first son so we've had all that stuff and we've had to be like monitored... You never know what's going on because they never tell you anything... I don't like it. (Ngaio, interview 3)

Ngaio felt the disciplinary gaze of CYF. While she was subject to their scrutiny, she felt that CYF workers did not communicate with her properly - maintaining a clear power imbalance between 'who is gazing' (CYF) and who is 'the object of the gaze' (Ngaio). Mere provides another example of this kind of power imbalance:

They turned up on my doorstep... apparently we were beating up the kids... 'Do you see anything on my kids? Do they look hurt? No, they look happy.' And I wouldn't let them in my house, because my house was a big mess, and 'cause they would have claimed that as neglect... So I just talked to them at the door. And they just wanted me to strip my kids down so they could see them and see if there's any bruises. (Mere, interview 6)

Because of history with her partner (Rewi), Mere was subject to CYF observation and questioning when she had her first baby. When she decided to keep having children (three in three years), she experienced intense scrutiny, with social workers even turning up to her house unannounced. The power imbalance between the social workers (who could show up unannounced) and Mere is apparent in the narrative above. However, in the event that Mere recounted (above), she resisted the totality of the gaze, by not allowing the social workers into her house. Tia also experienced CYF observation, after her son almost died from Sudden Infant Death Syndrome (SIDS):

Mum had spoken to them not to speak to me by myself, a few times... but they kept coming in and asking me questions, and I had already said to them, 'I'm not in the state of mind to answer questions,' and they'd just come back in, keep on coming in 
and out... I was not in the state of mind to be answering questions from them, I was worrying about my son, not them. (Tia, interview 2)

When her son was recovering in the hospital, Tia had hospital social workers and CYF monitoring her. Tia thought that the hospital social workers were being intrusive, and after refusing to talk to them without her mother present they called in CYF. In another interview, Tia commented that she had CYF 'on her back' for 3 months because of this, and suggested that it was intimidating. This is an example of hospital social workers working with CYF to cast the disciplinary gaze of 'social' services further, encompassing all aspects of young mothers' lives.

\section{Distrust and Disempowerment}

As objects of the disciplinary gaze, Waimarie, Marama, Mere, Tia and Ngaio were treated as suspicious, asked 'trick' questions, and/or had their trust breached by CYF representatives, social workers, or whānau acting on CYF's behalf. This led them to distrust those that were purportedly there to support them.

An example of repeated breach of trust is from Marama:

[CYF were] trying to trick me with questions like, 'So you would leave your daughter with your mum if you go out drinking and that and do drugs and that?... And then they tried to ask me that again and I told them again, 'I don't do it!' They just wouldn't listen to me. Trying to be real assholes... It was just ticking me off. (Marama, interview 1)

The social worker here doesn't know how to keep her mouth shut. She doesn't keep anything confidential... she's just a big mouth. (Marama, interview 3)

Marama experienced repeated 'trick' questioning following the birth of her daughter. She became so annoyed with this tactic that she described the CYF workers as 'assholes'. Later on in her motherhood journey Marama also had negative experiences with the social worker connected to her teen pregnancy unit (TPU), who breached her trust by sharing information about her with CYF. This is another example of social workers (this 
time in schools rather than hospitals) working with CYF to keep thorough surveillance over young mothers.

Mere's brother recounted what he viewed as sly practices of CYF representatives, who questioned Mere and her whānau immediately following the birth of her first child:

They [first few days in hospital] were shit because of CYF. They were being hōhā [exasperating] trying to intervene... they were mainly doing it real low key, like riddle questions. (Mere's brother, whānau interview 2)

As with Marama, the questioning techniques of CYF seemed unscrupulous/insensitive. Tia also talked about experiencing this:

They [CYF] do this slimy checkup sort of thing... and they want to come into the house to make sure that it's kiddy-proofed and all that sort of stuff. (Tia, interview 4)

Tia talked about the 'slimy' techniques of CYF, and shared a message for other teen parents that is, "Just don't let them [CYF] get involved. Do whatever you can to get them out of the picture" (Tia, interview 4). As with Mere, CYF workers wanted to go inside her home, expanding the gaze into her private space. She did not challenge their intervention, or interest in her, so much as their untrustworthy seeming techniques.

Ngaio felt lied to, repeatedly, by CYF:

CYF said, 'As long as you can apply what you've learned,' then we shouldn't [lose custody of new baby]... and it's like I'm not sure because they lie and lie and lie and lie... They just hold too much power... They pretty much play God with everybody's babies... They said that I would get Ariki back at the end of it and that never happened... They told me so many things and then they've lied... It's like they treat babies like they're just a bit of paper. (Ngaio, interview 2) 
Ngaio felt dehumanized, or thingified, by the way CYF treated her and her son Ariki. She felt powerless and intensely distrustful because of the punitive, non-supportive measures that she was experiencing.

Waimarie and Marama had their parenting rights revoked by CYF, formally or informally, with their mothers taking custody of their children. This caused tension:

When we argue [Mum] uses my baby against me, like she calls me useless and that. She's a bitch, I hate her. (Waimarie, interview 3)

Waimarie felt disempowered by her mother, who did not allow her responsibility to care for her own son. In this case, her mother was acting as enforcer of CYF punitive mechanisms.

Mum kicked me out of the house... rang [CYF] up... and got custody of Terina. Mum told CYF that I smacked her out of nowhere, but that was all shit... I'd say I'm [a good mother] when I see her. But then when I don't, it's like I don't feel like I'm the one that's there for her... but then I can't. Even though I really want to be there with her. But I just can't, 'cause I'm not allowed to be around her until Friday till Sundays. (Marama, interview 4)

Similarly to Waimarie's experiences, Marama's mother acted as an informant to CYF, taking away her ability to mother. So, like Waimarie, Marama's experiences of disempowerment were directed towards her mother rather than CYF. Marama resigned herself to only seeing her daughter in the weekend because she had no other choice. She felt like she had to conform to the requirements put in place by CYF and her mother.

Ngaio, who lost custody and (most) access to her first son, unsurprisingly expressed the most feelings of disempowerment, and embitterment towards CYF:

They've pretty much got all the power. When you get threatened... if you don't do this then this is what's going to happen to you. And so you don't really say anything 
'cause you're too scared of what they're going to do... Yeah, we're not excited [about second pregnancy], we're scared... we're very scared. (Ngaio, interview 2)

It doesn't matter 'cause there's nothing I can do. (Ngaio, interview 2)

Ngaio talked about conforming to CYF rules, by not saying anything , for fear of creating more trouble for herself. She felt like she had no choice in the matter. Her experiences with CYF did not leave her feeling supported. In contrast, she felt the punitive force of the state, as a disciplinary mechanism. Mere also talked about trying to appease CYF:

You just [have to] play their game... So I just like do all the things they said, just to make us look good, and then they leave us alone... I just want them to go away, just leave us alone. I don't know, I'm just scared that they're going to take my kids off me. (Mere, interview 6)

Mere's response could be viewed as a kind of begrudging conformity, maintaining the stability and continuity (Merton, 1968) of the CYF system. But from a postcolonial persepctive this might be viewed as a sly civility (Bhabha, 1994), affording Mere some agency. By using the figure of speech to 'just play their game' to describe how to avoid further reprimand, Mere indicated that she is adept at displacing the gaze back onto CYF, creating a knowledgeable repertoire of all the 'right things'. However, Mere did end the response with feelings of frustration and fear surrounding experiences with CYF. Whether she felt completely disempowered or not, she did not speak favourably of her interactions with social workers.

\section{Self-doubt/Epidermalization}

Epidermalization is the ontological taking-on of 'Otherness' (Fanon, 2008). Waimarie, Ngaio and Tia experienced some kind of internalization, or 'epidermalization' of the pathologization of their identities as young Māori mothers, and were led to doubt their own mothering capabilities. 
I know that if my mum goes and baby stays with me I won't be able to look after him properly... 'Cause every time my mum's not around he's real unsettled. (Waimarie, interview 3)

Because Waimarie was given very few chances to work on her mothering skills, she ended up believing that she was not a capable mother.

I held him [at the birth] and I cried, I was both sad and then I was happy because I had him. I knew then that I was like 'I need to do what's right for you and it's not me,' and so I decided then that, 'Yep that's what I want to do, he needs to be adopted to have the best life he could possibly have.' (Ngaio, interview 1)

Ngaio was pressured (by her mother) to have her first son adopted out. And so she doubted her own abilities to look after him, and tried to organize an adoption.

Through the children's ward we felt like we were the perpetrators... like Tia was being constantly watched, constantly harassed. And it made her feel less and less of a mother, to a point where she did get quite depressed and not want to have to deal with Kauri because she was too scared. (Tia's mother, whānau interview 1)

Tia's mother recounted the change in Tia's demeanour because of the way the whānau were being treated in the hospital after almost losing her baby to SIDS. She did not think that Tia was adequately supported during that time of extreme stress.

These three young women were made to doubt their own mothering capabilities because of the judgemental, disciplinary gaze of authority figures. For Waimarie and Ngaio it was their own mothers who made them feel inadequate. Tia had the support of her mother, but the hospital social workers made her feel inadequate. The disciplinary gaze regulated these young mothers by making them believe that they were abnormal and in need of regulation. 


\section{To Conform or to Disengage?}

Overwhelming feelings of disempowerment and distrust (and sometimes self-doubt) led these five young mothers to either conform to CYF requirements, or disengage from services as much as possible (or a combination of the two). As discussed earlier, Marama conformed to access arrangements with her mother (just so she could spend time with her daughter), and Waimarie felt like she had no choice but to let her mother take over the care of her son. Mere also felt like she had to 'play a game' with CYF in order to avoid having her children removed. However, she also actively avoided social workers because of her negative experiences with them:

When I hear the word 'social worker', nah, I don't like that word only 'cause I'm gonna think that [they're] CYF and that they're going to report everything to CYF. So I'll just stay away from them and won't take their advice or whatever they're trying to do to us. (Mere, interview 4)

Rather than feel supported by social workers, Mere felt threatened, and so she attempted to disengage from their services as much as possible. Tia also disengaged from social workers as much as she could:

I was ignoring every question that [the hospital social workers] asked, and then I'd just get up and leave and take my son with me and just go walking around... I just couldn't go back there [to the hospital], I just don't want to go back there. (Tia, interview 2)

Tia's experiences with hospital social workers (as discussed earlier) led her to disengage from their services, and feel negatively about the hospital in general. Tia did not let her son's health suffer for it, but her 'walking around' to avoid the hospital social workers can be seen as her claiming some agency in that very disempowering situation.

Ngaio's narratives were filled with feelings of disempowerment and anguish. She wanted to disengage from social services, but when she became pregnant with her second son, she resigned herself to CYF regulations. Ngaios sister-in-law talked about how Ngaio tried to prove to CYF that she was a good, responsible mother: 
Well they decided to do all these things, and they actually told CYF what they were going to do. They don't want CYF to tell them what to do so they're trying to prove to them that they can be independent and do their own things. (Ngaio's 'sister-inlaw', whānau interview 1)

From Ngaio's sister-in-law's response, we can see that (in attempting to appease CYF) Ngaio and her partner (Charlie) began to regulate themselves in order to prove their parenting abilities. For Foucault (1988a), such 'techniques of the self' (self-government techniques) are ambivalent, and offer the potential for both subjection to certain moral codes, and also potential for creating an ethical relationship with one's self. This is relevant to Ngaio's narrative as she subjected herself to the moral codes set out by CYF, and in doing so submitted to the authority of this state entity. However, in doing so, she also enacted agency in her life, and gave herself hope that she might keep custody of her second son. By learning the role of 'appropriate' mother, through parenting classes, Ngaio was supported and regulated. And the regulation did not stop there. Eventually, Ngaio was given an ultimatum to leave Charlie in order to keep custody of Wiremu, and for the possibility of spending more time with Ariki:

No, like we just can't live together. They've given me the choice. I either choose Charlie and Wiremu goes with my Aunty or I choose Wiremu and Charlie goes, and I could never ever have like Ariki at my house if I was with Charlie because [he] would be there. (Ngaio, interview 3)

Ngaio made the choice to prioritise her babies. Cruikshank (1996) argues that women are often coerced by the courts, in the name of 'empowerment', to attend therapeutic programs and parenting courses, in order to get the custody of their children back (like with Ngaio). In this way, the threat of removing children is "a coercive apparatus for preparing mothers to become the kind of mothers deemed appropriate by society" (Cruikshank, 1996, 234). This is evident in Ngaio's narratives. She was given seriously restricted choices, and in the end an ultimatum. She was disciplined by CYF - shaped into a 'more approriate' mother by attending courses and leaving her partner. However, she still did not get custody of her first son back, and felt pessimistic about her chances at the time of the last interview. 
The five young women discussed in this section were all subject to the disciplinary gaze of CYF because of their non-normative lives. Their lived realities were deemed abnormal according to Eurocentric conceptions of normal cognitive development, normal life course trajectory, and appropriate life choices (regarding living conditions and lifestyle). The state wields the ultimate punitive power, to be able to remove children from their care, or to observe and regulate their behaviour through threats both real and thinly veiled. And so, the 'support' of social services also serves a disciplinary function. These young Māori mothers were observed, questioned, judged, and enveloped in fear. Sometimes (as is the case with Marama and Waimarie) their whānau were complicit in their regulation. Consequences of being objects of this gaze included feeling of distrust and disempowerment, self-doubt/'epidermalization', a disengagement from services, conformity, or in Mere's case, a sly civility.

\section{Objects of the Disciplinary Gaze (discussion)}

Rose argues that the practice and articulation of individual freedom is always "surrounded by a web of vocabularies, injunctions, promises, dire warnings and threats of intervention, organized increasingly around a proliferation of norms and normativities" (Rose, 1996, 46). Those activities that were previously left to the private domain (such as matters of parenting) have been tapped into by experts and professionals acting as judges of normality (Foucault, 1995; Rose, 1999; Rose, 1996). The family has become "instrumentalized as a social machine - both made social and utilized to create sociality - implanting the techniques of responsible citizenship" (Rose, 1996, 49). Discipline imposes on society an order where "every form of non-conforming is punishable" (Foucault, 1995, 179). Families who appear to stray from the 'normal' are regulated/disciplined in order to normalize them, and engender the 'right' kind of children to be raised within them. The normalizing, disciplining functions of the education system, of social welfare and housing services, and the ultimate punitive power of Child, Youth and Family can be seen as part of the 'disciplinary gaze' of our neoliberal/neocolonial nation state. 
The education system, compulsory and inclusive in its 'catching up' of children, was also exclusionary and disempowering for most of the young mothers in this study. While medical discourse (such as Boden et al., 2008; and Ministry of Social Development, 2010 ) tends to highlight the negative effects that teen pregnancy has on educational achievement, the young women in this study were mostly disengaged from education before their pregnancies. In fact, for those young women who were able to attend a TPU upon becoming pregnant, their academic achievement tended to be higher than those who finished their schooling before becoming pregnant. However, even with reasonable academic success (such as NCEA level 2 or 3), only one of the young women in this study was able to secure and maintain full time work. This left the remaining women perpetually reliant on WINZ support (or familial support for Waimarie), which subjected them to increased surveillance and sanctions into their personal lives.

The social welfare and social housing systems, adminstered by Work and Income New Zealand and Housing New Zealand Corporation respectively, provided support for the young women in this study - but with obligations and/or criteria. All of the young mothers (except Ariana and Waimarie) relied on a benefit from WINZ to survive, and in doing so, they were subject to the discriminatory and disrespectful attitudes of some staff, and also to obligations that sometimes seemed ineffectual. Most of the young women talked about trying to avoid WINZ as much as possible, and this effect might be seen as a failure of the system. But if we take a Foucauldian stance, we might view this disengagement as actively produced by the WINZ system. By treating these young women like scroungers and making them feel inferior, these young women are less likely to go to WINZ for assistance, and are thus less likely to receive all the benefits that they are entitled to. The HNZC system was rarely accessed by the young women in this study because of the difficulties experienced trying to navigate it and its criteria for eligibility. Most of the young mothers ended up boarding/renting/staying with family in order to have a roof over their heads. But this often meant overcrowding, moving around when relationships became frayed, and a sense of insecurity. The ability of the state to allow (or encourage) these poor living circumstances might be viewed as a technique to create and maintain a docile, politically safe 'sub-proletariat' class (Wacquant, 2009). 
The five young mothers who became targets of Child, Youth and Family intervention, experienced the puntive might of social services. CYF observed, questioned, gave ultimatums, and imposed sanctions on these mothers, thus attempting to discipline them through careful regulation. The young women experiencing CYF intervention lost trust in social services, felt disempowered and sometimes doubted themselves. They reacted by disengaging from services if possible, by begrudgingly conforming to CYF procedures when they needed to, and in one case at least 'playing the game' - opting for a sly civility.

By not conforming to hegemonic conventions of appropriate child rearing age and context (Reekie, 1997), the young women in this study were subject to a "microeconomy of privileges and impositions" (Foucault, 1995, 180) that played out in public and private. The 'social' services discussed in this chapter are inclusive in their surveillance - the panoptical, disciplinary gaze is all-seeing. Its branching out across different social spheres - the school, the welfare office, the home, and its connecting nodes ensure that young Māori mothers are regulated from many different angles. Being a target of the gaze, knowable bodies, the young women in this study (and sometimes their whānau) were encapsulated in uneven power relations of observer/observed, normal/abnormal, competent/incompetent. 


\section{CHAPTER SIX: THE COLONIAL GAZE (ĀTETANGA!/RESISTANCE!)}

In our post/neo-colonial society, the medical gaze and the disciplinary gaze can be subsumed under the broader colonial gaze. The colonial gaze is also embedded in the principles of the Enlightenment, on ideas of rationality, civilisation, and progress. For colonised peoples, the colonial gaze transfixes the Other identity as abnormal and savage, in need of saving/civilising, yet impossible to fully save/civilise (Bhabha, 1994; Fanon, 2008). In Aotearoa New Zealand, the colonial gaze places Māori as the target.

Colonization is a process of power/domination that functions through the gathering and interpreting of knowledge about the Other, and which subsequently reinforces the colonizer's own self-image as civilized/superior (Bhabha, 1994). According to Bhabha, through "'knowing' the native population in these terms, discriminatory and authoritarian forms of political control are considered appropriate" and so Others are "then deemed to be both the cause and effect of the system, imprisoned in the circle of interpretation" (1994, 83). Bhabha draws on Césaire's (1972) 'thingification' to articulate the disempowering and dehumanizing effects of colonization for Indigenous peoples.

The effects of colonization continue in Aotearoa New Zealand today, as in other 'post'colonial nations. Continued social, health, and economic disparities between Indigenous peoples and non-Indigenous people are evidence of this, "despite political or individual rhetoric that may claim otherwise" (Biggs \& Baird, 2009, 2). Young Māori mothers challenge cultural, social and medical norms by being non-Pākehā, by engaging in nonnormative ('too young') sexual (and social) activities, and choosing to mother 'too young'. Young mothers (usually associated with being Māori) are often portrayed as a burden on the health and social welfare systems, and as incapable/negligent (Breheny, 2006). However, by drawing upon Bhabha, Foucault and Butler, and their theories of resistance, we can problematize these interpretations. 
Cultural difference, the process of negotiation allowing self-identification, muddies the waters of colonial knowledge and in doing so changes the identity of both the colonized and the colonizer. By desiring, seeking, being more than a static given identity, subordinated peoples can re-appropriate themselves and their histories through the act of self-articulation (Bhabha, 1994). This takes place in the Third Space, between the speaker and the listener, where discursive conditions enable signs to "be appropriated, translated, rehistoricized and read anew" (Bhabha, 1994, 37). In the Third Space, the roles of the seer and the seen can be reversed (Bhabha, 1994). As with Foucault, Bhabha argues that the colonizing gaze of disciplinary apparatuses depends on surveillance for "strategies of objectification, normalization and discipline" $(1994,83)$. Bhabha offers a theory of resistance to this totalizing power, where "the look of surveillance returns as the displacing gaze of the disciplined, where the observer becomes the observed and 'partial' representation rearticulates the whole notion of identity and alienates it from essence" $(1994,89)$.

The Third Space produces new forms of representation including mimicry, sly civility and hybridity (Bhabha, 1994). Mimicry, the partial representation of the Other through a mask of conformity, turns the gaze of the observer/colonizer back on itself. Sly civility, the performance of the Other as the good subject/object, thinly veils the Other's contempt/mockery, a private joke on the colonizer's authority. Hybridity appropriates and merges representations from both colonizer and colonized, producing identities that challenge the "rules of recognition" (Bhabha, 1994, 114), ambivalently "disciplinary and disseminatory" (Bhabha, 1994, 112). Mimicry, sly civility and hybridity elude resemblance, instead producing "a subversive strategy of subaltern agency that negotiates its own authority through a process of iterative 'unpicking' and incommensurable, insurgent relinking" (Bhabha, 1994, 185). Self-enunciation, talkingback through iterative subjectivity, is a strategy of resistance.

Foucault also offers a theory of resistance to domination. Foucault opposes binary views of power, instead arguing that it "comes from below" (1980, 94). For Foucault (1980), resistance is present everywhere, even in those most downtrodden places. Foucault states "[p]ower is everywhere; not because it embraces everything, but because it comes from everywhere" $(1980,93)$. There are no relations, familial, sexual or 
otherwise, exterior to relations of power. Power is both cause and effect of relations on every level (Foucault, 2009). Hence, individuals are subject to power, but also active agents of power. They shape and are shaped by power (Foucault, 1980). Power, once dispersed, is liable to a life of its own, to change, to be appropriated. Individuals are able to determine their own identities through ethical self-formation, the work that one does on oneself, to 'know oneself' (Foucault, 2010). This affords subjects agency, albeit within the matrix of power that is ever changing (yet ever-present), and offers endless possibilities for resistance.

Butler's (2006) theory of signification and identity as performative is valuable when considering how subjects are formed. Identity, as a signifying practice, is "constituted by but perhaps not determined by discourse" (Butler, 2006, 195). For Butler (2006), the rules of signification are repressive and also productive, as they enable new forms of signification to be enacted. This is where agency can be found, "within the possibility of a variation on...repetition" (Butler, 2006, 198). Following from Foucault's concept of power/resistance (1980), Butler argues that "it is only within the practices of repetitive signifying that a subversion of identity becomes possible" (Butler, 2006, 198). For Butler, if we view identity as an effect (produced by repetitive performance), we can see new possibilities for agency, where identity is "neither fatally determined nor fully artificial and arbitrary" (Butler, 2006, 201).

Using these complementary concepts of enunciation (Bhabha, 1994), power/resistance (Foucault, 1980), and signification (Butler, 2006), we can problematize dominant discourses that speak 'of' and 'for' young Māori mothers, and that (in doing so) interpret them as abnormal, as perpetually Other. Dominant developmental and medical discourses about adolescence and teen parenthood can be seen as certain games of veridiction, neither universal nor accidental. Through exploring the ways in which these young Māori mothers articulate/enunciate their own subjectivities we find a Third Space where self-enunciation/self-signification/self-formation resists cultural hegemony, subverts normative assumptions about appropriate life course/life choices, and problematizes stereotypes. 
This chapter is divided into four sections. First, I discuss resistance in the form of 'taonga tuku iho' (treasures to pass on), including the continuation of whakapapa (genealogy) and Mātauranga Māori (Māori knowledge systems). Second, I discuss 'mana motuhake' (autonomy/self-determination), including resistance to social prejudices and stereotypes. Third, I discuss 'ngā tūmanako' (aspirations/hopes). Finally, I reflect on how these acts of resistance are situated in complex fields of power (Foucault, 1980), considering the works of Foucault, Bhabha and Butler, as well as critical youth theory and Indigenous perspectives.

\section{Taongo Tuku Iho (treasures to pass on)}

\section{A dying race?}

The colonial fantasy of the dying race (Jordan \& Weedon, 1995), a by-product of social Darwinism, saw Māori (like other Indigenous peoples) as inevitably and justifiably doomed. An example of this rhetoric is Edward Markham's 1830s claim that in New Zealand, like other colonies, "Rum, Blankets, Muskets, Tobacco and Diseases have been the great destroyers [of Māori life]; but [that] the Almighty intended it should be so or it would not have been allowed, Out of Evil comes Good" (Markham, 1963, 83). The 'survival of the fittest' axiom is representative of colonial attitudes to Māori and other Indigenous peoples in the $19^{\text {th }}$ century, and was used as a justification for their rapidly declining populations (Jordan \& Weedon, 1995) - which happened to greatly improve the success of colonial powers. In Aotearoa New Zealand there were simply less Māori to fight back.

I just knew I wanted to keep him. I wasn't going to terminate him. (Irihapete, interview 1)

By becoming mothers and by continuing their whakapapa (genealogy), these women are resisting the historical decimation of Māori in Aotearoa New Zealand. Irihapete's statement above is illustrative of the sentiment expressed by most of the young women in this study, as most did not consider having abortions. For some of the mothers, the fact that they had already had an abortion or a miscarriage, and felt regret or sadness 
afterwards, influenced their positive feelings about their next pregnancy. An example of this is from Manaia:

I just wanted to keep it 'cause I'd already had an abortion... Now that I really understand what abortion is I just wanted to keep it. (Manaia, interview 1)

Often it was the support of their whānau that encouraged them to continue with their pregnancy. An example of this from one of Tia's interviews:

At first I wanted to get an abortion... 'Cause I wasn't with the dad and I didn't wanna be a single mum raising a kid... but then [my parents] ended up giving me the support so I ended up changing my mind. (Tia, interview 1)

Parents and siblings were often cited as the most important source of support for the young women in this study. With the exception of Ngaio, whose mother encouraged her to abort and then adopt out her baby (with the father of the baby taking no responsibility), these young mothers were generally supported by their whānau in their decisions, even if it took a while for some individuals to accept the pregnancies. For example, Anahera's mother described her initial reaction to Anahera's pregnancy:

I wouldn't say [it was] a shock, I would say a disappointment... [But] once we'd talked it through... I got really excited. (Anahera's mother, whānau interview 1)

Most whānau members that were interviewed described similar feelings, although 'shock' frequently came up in regards to the younger participants especially. They generally spoke of their acceptance of the pregnancies, and joy of having a new family member.

According to Bhabha (1994), colonial power produces (for itself) objects of desire, imaginary and fetishized (the image of the dying race is one of these fantasies). But it is through the enunciation of difference that these objects of desire (Others) may subvert the intended disciplinary effects of the colonizing, normalizing gaze. By becoming pregnant at a young age, the women in this study challenge Eurocentric conceptions of 
appropriate sexuality. They challenge normative ideas about appropriate child rearing age by choosing to keep their pregnancies and raise their children (if possible). Hence, by becoming mothers at a young age, by not submitting to the norm, these women subvert the normalizing gaze of medical and developmental discourses. They resist these discourses that maintain that they should not parent so young, and by doing so they also resist some of the effects of colonization on the Māori population.

\section{A dying culture?}

Probably there's lots of tikanga Māori things [we practice] but we just take them for granted. (Hana's mother, whānau interview 1)

As in all colonial nations, the continuation of (white) power is not just reliant on physical domination, genocide etcetera (although these strategies have been deployed with great success), but also relies on "racial and cultural hegemony, upon a structure of widely accepted beliefs and values that helps to legitimate a system of racial difference and oppression" (Jordan \& Weedon, 1995, 493). Not only are these young women continuing their physical whakapapa (genealogies) despite this digressing from societal age norms, they are also passing on their knowledge of Mātauranga Māori (Māori knowledge systems), including tikanga Māori (Māori cultural practices). This resists historical assimilation strategies and the colonial legacy of (Indigenous) cultural decimation.

All of the young women in this study placed importance on the continuation of te reo Māori for themselves and their whānau. This resists the long-term effects of assimilationist colonial strategies, such as the Native Schools Act of 1867 (that banned te reo Māori in schools) and the encouragement of Māori diaspora to urban centres in the mid-20 $0^{\text {th }}$ century; and the symbolic power/privilege afforded to the English language in Aotearoa New Zealand.

Dad's dad and them were banned from speaking Māori back in the day. It was the same for my mum... I try to teach my son as much Māori as I can. I wish I could speak more. (Pania, interview 1) 
Not actually really knowing [te reo Mãori] properly [holds me back]. I really, I love the language, love it with a passion... like I know a few sentences but I can understand it more than I can speak it. (Pania, interview 6)

As Pania articulated above, the historic loss of te reo Māori has had profound effects on young Māori today. Pania, like many others, lamented the fact that she could not speak as much te reo Māori as she would like to, but was resolved to teach her child as much as possible. Most of the young women in this study shared similar desires, to better their own knowledge of te reo Māori for the sake of their children. An example of this is from Irihapete:

I'll [go along to kōhanga reo] so I can learn as well, learn a bit of Māori. (Irihapete, interview 1)

For many of the mothers, including Irihapete (above), taking their children to kōhanga reo (Māori medium preschool) was an important opportunity for them to engage with te reo Māori. The privileging of te reo Māori medium education resists the hegemonic domination of the English language and European culture.

While most of the young mothers in this study felt like they lacked proficiency in te reo Māori, a small number attended Māori medium education beyond kōhanga reo, meaning that they felt confident in te reo Māori. However, sometimes this was associated with less confidence in English and general academia. An example of this is from Anahera:

[I'm] confident [at te reo Māori]. I went to kura and kōhanga up until high school, and then struggled a bit in high school because [te reo Māori] was my first language. (Anahera, interview 5)

Anahera felt like her mainstream education suffered because te reo Māori was her first language. Hana's mother also discussed this predicament for her daughter:

Unfortunately, their Pākehā took a second [place]... They're not quite literate in the Pākehā world... which is sad 'cause sometimes you need that stuff... I was really 
proud of them that they kept that [Mãori] part with them... but the flip side is that they don't have academic kind of knowledge. (Hana's mother, whānau interview 1)

The belief that it has to be a choice between achieving literacy in te reo Māori and failing in academia, or achieving in academia but disregarding te reo Māori, illuminates a long standing consequence of colonization - the privileging of Eurocentric beliefs and values (like academia). For our grandparents' (or great grandparents') generation, it was a highly restricted choice. To become proficient in English and the English ways meant more chance of success in the colonial society. The insidious effect of this restriction in options -an ambivalence towards te reo Māori and Mātauranga Māori - persists today.

Most of the young women in this study talked about continuing (or wanting to continue) tikanga Māori (Māori cultural practices) with their children. Practices such as: removing shoes in the house, karakia (prayers), waiata (songs), kapa haka (singing and dancing performance), mirimiri (massage), visiting marae (tribal homeland) and urupā (cemeteries), and being able to recite whakapapa (genealogy) were discussed.

I've still got baby's whenua which I want to take to [our tribal area]. (Kiri, interview 1)

In particular, a majority of the young women and/or their whānau discussed the importance of the tikanga of saving baby's pito (umbilical cord) and whenua (placenta) (afterbirth), to bury under a plant, either at home or on their ancestral homeland. This cultural practice binds new whānau members to their ancestral whenua (also the Māori term for land) and to Papatuanuku (Earth mother).

By practicing taonga tuku iho (treasures to pass on), through their whakapapa (genealogies), and the sharing of Mātauranga Māori (Māori knowledge systems) including tikanga Māori (Māori cultural practices), the young mothers in this study resist the denigration of their Māori identity by hegemonic colonial powers. This is what Bhabha (1994) might call the resistance strategy of hybridity. Hybridity is a form of selfenunciation, akin to Butler's (2006) self-signification, and Foucault's (2010) ethical self- 
formation. These young women participate in society, taking on certain Pākehā, normative values and practices. However, they also actively go against the norm. These hybrid identities, that challenge normative conceptions of youth, development, motherhood and being, mixing Māori and Pākehā practices/values, challenge the hegemony and the colonial binary of Us/Other.

\section{Mana Motuhake (autonomy/self-determination)}

Teen pregnancy/motherhood, which challenges normative conceptions of youth - as young, carefree, innocent, and chaste, is often posed as a public health issue and/or a social problem, with poor health, social, and economic outcomes typically listed as its 'dangers' (Breheny \& Stephens, 2010; Breheny, 2006; Breheny, 2008; SmithBattle, 2009; Yardley, 2008). In Aotearoa New Zealand it is associated with low educational achievement, welfare dependency, significantly low family income; and, being 'Māori' (Families Commission, 2011). These statistics engender deficit views of young (Māori) mothers, pathologizing their identities, and propagating negative stereotypes and prejudice. As Collins points out, they "do little to reduce the incidence of teenage pregnancy and much to stigmatise and disempower teenage mothers" $(2005,3)$, contributing to what Bhabha (1994) might call an imprisoning 'circle of interpretation', where teen mothers are considered deviant and so treated as deviant, and being subject to increased surveillance - a medical and disciplinary (adult) gaze. However, the young women in this study showed resilience in the face of prejudice, and maintained a sense of agency, by challenging or rising above those who sought to denigrate them. They articulated their own identities - as strong, loving and ambitious mothers.

\section{Resisting Racism}

[I've experienced racism]. I think about it and just ignore it. Not let my anger take over me... [I think CYF were judging me] because I'm a brown Māori girl and I reckon it would be different with a white Pākehā girl. (Marama, interview 1)

Many of the young women in this study (and their whānau) talked about experiencing racism - by the general public, and by individuals working in public services (as discussed in previous chapters). Marama (above) is one example of how 'support' 
services made participants feel marginalized. She chose to ignore the treatment that she perceived as racist, when dealing with CYF social workers after the birth of her daughter. She resisted her poor treatment with what Bhabha (1994) might call sly civility. Marama acquiesced with CYF questioning, which resulted in a smoother experience, where they were satisfied to leave her (and her mother) to look after baby. She ignored the discrimination on the surface, but underneath this she processed the interaction and took note of the unfairness of it.

Resisting the effects of ethnicity-based discrimination by ignoring it and not letting anger take over (as with Marama above) was a common theme throughout the young mothers' narratives. However, many of the young women chose to speak-back or 'fight'back as well. An example of this is from Tui:

I see people looking at me like they think... like people ask me, 'Is it all Māori and Island girls that come to TPU?' And I say, 'No, it's not. There's actually quite a few white girls that come here.' And they just always assume that it's Mãori girls here. Like last year we had more white girls than Māori girls... Yeah, there is a judgement about teen mums... I just leave it. I don't care. (Tui, interview 2)

Public scrutiny was often negative and frustrating. Some of the young mothers (like Tui above) attempted to challenge prejudices by providing more accurate information (to those being ignorant). Tui asserted her authority on the subject of TPUs, and in doing so, self-enunciated her own agentic identity. Similarly, when asked if she had ever experienced racism, Manaia also recounted a situation where she spoke-back:

[The restaurant staff] just looked at me and looked away and then left me there for a bit... I just said, 'Are you going to serve me or not? You know I'm here and you're just being stuck up and don't want to serve me.' (Manaia, interview 3)

Manaia thought that the restaurant staff were being racist towards her. She did not accept the 'stuck up' treatment that she believed she was experiencing, and she demanded to be treated with respect. Manaia refused to be disempowered by the prejudicial attitudes of others. 
Only at school [I experienced racism]... [I] fought back, did what I wanted to do. (Mere, interview 3)

As discussed in the previous chapter, many of the young mothers in this study talked about disengaging from the education system because of racism or attitudes that they perceived of as discriminatory/negative. Refusing to go to school (truancy), being belligerent (as illustrated by Mere above), getting excluded, or quitting school early were very common themes. These overt acts of resistance (differing from the likes of sly civility) have detrimental effects on academic achievement. So they can be viewed of as detrimental to the young women enacting them. However, they also afford these young women agency, and negate the disempowering effects of a totalizing colonial gaze.

\section{Too-Young-To-Mother?}

Teenage pregnancy is almost like a click of the tongue. Like, 'Tsk, oh my God!' [But] I think [it's] handled in a more familiar way [in Mãori communities], where it's not an embarrassment... nobody will look down at you. They will just accept it. (Anahera's mother, whānau interview 1)

Some of the mothers of the young women in this study (as illustrated by Anahera's mother above) shared stories of being judged, and sometimes reprimanded publicly, because they had 'let' their daughters get pregnant too young. However, these grandmothers also talked about their joy because of their mokopuna (grandchildren), and expressed pride about the prevalence of more accepting attitudes in Māori culture. By denying the validity of the deficit view of teen pregnancy/mothers, maintaining that it is 'just' a view - and a colonial view at that, resists the disempowering effects of such prejudicial attitudes. This is a self-articulation/enunciation of what whānau 'should' look like.

As with Anahera's mother, who talked of experiencing the 'click of the tongue' regarding teen pregnancy, the young mothers themselves frequently spoke of this 'gaze': 
Being a young mum, yeah, there's a lot of people out there that stare and look at you weird. (Irihapete, interview 3)

As articulated by Irihapete above, most of the young women in this study talked about experiencing discrimination because of their identities as young ('too young') mothers. Like the narratives about racism, many of the narratives about discrimination due to being-too-young-to-mother were imbued with resistance. Most of the young women talked about ignoring stares/comments, not worrying about it/thinking that those people don't matter, and being proud of their achievements. Kiri talked about smiling in the face of her 'aggressors':

I've noticed some weird looks people give me 'cause I'm a young mum, and... you sort of smile at people and think, 'Is there a reason you're looking at me funny or have I got something on my face?'... It's not a problem to me. I actually prefer [being a young mum]... I don't really have any problem when people give me funny looks to be honest. I think that's their problem and I'm pretty happy in the place I am, so no worries. (Kiri, interview 3)

This illustrates sly civility (Bhabha, 1994), and shows how Kiri displaced the colonial gaze (with its Eurocentric ideas of normal child rearing age), and established her own identity/reality as good - even 'better' than the established norm. Choosing to ignore stigma and focus on their achievements were the most common kinds of resistance to the disempowering effects of 'too-young-to-mother' discrimination. However, some of the young women (as with reactions to racism) chose to speak-back:

This guy was having an argument with my friend [and she's a young mum too]... and he was telling her to go and get a job, but she's studying... I was thinking, 'Well you're working at a gas station! She's getting her qualifications to get a good job to provide.' So I was like, 'Don't tell her to get a job!'... I was like, 'You know what you're doing so who cares? Don't even comment back. He's just a waste of your time.' (Awhina, interview 3) 
Awhina recalled a situation where a gas station attendant was berating her friend, insinuating that she was a 'scrounger' (LaClau \& Mouffe, 2001). By standing up for her friend, and herself as a fellow young mother, Awhina denied this view. She reminded her friend that she was doing well - even 'better' than the person vilifying her. This is resistance by self-articulation/enunciation, and self-esteem.

\section{Challenging Assumptions}

Many of the young women in this study (and some of their whānau) talked about having to deal with ignorant assumptions about their lifestyles and mothering abilities. The most common assumptions discussed, all very interconnected (and feeding into one another), were: that they are alcoholics and/or drug abusers; that they are negligent or incapable mothers; and that they could not love their children as much as more mature women (because it is assumed their pregnancies were mistakes).

Some of the young mothers in this study talked about the negative judgements made about teen mothers who retain a social life. An example of this is from Tui:

People do judge me. I think people judge all teen mums who drink and... we're not alcoholics. And the thing that people ask me when I go out is... 'Where's baby?' I'm like, 'She's not here.' (Tui, interview 2)

Questions like 'Where's baby?' suggest that a teen mother's place is at home with her baby. This is a very patriarchal picture of what motherhood should look like. The assumption that teens need to give up their adolescence when they become mothers positions mothers as undeserving of a break or social life. Tui was also frustrated that people assumed she was an alcoholic. Tui resisted prejudiced attitudes towards her by speaking-back. However, she also discussed feeling disempowered and depressed by some comments that she received.

Another common assumption made about the teen mothers in this study was that they were incapable of caring for their children. Manaia described this kind of judgement: 
If your baby's crying older people will be thinking, 'Can you even look after your kid if he's crying, like are you going to do something?'...Yeah [I feel judged a lot], like they think 'cause we're young we can't do it... I just ignore it and keep my head up and smile and think, 'Well I'm young and I've got a baby, but I'm not bumming it. I'm still achieving stuff.' (Manaia, interview 2)

Many of the young mothers talked about the pervasiveness of this assumption - that they are incapable, present in the attitudes of professionals working in health and social services, the general public, and sometimes from members of their own whānau. As Manaia articulated (above), there appears to be a double standard for young mothers that if 'their' child is crying it is because they do not know how to look after them (not just because children cry).

Associated with the assumption that teen mothers are incapable of mothering properly, is the assumption that they have children because of carelessness, and thus do not really love them (as much as more mature women would). Most of the young women in this study could have aborted their pregnancies (they found out that they were pregnant early enough), but chose not to. And like Tia and Awhina (below), they loved and cherished their children as with any mother:

I do put my son's needs before mine. Being a perfect mother is just impossible... but you can always be a loving and caring mother, like I am. (Tia, interview 5)

When she laughs and smiles... starting to crawl, like those things... Just having her around [is cool]. 'Cause this is cool. (Awhina, interview 1)

The young women in this study all consistently spoke of their love and devotion for their children. Although some of them admitted that waiting until they were a little older to have children might have made life easier, none of them spoke of regretting having their children. In fact, most of them outwardly said that they do not regret it, that they love and enjoy motherhood, and that their lives have been improved by it. 
Baby was fussing, and she said, 'It's all right baby, it's all right. We love you.' It was little bits like, 'Don't cry.' When you hear that and you just see the love. It's still the same. The three of them just love each other and it centres on that little boy. (Anahera's mother, whānau interview 1)

The young mothers in this study challenge the idea that being young equates to being incapable/negligent. As Anahera's mother articulated (above), the love is 'the same'. Being young does not detract from the love mothers feel for their babies.

The young women in this study resisted racism, age-based discrimination, and negative assumptions about young mothers (as irresponsible and negligent) by challenging and refusing to be disempowered by negative attitudes towards them, and by loving and prioritizing their babies. They resisted being stigmatized by actively unpathologizing their identities; by self-articulating/enunciating themselves as positive, loving, and capable mothers - as not 'deficit'.

\section{Ngā Tūmanako (hopes/aspirations)}

I just want to work, work, and work, and hopefully get somewhere... Some people call me dreamer. (Waimarie, interview 2)

The young mothers in this study resisted stereotypes of scroungers by hoping, dreaming and aspiring for better lives for themselves and their whānau. They resisted the disempowering effects of marginalisation (of being poor, young, Māori and mothering) by working on themselves - to 'better' themselves and better their job (employability) prospects. According to Foucault (2010; 2001; 1986), when importance is placed on the relationship of the self to the self (working on the self), a space is opened up for ethical self-formation (rather than discipline) - an inner gaze, where one can shape one's own identity. The work that we do on ourselves, to improve ourselves and become ethical selves, can be oppressive/normalizing (techniques of power/domination) and it can also encourage agency and emancipatory selfformation/self-creation (Mclaren, 2004; O'Grady, 2004). The categories that we use to articulate our identity are "the very normalizing categories that constrain us" 
(McWhorter, 2004, 155), but we can resist their totalizing effects by constantly resignifying, subverting those constrained categories (Butler, 2006). The selfimprovement work and desires of the young mothers in this study can be seen as both normalizing (regulating) and self-forming, and as such, are very complex.

\section{'Success'}

[I want to] show my son that if you're young you can still do it, like being young and having a baby, it's not over for you. You can still achieve all of this and that if you just try. 'Cause I can go to polytech now, 'cause I've got the credits. (Manaia, interview 2)

Education was identified as an important precursor to success by the young women in this study, as expressed by Manaia (above), and while many had been disengaged from education prior to their pregnancies, re-engaging with education (or engaging better with education) because of their new identities as mothers was a common theme. One example of this is from Kiri who, at the time of the last interview, had NCEA level 1 and was studying through an online course to improve her credentials:

I'm mostly just trying to secure a better future for my son... because I'm not very qualified and I don't have much educational experience. I didn't do very well at school... he's my motivation to try and get myself a little bit more qualified. (Kiri, interview 3)

Kiri, like many others, spoke of the desire to become better qualified, to provide a better future for her child. Her son was her main motivating factor. Other participants wanted to finish school to prove to their family or the general (prejudicial) public that having a child did not mean an end to their education. Two examples of this are from Marama and Tui:

I wanted to show my family I could still graduate, like still go to school even though I have a baby. (Marama, interview 2) 
I want to be a TV presenter... I want to prove people wrong about teen mums... I've had thoughts about dropping out of school. I've thought about it heaps of times... people are still going to me, 'Are you at school?' and I go, 'Yeah, I've stayed in school.' (Tui, interview 2)

Marama and Tui felt like they needed to prove people (including their whānau) wrong about teen mothers - by getting a good education and being successful.

The young women in this study overwhelmingly hoped for a better future for themselves, where they would have a 'good' job and financial security, and be able to provide for their children without depending on anyone else. Participants aspired to careers (not a lifetime of benefit receipt). These young women talked about wanting to be accountants, lawyers, computer technicians, nurses, police officers, behavioural analysts, military personnel, social workers, TV presenters, and early childhood teachers. Some of them expressed the desire to work in a field where they could help other young mothers and children. An example of this is from Hana:

I want to be a social worker but not a normal social worker. I want to help young pregnant mothers that have no support 'cause when I was pregnant and was trying to get help no one actually understood where I was coming from, because they had never been in that situation before. (Hana, interview 6)

Hana wanted to improve the current system by becoming a 'non' normal social worker one who is empathetic (unlike those who she dealt with when she was pregnant). For some other young women, they just wanted to have a job (any job) and a healthy home for their whānau. All of the young mothers in this study (except Ariana who was working) talked about wanting to find a job rather than stay on a benefit. None of them hoped for a lifetime of welfare dependency.

As discussed in the previous chapter, the young mothers in this study found living on a benefit incredibly difficult. They hoped for more opportunities for themselves and their whānau. An illustration of this hope is from Tina: 
I'm looking for a job because the benefit isn't really helping much. I want to get a job to give them a better life, so I can start saving for them, for their school, for after they leave school, like if they want to go to uni or something, or go overseas... (Tina, interview 3)

As with Tina (above), most participants wanted to be able to work and provide for their whānau. However, many of these participants also found it extremely difficult to find a job that would be flexible enough to work around their (usually) full time care of their children. Even if their children attended an early childhood education centre, there were often issues around the logistics of dropping them off and picking them up, and during times of illness. Sometimes whānau members could help with such things, but that reliance on others could cause tension. Some young women, like Waimarie (below), also acknowledged that their lack of experience/skill sets made it difficult to get into the job market.

On a CV you gotta write down things you've done like, 'I have gotten a scholarship for this,' and I have got nothing like that to say. (Waimarie, interview 2)

This is just one example of how many of the young mothers in this study spoke of their fears of not being able to find a job, or even get an interview for a job. Some of the young women, and sometimes their partners too, talked about filling in numerous applications for jobs and rarely ever getting an interview. Many of them discussed the poor state of the job market, and the lack of options out there.

\section{Wanting better for their children}

While most of the young women in this study relied on receiving a welfare benefit in order to live, none of them desired to remain in that situation, and they did not want their children to rely on a benefit when they grew up. This can be seen as an 'epidermalization' (Fanon, 2008) of negative views of welfare dependency and scroungers. These young women came to see their reliance on the welfare system as the colonial gaze casts it - as lazy/irresponsible. They did not want their children to be the same 'failures'. Ngaio and Mere provided illustrative examples of this: 
My kids, I don't want them to think that it's okay to be on a benefit and that's all you do for the rest of your life 'cause it's not. It's there for when you need it. I think that's why I want to be in the army so much 'cause I want them to have that discipline. I want them to be motivated. I don't want them to be lazy. (Ngaio, interview 4)

Ngaio told the interviewer that she did not like being on a benefit, and that she wanted her children to know that it is not a good path. She wanted them to be disciplined, motivated and active. Ngaio appears to be distancing herself from the negative stereotypes about young mothers, and wants to prove that she is not one of 'them'.

We don't want him to be a drop out... Just hope he gets a successful job, not be like me and his dad.... I don't want him to get in trouble... [I'd like] Rewi to have a job. Us having our own house. My kids to be in a good environment. (Mere, interview 5)

Similarly to Ngaio, Mere (above) talked about wanting her children to 'not' be like her or their father - to not be 'drop outs'. This was a common theme amongst the young mothers in this study - they had aspirations for a better future for their children. Many of them talked about wanting their children to have stability, happiness, a good education and a successful career. They talked about wanting their children to avoid falling into a life of drugs, alcohol, violence, or crime. These aspirations, such as wanting their children to stay in school (even though their own experiences in education were frequently negative), are very normative. They do not appear to challenge the status quo. However, by aspiring to them, these young women resisted the disempowering effects of their marginalized positions in our neoliberal/neo-colonial society

I'm happy because I've got my baby... [and] I got goals. (Pania, interview 1)

The young women in this study worked on themselves, to be better mothers, and to improve their living situations if they could. Their aspirations for employment and for more material wealth/security can be seen as adhering to normative conceptions about success. However, by aspiring to these things, they also challenged stereotypes about welfare dependent scroungers. These young women resisted the disempowering effects 
of their subjugated positions as young (not mature/lacking workforce experience) Māori (not Pākehā/lacking white privilege) mothers (not ideal workers), by hoping and yearning for a better life for themselves and their whānau.

\section{Complexities of Ātetanga (discussion)}

The women in this study occupy marginalized positions in our society, yet they resist. They resist the physical and cultural decimation of colonization by giving taonga tuku iho (treasures to be passed on) - by continuing their whakapapa (genealogy) and passing on their knowledge of Mātauranga Māori (Māori knowledge systems). They resist the disempowering effects of Eurocentric/colonial and prejudicial attitudes by standing up for themselves and their whānau in the face of discrimination, by being selfdetermining, by striving for mana motuhake (autonomy). They resist assumptions about their identities as victimized or negligent, the image of the irresponsible and/or incapable young mother, by loving their children and loving motherhood, by nurturing their whānau (family). They resist negative stereotypes about welfare scroungers, and the disempowering effects of living in a world lacking opportunities, by having ngā tūmanako (hopes/aspirations) for a better future for themselves and their whānau, for wanting more, and for working towards those goals despite many obstacles.

The young mothers in this study challenged the colonial gaze by refusing to conform to normative (Eurocentric) conceptions of appropriate child rearing age. Being nonnormative comes at a price - these women are thrust into the spotlight of multiple gazes, of medical and social services, and of the general public. The risks and negative stereotypes associated with mothering young (and Māori) cast these women in a deficit light, pre-labelled as problematic (Smith, 1999), and accordingly treated as such. These young women resisted such deficit views - by ignoring and speaking-back, by performing sly civility and hybridity, and by active self-formation. This enabled them to claim some agency. They articulated/enunciated their own identities. However, these acts of resistance are not without 'dangers'. Resistance is situated within very complex fields of power relations (Foucault, 1980), where individual agency is possible yet conditional on a number of influences (Gannon \& Davies, 2007). 
By seemingly having to choose between a Māori medium education/Māori literacy, associated with cultural confidence but not academic success, or a mainstream Eurocentric education, associated with ignorance about Mātauranga Māori and racism, it appears that these young women are really faced with a choice between resisting cultural assimilation (and not quite fitting in to 'normal' society) and assimilation to Eurocentric systems. In this case, resisting cultural assimilation might adversely impact opportunities for 'success' in our colonial society. Even by forming hybrid identities (Bhabha, 1994), taking on some tikanga Māori amongst their lives lived within a Eurocentric system, these young women are self-articulating, yet identifiably nonnormative because of it.

The young mothers in this study utilized a number of different techniques for resisting the harmful effects of prejudicial/discriminatory treatment. Ignoring comments/stares enabled these women to avoid confrontation, and feel like they were rising above such negativity. However, by ignoring prejudiced individuals, this resistance can seem complicit in maintaining such cultural hegemony. Likewise, sly-civility (Bhabha, 1994) can be seen as barely unsettling the normalizing gaze. Speaking-back allowed some of the young women a space for confronting those who stigmatize them. However, this might end up reinforcing the negative views held by those who are spoken-back to. Speaking-back to individuals is unlikely to impact upon the underlying issue here - that young (Māori) mothers are stigmatized by a Eurocentric, paternalistic, disciplinary social system (that was founded on colonization).

Ethical self-formation (Foucault, 1990), taken on by the women in this study to work towards a 'more successful' life, can be viewed as both conforming to and resisting normative expectations of appropriate life course. While some aspired to work in a field where they could change public perceptions of, or help, teen mothers, visions of success were usually articulated in very individualistic, Eurocentric terms - a well-paid career, a nice house and car. These aspirations resist the disempowering effects of living marginal lives. However, these aspirations also conform to Eurocentric, neoliberal, normative ideals, and do not challenge the injustice of a system where the odds are stacked against young (Māori) mothers. 
This discussion is not intended as a criticism of the vital work that these young women do, resisting their marginalization and maintaining a sense of autonomy/selfdetermination. Kia kaha ngā wāhine toa. This is a criticism of the narrow terms of normality (Rose, 1999) that work constitutively to produce and maintain cultural hegemony. Just because structures of domination/oppression seem inescapable, it does not mean we should admit defeat. On the contrary, all the more reason to challenge ourselves constantly. As Foucault states, "knowledge is not made for understanding; it is made for cutting" $(1977,154)$. This chapter has been intended to illuminate the precarious spaces that young Māori mothers occupy, to honour their resistance, and to challenge what is. 


\section{POROPOROAKI (farewell)}

\section{Conclusion}

The majority of research on teen pregnancy/motherhood in Aotearoa New Zealand is 'risk' focused and quantitative and biomedical in form (Collins, 2010). This kind of research focuses on the 'dangers' of teen parenting, such as educational underachievement and welfare dependency (Ministry of Social Development, 2010); and links teen pregnancy to poverty and being 'Māori' (Families Commission, 2011). Health interventions tend to focus on identifying, and regulating 'deviant' individuals (and their families) rather than addressing the systemic inequalities that lead to the interconnectedness of poverty, ethnic minority membership and poor health outcomes (Breheny \& Stephens, 2008).

Recent qualitative research exploring the lived experiences of teen mothers in Aotearoa New Zealand challenge some common perceptions. Makowharemahihi et al., (2014) found that pregnant teens do engage with health practitioners early, but that they still face barriers to optimal care. Rawiri (2007) suggests that many teens disengage from education prior to becoming pregnant, and that motherhood can actually improve their life outcomes. Collins $(2010 ; 2005)$ argues that teen mothers often feel stigmatized, and therefore avoid or disengage from support services when they need them. These studies corroborate international qualitative research that challenge how teen pregnancy is framed as a public health issue and social deviance - creating stigma and exclusion.

In Aotearoa New Zealand, the power systems that be are built upon the process of colonization, including the economic, cultural/social and political disempowerment of Māori (Smith, 1999). Through the colonial gaze, the privileged position of being Pākehā (New Zealand European/NZE) is maintained. Young Māori (adolescent) women are almost three times more likely to become mothers than their NZE counterparts (Families Commission, 2011). Thus, they are subject to a colonial gaze (Bhabha, 1994; Fanon, 2008) that posits them as Other by their ethnicity and non-normative culture, a medical gaze (Foucault, 2003a) that considers teen pregnancy an abnormality, and a 
disciplinary gaze (Foucault, 1995) that sees them as deviant and in need of regulation. These gazes are all kindred in their Enlightenment rationales. Indeed, the medical and disciplinary gazes can be considered as part of the colonial gaze, and the medical and colonial gazes can be considered as disciplinary in their intent.

The medical gaze observes the human body, dehumanizing illness and abnormality, confining, and regulating by way of treatment/cure (Foucault, 2003a). The disciplinary gaze observes the behaviour/actions of the human body, separating, ranking and individualizing, and regulating by way of discipline/normalization (Foucault, 1995). The medical and disciplinary gazes are all-seeing and all-judging. They are interconnected by their shared goals - the eradication of abnormality/deviance. However, while they seek to reduce abnormality/deviance, they also produce fields of knowledge and power that maintain inequalities. Hence, Foucault's argument, that 'power is productive' (2003b; 1995; 1980; 1973). The medical and disciplinary gazes produce fields of knowledge that reinforce their authority, and subject 'the body' to their rules. However, for Foucault, resistance and power do not exist without the other (1980). This affords subjects agency, albeit 'contingent and situated' (Gannon \& Davies, 2007)- although we are influenced and constrained by discourse/power structures, we also have agency to redirect/resist these forces (Butler, 2006; 2004).

The colonial gaze locks Māori into a perpetual state of 'Otherness', targets of disciplinary and normalizing apparatuses. By creating this binary of Us/Other, the colonial gaze is assured and reassured - the identity of the Us is dependent on the imposed identity of the Other (Bhabha, 1994; Fanon, 2008). The Other is 'thingified' (Césaire, 1972), fetishized - an object of desire and fantasy (Bhabha, 1994). The colonial gaze sees the inferiority of the Other as something to be worked upon, savagery to be civilized through strict regulation (Bhabha, 1994; Fanon, 2008). Yet, it is through the enunciation of cultural difference that these objects of desire may subvert the intended disciplinary effects of the colonizing, normalizing gaze. Césaire (1972), Fanon (2008), and Bhabha (1994) argue that colonial power produces knowable, dehumanized Others, as objects to be exploited and contained. Yet the very existence of the Other, creates an ambivalent 'Third Space', a space between the Us and the Other, where self- 
articulation/enunciation occurs, and where new, subversive signs of identity may hence appear (Bhabha, 1994).

This research, as part of the E Hine study, adds to the (limited) qualitative work undertaken in Aotearoa New Zealand specifically exploring the lived realities of teen Māori mothers. The objectives - to understand the life circumstances of teen Māori mothers, to examine the role of the state in their lives, and to consider policy implications, as well as the theoretical orientation of this thesis have informed the interpretation of the data. From an incredibly rich data set (84 interviews), the following insights have been garnered.

The proliferation of Māori in negative health statistics (Ministry of Health, 2015) establishes Māori as perpetually deficit, abnormal/unhealthy, and in need of intervention. In the medical gaze, teen pregnancy is another abnormality, in need of prevention and regulation. By mothering 'too young' the women in this study were subject to the gaze of health practitioners, in hospitals, general practices and sometimes their homes, who would judge their (and their children's) health according to Eurocentric ideas of normality. Many of the young women (and their whānau) described demeaning interactions with health practitioners or hospital staff. These experiences were exclusionary and often made the participants feel disempowered and discriminated against, causing them to lose trust in the health system and disengage from it physically (like checking out of hospital early) or emotionally (becoming vexed).

Some participants associated their negative experiences to racism or too-young-tomother discrimination. These young women were constantly reminded of their subjugated position in our society as 'abnormal'. As objects of the disciplining/normalizing medical gaze, these young mothers felt the judgement impressed upon them. In response to that, many participants talked about preferring to see Māori health practitioners because (it was perceived) they would not inflict the same level of judgement on them. This can be viewed as an attempt to avoid the totalizing effects of the medical gaze - as an act of resistance. 
The disciplinary gaze also subjected the young women in this study to judgement and regulation. Most of the young mothers disengaged from school prior to becoming pregnant. This, as well as statistical data on educational attainment (where Māori overwhelmingly fare worse than NZE students) (Ministry of Education, 2014b), indicates that the education system is exclusionary for rangatahi Māori (Māori youth), and that this affects educational attainment - rather than pregnancy. In fact, the outcomes of those young women who were able to attend a Teen Pregnancy Unit (TPU), were generally better than the women who had finished school prior to becoming pregnant. This indicates that their pregnancies positively influenced their educational attainment (because they were able to attend a generally more supportive environment).

However, even with reasonable academic success, these young women were mostly unsuccessful at finding work. Only one of the young mothers was able to secure full time employment. The other participants relied on benefits from Work and Income New Zealand (WINZ), and/or family support. Being beneficiaries subjected these young mothers to a more intense disciplinary gaze - more discriminatory attitudes, more surveillance and regulation, and more disempowerment. It also kept them in a cycle of poverty and housing instability. Most of the young women talked about trying to avoid WINZ as much as possible, and this effect might be seen as a failure of the system. However, this could be viewed as a success of the system, to treat these women like scroungers, to 'encourage' them to take personal responsibility and stop relying on the state. A lack of financial stability for most of the young mothers resulted in a lack of housing stability. Difficulties navigating the HNZC system and the private market meant that most of the young women ended up boarding, renting, or staying with family. This often meant overcrowding, and caused tensions. The ability of the state to allow (or encourage) these poor living circumstances might be viewed as a technique to create and maintain a docile, politically safe 'sub-proletariat' class (Wacquant, 2009).

The most overtly disciplinary power that the state wields over whānau in Aotearoa New Zealand is arguably that of Child, Youth and Family (CYF). CYF has the ultimate punitive power to remove children from their whānau, or to observe, question, give ultimatums, and impose sanctions with little recourse. This can be viewed as a disicplinary 
apparatus, a way of the state reaching into the 'private' sphere of the family, through their children (Rose, 1999), thus making 'the child' a powerful tool of coercion. CYF sought to regulate and normalize five of the young mothers in this study. Due to negative interactions, these women became distrustful of CYF and social workers, or felt animosity towards their own mothers when it was their mothers enforcing CYF regulations. These five young women felt disempowered, and sometimes doubted themselves. They resisted further disempowerment by disengaging from social services as much as they could, conforming to CYF procedures when they had to, and in one case at least 'playing the game' - opting for a sly civility (Bhabha, 1994).

The colonial gaze, which sees the young mothers in this study as abnormal, deviant, and Other, works with the medical gaze and the disciplinary gaze. All of these gazes marginalize 'Otherness'. The women in this study occupy marginalized positions in our society, yet they resist. By having babies and continuing their whakapapa (genealogy), and by passing on their knowledge of Mātauranga Māori (Māori knowledge systems) they resisted the physical and cultural decimation of colonization. They resisted through hybridity (Bhabha, 1994) - by adapting to our colonial society, but still retaining aspects of te ao Māori (the world of Māori). They ignored, spoke-back to, or enacted sly civility (Bhabha, 1994) against those discriminating against them, standing up for themselves (overtly or covertly), claiming some agency and mana motuhake (autonomy). They resisted derogatory assumptions made about their mothering abilities by loving their children and taking pride in their whānau. When it came to ngā tūmanako (hopes/aspirations) and thinking forward, the young women in this study appeared to conform to normative conceptions of success, to work on themselves - to become self-actualising citizens (Rose, 1996). However, in doing so, they resisted the disempowering effects of living marginalised lives.

The young mothers in this study resisted the disempowering effects of the 'gaze' by selfarticulating/enunciating their own identities (Bhabha, 1994; Butler, 2006). However, the very acts of resistance that allowed these young women to assert some agency and avoid disempowerment might also work against them. By taking on hybridity (retaining cultural practices), these women are 'non-normative' and so are subject to the normalizing gaze that is intent on disciplining non-normative individuals (through 
different apparatuses of the state, the family, and the self). By ignoring discriminatory actions, or enacting sly civility, these young women do not overtly challenge the hegemonic status quo. And by speaking-back to individuals, these young mothers might add fuel to prejudicial fire. Whatever strategies of resistance they deploy, there is risk for these marginalised young women.

\section{Reflections and Possibilities for Further Research}

This thesis explores the pregnancy and early motherhood experiences of 15 young Māori mothers, aged 14-19 years old when they first gave birth, and for some of them, the perspectives of whānau members. While this data set was less than half of the total data collected for the E Hine study (n44 and whānau), it was rich and extensive.

With 84 interviews to analyse, the themes that arose numbered too many to include in this thesis. By focusing on those themes most relevant to my objectives, other points of interest were left behind. While this extensive set of data allowed a broader understanding of the lived realities of Māori teen mothers, a discussion of other areas and themes would be insightful. For example, specifically exploring whānau (and partner) relationships might engender a deeper understanding of these young women's lives.

As I did not conduct the interviews myself, there were moments (in the interviews) where I would have liked to probe for more information, but I was not able to do so. Subsequently, there are some areas that I think would benefit from following-up with the young women. For example, some young women briefly mentioned dealing with social workers, but the extent of those relationships were not determined in the interview. I would have liked to follow-up with some of the participants (with further interviews), but the size of the data set meant that this was not manageable.

While this study included the perspectives of some (six) of the young mother's partners, these interviews were usually conducted with the young women present. This might have affected the young men's responses, which were typically fairly brief. Interviewing 
young fathers on their own might elucidate a more detailed understanding of their perspectives.

Finally, during the final interviews, the young mothers were asked about where they see themselves in five years' time. It would be interesting to revisit them after that five years, to see how their hopes and aspirations have materialised or changed.

\section{Implications of the Research}

This research contributes to a growing number of studies that displace the deficit lens directed at teen mothers, in particular - Māori teen mothers. In the face of adversity, the young women in this study strive for autonomy.

The research findings suggest that institutional protocols and procedures form barriers to success rather than facilitate positive outcomes for young (teen) Māori mothers. These findings have implications for reconceptualising health and social support service practices. Health practitioners, social service/support workers, and public sector employees would benefit from engaging with this research. Key points to take away are:

1. The socio-historic context of Aotearoa New Zealand (colonization) has led to significant socio-economic and health gaps between Māori and Pākehā. The lives of teen Māori mothers need to be understood within this context.

2. Teen Māori mothers live complex, nuanced lives and do not see their identities (as young mothers) as problematic. Treating them as problematic does not facilitate positive outcomes. Support services that treat teen Māori mothers with empathy and respect, developing positive relationships, engender positive outcomes.

3. The young women in this study hope and strive for a better future for themselves and their whānau. Services that recognise this, and encourage the realisation of those aspirations, will empower (rather than disempower) young Māori mothers. 
This research is for the young women who took part in the E Hine project. I hope that their voices will be heard. 


\section{REFERENCES}

Arai, L. (2011). The Surveillance of Children, Young People and Families, in L. O’Dell, and S. Leverett (Eds), Working With Children and Young People: Co-constructing Practice (pp.41-54). Milton Keynes: Palgrave Macmillan.

Arai, L. (2009). Teenage Pregnancy: The making and unmaking of a problem. Bristol: Policy Press.

Bargh, M. (2007). Introduction. In M. Bargh (Ed.), Resistance: An Indigenous Response to Neoliberalism (pp. 1-21). Wellington: Huia Publishers.

Bhabha, H., K. (1994). The Location of Culture. London: Routledge.

Biggs, D. W \& Baird, B. (2009). Introduction: The Racial Politics of Bodies, Nations and Knowledges. In D. W. Biggs \& B. Baird (Eds), The Racial Politics of Bodies, Nations and Knowledges (pp. 1-10). Newcastle upon Tyne: Cambridge Scholars Publishing.

Bloch, M. N., Kennedy, D., Lightfoot, T., \& Weyenberg, D. (2006). Introduction: Education and the Global/Local Construction of the Universal, Modern, and Globalized Child, School, and Nation. In M. N. Bloch, D. Kennedy, T. Lightfoot, \& D. Weyenberg (Eds), The Child in the World/The World in the Child: Education and the Configuration of a Universal, Modern, and Globalized Childhood (pp. 3-20). New York: Palgrave Macmillan.

Boden, J. M., Fergusson, D. M., \& John Horwood, L. (2008). Early Motherhood and Subsequent Life Outcomes. Journal of Child Psychology and Psychiatry, 49(2), 151-160.

Breheny, M., \& Stephens, C. (2010). Youth or Disadvantage? The Construction of Teenage Mothers in Medical Journals. Culture, Health \& Sexuality, 12(3), 307-322.

Breheny, M., \& Stephens, C. (2008). Breaking the Cycle: Constructing Intergenerational Explanations for Disadvantage. Journal of Health Psychology, 13(6), 754-763. 
Breheny, M. R. (2006). Constructions Of Adolescent Motherhood: Discourse Analysis Of The Health Professional Literature And Health Professionals' Talk About Young Mothers. Unpublished PhD thesis, Massey University, Palmerston North.

Browne, A. J., \& Fiske, J. (2001). First Nations Women's Encounters with Mainstream Health Care Services. Western Journal of Nursing Research, 23(2), 126-147.

Burchell, G. (1996). Liberal government and techniques of the self. In A. Barry, T. Osborne \& N. S. Rose (Eds), Foucault and Political Reason: Liberalism, Neo-liberalism, and Rationalities of Government (pp. 19-36). University of Chicago Press.

Butler, J. (2006). Gender Trouble: Feminism and the Subversion of Identity. New York: Routledge Classics. (Original work published 1990)

Butler, J. (2004). Bodies and Power Revisited. In Taylor, D., \& Vintges, K. (Eds), Feminism and the Final Foucault (pp. 183-196). Urbana and Chicago: University of Illinois Press.

Came, H., A. (2012). Institutional Racism and the Dynamics of Privilege in Public Health. Unpublished PhD thesis, Waikato University.

Césaire, A. (1972). Discourse on Colonialism. New York: Monthly Review Press. (Original work published 1955)

Collins, B. (2010). Resilience in Teenage Mothers: A follow-up study. Wellington: Ministry of Social Development.

Collins, B. (2005). Missing Voices: Teenage Pregnancy and Social Policy. Unpublished PhD thesis, Victoria University of Wellington.

Cox, R. W. (1983). Gramsci, Hegemony and International Relations: An Essay in Method. Millennium-Journal of International Studies, 12(2), 162-175. 
Cruikshank, B. (1996). Revolutions Within: Self-Government and Self-Esteem. In A. Barry, T. Osborne \& N. S. Rose (Eds), Foucault and Political Reason: Liberalism, Neoliberalism, and Rationalities of Government (pp. 231-252). University of Chicago Press.

Dean, M. (1996). Foucault, Government and the Enfolding of Authority. In A. Barry, T. Osborne \& N. S. Rose (Eds), Foucault and Political Reason: Liberalism, Neo-liberalism, and Rationalities of Government (pp. 209-230). University of Chicago Press.

Dew, K. (2014). Patient-Centered Care or Discrimination? In A. G. Jutel \& K. Dew (Eds), Social Issues in Diagnosis: An Introduction for Students and Clinicians (pp. 93-104). Baltimore: John Hopkins University Press.

Durie, M. (2004). An Indigenous Model of Health Promotion. Health Promotion Journal of Australia, 15(3), 181-185.

Durie, M. H. (1997). Identity, Nationhood and Implications. New Zealand Journal of Psychology, 26(2), 33.

Families Commission (2011). Teenage Pregnancy and Parenting: An Overview. Wellington: Families Commission.

Fergusson, D. M., \& Woodward, L. J. (2000). Teenage pregnancy and female educational underachievement: A prospective study of a New Zealand birth cohort. Journal of Marriage and Family, 62(1), 147-161.

Flynn, M., Carne, S., \& Soa-Lafoa'I, M. (2010). Māori Housing Trends 2010. Wellington: Housing New Zealand Corporation.

Foucault, M. (2014). On the Government of the Living: Lectures at the Collège de France 1979-1980. M. Senellart, F. Ewald, A. Fontana \& A. I. Davidson (Eds). London: Palgrave Macmillan. 
Foucault, M. (2010). The Government of Self and Others: Lectures at the Collège de France 1982-1983. F. Ewald, A. Fontana \& A. I. Davidson (Eds). London: Palgrave Macmillan.

Foucault, M. (2009). Security, Territory, Population: Lectures at the Collège de France 1977-1978. M. Senellart (Ed.). New York: Palgrave Macmillan.

Foucault, M. (2003a). The Birth of the Clinic: An Archaeology of Medical Perception. London: Routledge Classics. (Original work published 1963)

Foucault, M. (2003b). Abnormal: Lectures at the Collège de France 1974-1975. V. Marchetti, A. Salomoni, F. Ewald, \& A. Fontana (Eds). London: Verso.

Foucault, M. (2002). The Order of Things: An Archaeology of the Human Sciences. London: Routledge Classics. (Original work published 1966)

Foucault, M. (2001). The Hermeneutics of the Subject: Lectures At The Collège de France 1981-82. F. Gros, F. Ewald, A. Fontana \& A. I. Davidson (Eds). New York: Palgrave Macmillan.

Foucault, M. (1997). The Politics of Truth. S. Lotringer \& L. Hochroth (Eds). New York: Semiotext(e). (A collection of works originally published 1978-1984)

Foucault, M. (1995). Discipline and Punish: The Birth of The Prison. New York: Vintage Books. (Original work published 1975)

Foucault, M. (1990). The History of Sexuality: Volume 2, The Use of Pleasure. New York: Vintage Books. (Original work published 1984)

Foucault, M. (1988a). Technologies of the Self. In L. H. Martin, H. Gutman, \& H. Hutton (Eds), Technologies of the Self: A Seminar with Michel Foucault (pp. 15-48). Amherst: University of Massachusetts Press. (A collection of works originally published 1982) 
Foucault, M. (1988b). Truth, Power, Self: An Interview With Michel Foucault October 25, 1982. In L. H. Martin, H. Gutman, \& H. Hutton (Eds), Technologies of the Self: A Seminar with Michel Foucault (pp. 8-14). Amherst: University of Massachusetts Press. (A collection of works originally published 1982)

Foucault, M. (1986). The History of Sexuality: Volume 3, The Care of the Self. New York: Pantheon Books. (Original work published 1984)

Foucault, M. (1980). The History of Sexuality: Volume I, an Introduction. New York: Vintage Books. (Original work published 1976)

Foucault, M. (1977). Nietzsche, Genealogy, History. In D., F. Bouchard (Ed.), Language, Counter-Memory, Practice: Selected Essays and Interviews (pp. 139-164). Ithaca: Cornell University Press. (Original work published 1971)

Foucault, M. (1973). Madness and Civilization: A History of Insanity in the Age of Reason. New York: Vintage Books (Original work published 1961)

Foucault, M. (1972). The Archaeology of Knowledge and the Discourse on Language. New York: Pantheon Books. (Original work published 1969)

Furstenberg, F. F. (2007). Destinies of the Disadvantaged: The politics of teen childbearing. New York: Russell Sage Foundation.

Gannon, S. \& Davies, B. (2007). Postmodern, Poststructural, and Critical Theories. In S. N. Hesse-Biber (Ed.) Handbook of Feminist Research Theory and Praxis (pp. 71-106). Thousand Oaks, California: Sage.

Gibbs, G. R. (2007). Analyzing Qualitative Data. London: SAGE.

Graham, M. (2014). Enabling Tertiary Education for Teen Mothers: Organisational insights. Unpublished (part of a) Master of Business, Auckland University of Technology. 
Gregson, J. (2010). The Culture of Teenage Mothers. Albany: State University of New York Press.

Hanna, B. (2001). Negotiating Motherhood: The struggles of teenage mothers. Journal of Advanced Nursing, 34(4), 456-464.

Hill, R. S. (2004). State Authority, Indigenous Autonomy: Crown-Māori Relations in New Zealand/Aotearoa 1900-1950. Wellington: Victoria University Press.

Hoskins, T. K. (2012). A Fine Risk: Ethics in Kaupapa Maori politics. New Zealand Journal of Education Studies. 47(2), 85-99.

Hultqvist, K. \& Dahlberg, G. (2001). Governing the Child in the New Millennium: Introduction. In K. Hultqvist \& G. Dahlberg (Eds), Governing the Child in the New Millennium (pp. 1-14). New York: RoutledgeFalmer.

Jackson, S. (2004). Identifying Future Research Needs for the Promotion of Young People's Sexual Health in New Zealand. Social Policy Journal of New Zealand, 123-136.

Jenks, C. (2001). The Pacing and Timing of Children's Bodies. In K. Hultqvist \& G. Dahlberg (Eds), Governing the Child in the New Millennium (pp. 68-84). New York: RoutledgeFalmer.

Jordan, G., \& Weedon, C. (1995). Cultural Politics: Class, gender, race, and the postmodern world. Oxford: Blackwell Publishers.

King, M. (2003). Penguin History of New Zealand. New Zealand: Penguin.

Laclau, E., and Mouffe, C. (2001). Hegemony and Socialist Strategy: Towards a radical democratic politics. London: Verso. (Original work published 1985) 
Larkins, S. L., Page, R. P., Panaretto, K. S., Scott, R., Mitchell, M. R., Alberts, V., Veitch, C. \& McGinty, S. (2007). Attitudes and Behaviours of Young Indigenous People in Townsville. Medical Journal of Australia. 186(10), 513-518.

Lawton, B., Cram, F., Makowharemahihi, C., Ngata, T., Robson, B., Brown, S., \& Campbell, W. (2013). Developing a kaupapa Māori research project to help reduce health disparities experienced by young Māori women and their babies. AlterNative: An International Journal of Indigenous Peoples, 9(3), 246-261.

Leitner, H., Sheppard, E. S., Sziarto, k. \& Marninganti, A. (2007). Contesting Urban Futures: Decentering Neoliberalism. In H. Leitner, J. Peck, \& E. S. Sheppard (Eds). (2007). Contesting Neoliberalism: Urban Frontiers (pp. 1-25). New York: Guilford Press.

Lesko, N. (2001a). Time Matters in Adolescence. In K. Hultqvist \& G. Dahlberg (Eds), Governing the Child in the New Millennium (pp. 35-67). New York: RoutledgeFalmer.

Lesko, N. (2001b). Act Your Age! A Cultural Construction of Adolescence. New York: RoutlegeFalmer.

Luker, K. (1996). Dubious conceptions: The politics of teenage pregnancy. Massachusetts: Harvard University Press.

Makowharemahihi, C., Lawton, B. A., Cram, F., Ngata, T., Brown, S., \& Robson, B. (2014). Initiation of Maternity Care for Young Māori Women Under 20 Years of Age. The New Zealand Medical Journal, 127(1393), 52-61.

Mann, M. M. (2013). International teen reproductive health and development: The Canadian First Nations Context. International Indigenous Policy Journal, 4(1), 1-32.

Markham, E. (1963). Edward Markham, 1801-1865: New Zealand or Recollections of it. E. H. McCormick (Ed.). Wellington: Government Printer. 
McLaren, M., A. (2004). Foucault and Feminism: Power, Resistance, Freedom. In D. Taylor \& K. Vintges (Eds) Feminism and the Final Foucault (pp. 214-234). Urbana and Chicago: University of Illinois Press.

McLeod, J. (2001). When Poststructuralism Meets Gender. In K. Hultqvist \& G. Dahlberg (Eds), Governing the Child in the New Millennium (pp. 259-289). New York:

RoutledgeFalmer.

McWhorter, L. (2004). Practicing Practicing. In D. Taylor \& K. Vintges (Eds) Feminism and the Final Foucault (pp. 143-162). Urbana and Chicago: University of Illinois Press.

Merton, R. K., 1968. Social Theory and Social Structure. New York: The Free Press.

Ministry of Education (2014a). Annual Report 2014. Wellington: Ministry of Education.

Ministry of Education (2014b). Ka Hikitia 2014: Snapshot of Today. Wellington: Ministry of Education.

Ministry of Health (2015). Mortality and Demographic Data 2012. Wellington: Ministry of Health.

Ministry of Social Development (2015). Modernising Child, Youth and Family: An Interim Report. Wellington: Ministry of Social Development.

Ministry of Social Development (2014). Children, Young Persons, and Their Families Act 1989 (reprint). Wellington: Ministry of Social Development.

Ministry of Social Development (2013). Annual Report 2012/13. Wellington: Ministry of Social Development.

Ministry of Social Development (2010). Teen Parents and Benefit Receipt-Paper to the Welfare Working Group. Wellington: Ministry of Social Development. 
Moewaka Barnes, H. (2010). Sexual Coercion, Resilience and Young Māori: A scoping review. Wellington: Ministry of Women's Affairs.

O’Grady, H. (2004). An Ethics of the Self. In D. Taylor \& K. Vintges (Eds), Feminism and the Final Foucault (pp. 91-117). Urbana and Chicago: University of Illinois Press.

O’Malley, P. (1996). Risk and Responsibility. In A. Barry, T. Osborne \& N. S. Rose (Eds), Foucault and Political Reason: Liberalism, Neo-liberalism, and Rationalities of Government (pp. 189-208). Chicago: University of Chicago Press.

Orange, C. (2004). An illustrated history of the Treaty of Waitangi. Wellington: Bridget Williams Books.

O'Sullivan, D. (2007). Beyond biculturalism: The politics of an indigenous minority. Wellington: Huia Publishers.

Parliament (2012). The Beehive Welfare Reform Factsheet and Q \& A: May 2012. Wellington: Parliament.

Pena, K. S. (2006). No Child Left Behind? The Specters of Almsgiving and Atonement: A Short Genealogy of the Saving Grace of U.S. Education. In M. N. Bloch, D. Kennedy, T. Lightfoot, \& D. Weyenberg (Eds), The Child in the World/The World in the Child: Education and the Configuration of a Universal, Modern, and Globalized Childhood (pp. 177-194). New York: Palgrave Macmillan.

Poata-Smith, Te Ahu E. (2008). Closing the Gaps? In N. Lunt, M. O’Brien and R. Stephens (Eds), New Zealand, new welfare (pp. 101-110). Melbourne: Cengage.

Raby, R. C. (2002). Growing Up Governed. Unpublished PhD Thesis in Sociology, York University, North York, Ontario. 
Rawiri, C. (2007). Adolescent Māori Mothers' Experiences with Social Support during Pregnancy, Birth and Motherhood and their Participation in Education. Unpublished Master of Social Sciences in Psychology, University of Waikato.

Reekie, G. (1997). History and the Bodies of the Illegitimately Pregnant Woman. Australian Feminist Studies, 12(25), 77-89.

Rimene, C., Hassan, C., \& Broughton, J. (1998). Ukaipo, the Place of Nuturing: Maori Women and Childbirth. Dunedin: University of Otago (Ngai Tahu Maori Health Research Unit, Department of Preventive and Social Medicine).

Rose, N. (1999). Governing the Soul: The Shaping of the Private Self. London: Free Association Books. (Original work published 1989)

Rose, N. (1996). Governing "Advanced" Liberal Democracies. In A. Barry, T. Osborne and N. S. Rose (Eds), Foucault and Political Reason: Liberalism, Neo-liberalism, and Rationalities of Government (pp. 37-64). Chicago: University of Chicago Press.

Senior, K. \& Chenhall, R., (2008). 'Walkin' about at night': The background to teenage pregnancy in a remote aboriginal community. Journal of Youth Studies, 11(3), 269-281.

Seth, S. (2014). The Politics of Knowledge: Or, How to Stop Being Eurocentric. History Compass. 12(4), 311-320.

Smith, G., Hoskins, T. K., and Jones, A. (2012). Kaupapa Māori: The dangers of domestication. New Zealand Journal of Education Studies. 47(2), 10-20.

Smith, L. T. (1999). Decolonizing Methodologies: Research and Indigenous Peoples. London: Zed Books.

SmithBattle, L. 2009. Reframing the risks and losses of teen mothering. American Journal of Maternal Child Nursing. 34, 122 - 8. 
Statistics New Zealand (2015). New Zealand in Profile: 2015. Wellington: Statistics New Zealand.

Statistics New Zealand (2014). 2013 Census QuickStats about housing. Wellington: Statistics New Zealand.

Tauri, J. (1998). Family Group Conferencing: A case-study of the Indigenisation of New Zealand's justice system. Current Issues in Criminal Justice. 10(2), 168-182.

Walkerdine, V. (2001). Safety and Danger: Childhood, Sexuality, and Space at the end of the Millennium. In K. Hultqvist \& G. Dahlberg (Eds), Governing the Child in the New Millennium (pp. 15-34). New York: RoutledgeFalmer.

Wacquant, L. (2009). Punishing the Poor: The Neoliberal Government of Social Insecurity. Durham and London: Duke University Press.

Ware, F. J. R. (2014). Whānau kōpepe: A Culturally Appropriate and Family Focused Approach to Support for Young Māori (Indigenous) Parents. Journal of Indigenous Social Development. 3(2), 1-20.

Watson, J., Hodson, K., Johnson, R., Kemp, K., \& May, J. (2002). Opinions of healthcare professionals regarding the maternity experiences of indigenous women in an acute care setting. Australian Journal of Rural Health, 10(3), 161-167.

Welfare Working Group (2011). Reducing Long-Term Benefit Dependency: Recommendations. Wellington: Victoria University of Wellington.

Weyenberg, D. (2006). The Quest for Health in Different Timespaces. In M. N. Bloch, D. Kennedy, T. Lightfoot, \& D. Weyenberg (Eds), The Child in the World/The World in the Child: Education and the Configuration of a Universal, Modern, and Globalized Childhood (pp. 99-117). New York: Palgrave Macmillan. 
Yardley, E. (2008). Teenage mothers' experiences of stigma. Journal of Youth Studies, 11(6), 671-684. 


\section{APPENDIX A: E HINE INTERVIEW SCHEDULE 1}

\section{E HINE INTERVIEW SCHEDULE 1: ALL COHORTS}

Tell me about you.....

- Where and who she grew up with, siblings, grandparents till now. Explore family changes, movements, significant events, and what it was like growing up. Identity, whakapapa, family traditions, ngā tikanga me te reo Māori, whānau. Explore whānau/parent expectations, achievements, things she loved to do with her whanau, who she admired, was close to, any jobs/responsibilities she had, her interests, difficult things she faced growing up, how she coped.

Tell me about school....

- What were her aspirations growing up, and why, and how has/is school helping her get there? Who is important to her at school i.e. best friend, wider friends, teachers, activities, what were the challenges. Explore whanau/parent expectations, achievements, things she does/doesn't enjoy at school.

Tell me about your relationship with your family...

- Who is she closest to, most supportive, how have they supported her, what challenges have they overcome, changes in living arrangements, what isn't going well, how is she coping.

Tell me about your relationship with the father of your baby...

- Explore how they met, how she feels about her relationship, (emotional, physical relationship), family reactions, challenges, her sexual relationship with her partner, did their try avoid getting pregnant, did they talk about contraception, getting pregnant.

- Her sexual relationship/s, contraception, knowledge and decisions about her and her body, family influence/support/advice.

Tell me about when you first found out you were pregnant....

- When and how did she realise she was pregnant, who did she go to first, what/who has been most supportive, explore her thinking and decision making about her pregnancy, what services did she access, how did she feel throughout this time, how did she tell her partner and family (and his family), what was their reaction, how did they work through it, where and how they help her make decisions. How did you find a midwife, who helped you, gave you information? How and what decisions did she make about her education, what has it been like, who has helped her?

- How she feels about becoming a mother, what she thought as a child and now as she prepares to be.

\section{Tell me about what it is like for you right now....}

- What's going well in her life, what makes her happy and what's making life difficult, what is the hardest things right now and how does she cope, where and how is she getting support (financial, housing, employment/education), changes to friendships, social impact, does she still have goals she wants to achieve. 